Florida International University FIU Digital Commons

\title{
Neuroendocrine control of a dynamic communication signal
}

Susan J. Allee

Florida International University

DOI: $10.25148 /$ etd.FI13101582

Follow this and additional works at: https://digitalcommons.fiu.edu/etd

Part of the Biology Commons

\section{Recommended Citation}

Allee, Susan J., "Neuroendocrine control of a dynamic communication signal" (2007). FIU Electronic Theses and Dissertations. 1093. https://digitalcommons.fiu.edu/etd/1093

This work is brought to you for free and open access by the University Graduate School at FIU Digital Commons. It has been accepted for inclusion in FIU Electronic Theses and Dissertations by an authorized administrator of FIU Digital Commons. For more information, please contact dcc@fiu.edu. 
FLORIDA INTERNATIONAL UNIVERSITY

Miami, Florida

NEUROENDOCRINE CONTROL OF A DYNAMIC COMMUNICATION

SIGNAL

A dissertation submitted in partial fulfillment of the

requirements for the degree of

DOCTOR OF PHILOSOPHY

in

BIOLOGY

by

Susan J. Allee

2007 
To: Interim Dean Mark Szuchman

College of Arts and Sciences

This dissertation, written by Susan J. Allee, and entitled Neuroendocrine Control of a Dynamic Communication Signal, having been approved in respect to style and intellectual content, is referred to you for judgment.

We have read this dissertation and recommend that it be approved.

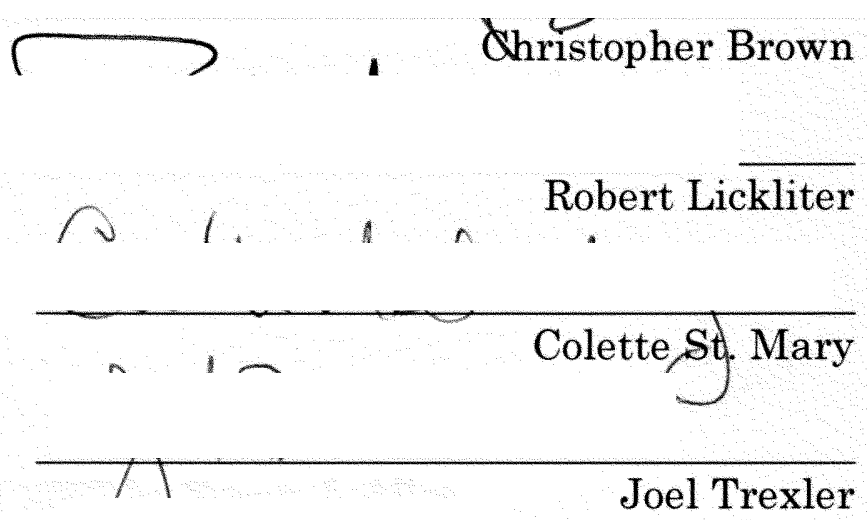

Philip K. Stoddard, Major Professor

Date of Defense: January 23, 2007

The dissertation of Susan J. Allee is approved.

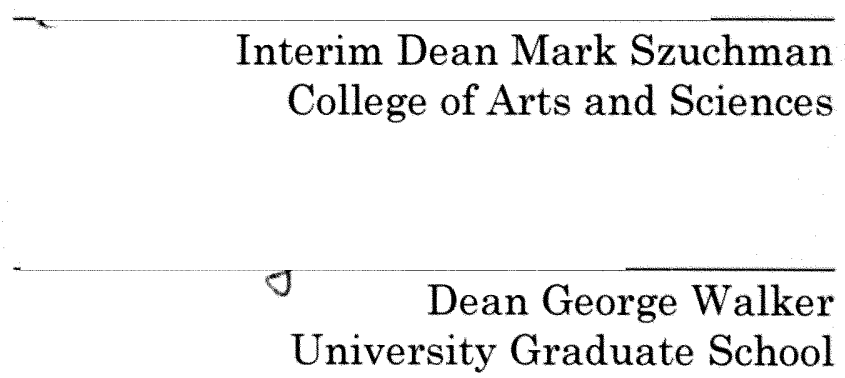

Florida International University, 2007 
(C) Copyright 2007 by Susan J. Allee All rights reserved. 


\section{DEDICATION}

I dedicate this dissertation to everyone who helped me realize my potential, understand my strengths, and clarify my goals. Thank you. 


\section{ACKNOWLEDGMENTS}

I thank my committee for sharing their expertise and experience with me, empowering me to complete this dissertation. Dr. Christopher Brown's initial guidance in endocrine functioning in fishes provided a platform for this research. Dr. Robert Lickliter's holistic approach to asking questions and synthesizing ideas sharpened my perspective. Dr. Colette St. Mary provided vigorous, unwavering camaraderie and intellectual support. Discussing aspects of my initial research ideas with her was immensely pleasurable and profoundly expanded my understanding of the subject. Dr. Joel Trexler's quantitative expertise and advice proved invaluable to the quality of this dissertation. Finally, I would like to thank my major professor, Dr. Philip Stoddard. From the beginning, he had faith in my ability to succeed with excellence. 


\title{
ABSTRACT OF THE DISSERTATION \\ NEUROENDOCRINE CONTROL OF A \\ DYNAMIC COMMUNICATION SIGNAL
}

by

\author{
Susan J. Allee \\ Florida International University, 2007 \\ Miami, Florida \\ Professor Philip K. Stoddard, Major Professor
}

Multiple physiological systems regulate the electric communication signal of the weakly electric gymnotiform fish, Brachyhypopomus pinnicaudatus. Fish were injected with neuroendocrine probes which identified pharmacologically relevant serotonin $(5 \cdot \mathrm{HT})$ receptors similar to the mammalian $5 \cdot \mathrm{HT}_{1 \mathrm{~A}} \mathrm{R}$ and $5-\mathrm{HT}_{2 \mathrm{~A}} \mathrm{R}$. Peptide hormones of the hypothalamic-pituitary-adrenal/interrenal axis also augment the electric waveform. These results indicate that the central serotonergic system interacts with the hypothalamic-pituitaryinterrenal system to regulate communication signals in this species. The same neuroendocrine probes were tested in females before and after introducing androgens to examine the relationship between sex steroid hormones, the serotonergic system, melanocortin peptides, and EOD modulations. Androgens caused an increase in female $B$. pinnicaudatus responsiveness to other pharmacological challenges, particularly to the melanocortin peptide adrenocorticotropic hormone (ACTH). A forced social 
challenge paradigm was administered to determine if androgens are responsible for controlling the signal modulations these fish exhibit when they encounter conspecifics. Males and females responded similarly to this social challenge construct, however introducing androgens caused implanted females to produce more exaggerated responses. These results confirm that androgens enhance an individual's capacity to produce an exaggerated response to challenge, however another unidentified factor appears to regulate sex-specific behaviors in this species. These results suggest that the rapid electric waveform modulations $B$. pinnicaudatus produces in response to conspecifics are situation-specific and controlled by activation of different serotonin receptor types and the subsequent effect on release of pituitary hormones. 


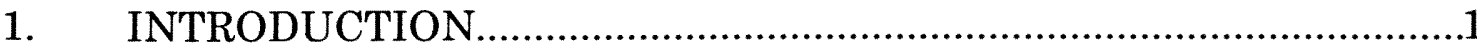

2. PHARMACOLOGICAL CHARACTERIZATION OF SEROTONIN AND MELANOCORTIN RESPONSIVE PATHWAYS THAT REGULATE MASCULINITY OF THE ACTION-POTENTIAL-BASED SOCIAL SIGNALS OF GYMNOTIFORM ELECTRIC FISH............................................. 11

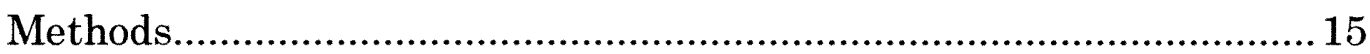

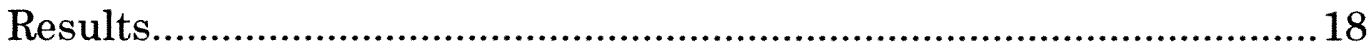

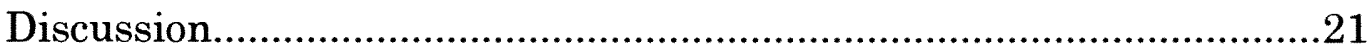

3. ANDROGENS ENHANCE PERIPHERAL RESPONSE TO MELANOCORTINS BUT SHOW LITTLE EFFECT ON CENTRAL CIRCADIAN RHYTHM GENERATION..........................35

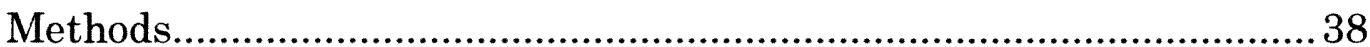

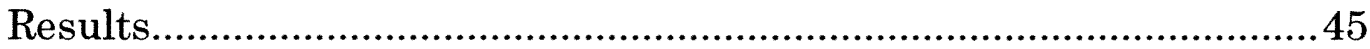

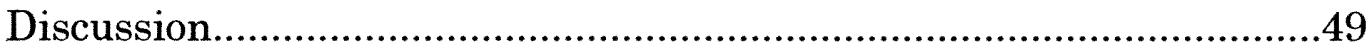

4. ANDROGENS ENHANCE RESPONSIVENESS TO SOCIAL CHALLENGE BUT DO NOT INDUCE SEXSPECIFIC BEHAVIOR TOWARD CONSPECIFICS USING A FORCED SOCIAL CHALLENGE PROTOCOL .............................68

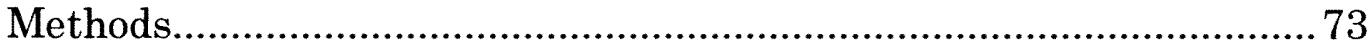

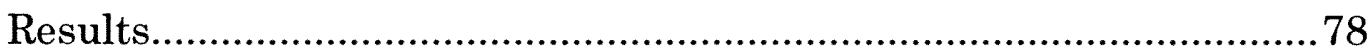

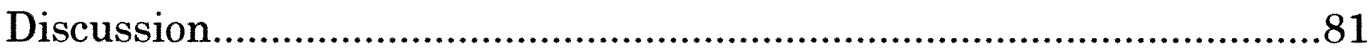

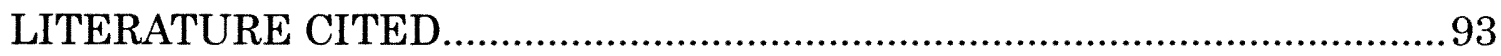

VITA 


\section{LIST OF TABLES}

TABLE

PAGE

2.1. Receptor affinities (pKis) for serotonergic agents used in this study

3.1. Androgen profiles in weakly electric fishes

3.2. Kruskal-Wallis p-values of effect of DHT implants on female EOD circadian oscillations.

3.3. Kruskal-Wallis $p$-values of effect of DHT implants on relative response to pharmacological challenge

3.4. Kruskal-Wallis p-values of effect of DHT implants on changes in relative response to pharmacological challenge.

3.5. Kruskal-Wallis p-values of effect of DHT implants on relative female, DHT female, and male responses to pharmacological challenge 


\section{LIST OF FIGURES}

FIGURE

PAGE

2.1. Measurement of Brachyhypopomus pinnicaudatus electric organ discharge (EOD) parameters

2.2. Injections of hypothalamic and pituitary hormones modulate EOD waveform.

2.3. Injections of $5 \cdot \mathrm{HT}_{2 \mathrm{~A}}$ receptor agonists modulate EOD $\tau_{\mathrm{P} 2}$, but not amplitude.

2.4. Blocking the $5 \cdot \mathrm{HT}_{2 \mathrm{~A}}$ receptor with ketanserin inhibits EOD modulations in response to 5 - $\mathrm{HT}$ challenge.

2.5. Injections of $5 \cdot \mathrm{HT}_{1 \mathrm{~A}}$ receptor agonists and antagonists modulate EOD waveform

2.6. Blocking the $5-\mathrm{HT}_{2 \mathrm{~A}}$ receptor with ketanserin does not inhibit EOD waveform modulation in $\tau_{\mathrm{P} 2}$, but it does inhibit amplitude modulations.

2.7. Models of possible $5-\mathrm{HT}_{1 \mathrm{~A}}$ and $5-\mathrm{HT}_{2}$ receptor alignments.

3.1. Single EOD waveform and 48-hours worth of EODs from one female Brachyhypopomus pinnicaudatus....

3.2. Absolute effect of DHT on EOD waveform 61

3.3. Effects of DHT implant dose on female EOD circadian oscillations

3.4. Comparison of female, DHT-female, and male EOD circadian oscillations.

3.5. Effects of DHT implants on female responses to 5-HT challenge 64

3.6. Effects of DHT on female responses to ACTH challenge. 65 
3.7. Example of effects of DHT on responses to pharmacological challenge with 5-HT and ACTH....................................................6 66

3.8. Comparison of female, DHT-implanted female, and male responses to challenge 67

4.1. Measurement of Brachyhypopomus pinnicaudatus electric organ discharge (EOD) parameters

4.2. Implanting DHT causes females to develop secondary sexual characteristics.

4.3. Effect of DHT implants on female responses to female challenge......... 90

4.4. Effect of DHT implants on female responses to male challenge........... 91

4.5. Comparison of female, DHT-implanted female, and male responses to social challenge. 


\section{LIST OF SYMBOLS}

$\tau_{\mathrm{P} 2}: \quad$ time constant of an inverse exponential function fit to the decay segment of the EOD waveform second phase, measured in milliseconds

Q:

female

Y:

androgen-implanted female

$O:$

male 


\section{LIST OF ACRONYMS}

5-HT:

8-OH-DPAT:

11-KT:

$\alpha-\mathrm{Me}^{-} 5-\mathrm{HT}:$

$\alpha-\mathrm{MSH}$ :

ACTH:

CRF:

DHT:

DOI:

EOD:

HPA/I:

MK212:

Pinni:

RIA:

$\mathrm{T}$ :

TRH:

WAY100635: 5-hydroxytryptamine (serotonin)

8-hydroxy-di- $n$-propylamino tetralin

\section{1-ketotestosterone}

$\alpha$-methyl-5-hydroxytryptamine

$\alpha$-melanocyte stimulating hormone

adrenocorticotropic hormone

corticotropin releasing hormone

$5 \alpha$-dihydrotestosterone

2,5-dimethoxy-4-iodoamphetamine

electric organ discharge

hypothalamic-pituitary-adrenal/interrenal axis

6-chloro-2-(1-piperazinyl) pyrazine

Brachyhypopomus pinnicaudatus

radioimmunoassay

testosterone

thyrotropin releasing hormone

$\mathrm{N}-$ [2-[4-(2-methoxyphenyl)-1-piperazinyl] ethyl]-N- (2pyridinyl) cyclohexanecarboxamide trihydrochloride 


\section{CHAPTER 1. INTRODUCTION}

Behavior changes as the result of ceaseless interactions between organisms and their social and physical environments. Communication is one mechanism organisms use to optimize these interactions. The American Heritage Dictionary of the English Language defines communication as "the transfer of information from one molecule, cell, or organism to another, as by chemical or electrical signals or by behaviors" (2000). Yet in physiological terms, execution of any behavior requires integrated control of information transfer to occur across all of these levels. Understanding how information is transferred across all biological levels of organization is the key to understanding how specific behaviors, including communication, are produced and controlled. The following chapters summarize the results of a research program designed to clarify the neuroendocrine mechanisms that produce and control a unique communication signal that changes in response to the social environment.

MODEL SYSTEM \& RATIONALE

Brachyhypopomus pinnicaudatus (Hopkins, 1991) is a South American weakly electric knifefish. Gymnotiform knifefish are small, eel-shaped nocturnal fish that produce a species-specific weak electric organ discharge (EOD) using a collection of modified muscle cells, or electrocytes. These cells are organized both in series and parallel to form the electric organ, which runs almost the entire length of the body in this species. The EOD can be 
measured simply by placing recording electrodes in water with the fish swimming and behaving normally; thus I am able to quantitatively, objectively, and non-invasively measure changes in behavior in real time. Each individual EOD that is produced corresponds precisely to neuronal activity in the hindbrain pacemaker nucleus and individual waveform characteristics reflect characteristics of the action potentials in the electrocytes. These direct connections between anatomy, physiology, and the resulting behavior make the EOD an incredibly powerful tool for studying the central and peripheral neuroendocrine control of behavior.

The EOD is used primarily for navigation; however it also functions as a communication signal. Waveform characteristics such as amplitude and duration convey information about the signaler such as species identity, sex, and social status to other electroreceptive fish (Hagedorn, 1986; Lissman, 1958, 1961). B. pinnicaudatus produces a biphasic, sinusoidal EOD that can be characterized in terms of peak-to-peak amplitude $\left(\mathrm{mV} \mathrm{cm}^{-1}\right)$ and duration (ms) of the entire waveform or of either phase individually. These fish emit EODs continuously and are specialists at modulating their waveform characteristics. EOD modulations occur along time courses that range from short-term, rapid changes (milliseconds), to changes that occur over hours or days (intermediate time course), to long term or seasonal changes.

In addition to displaying considerable plasticity and modulability in their waveforms, EODs generated by gymnotiform electric fish are often 
sexually dimorphic and the sex differences in their electric signals are controlled by steroid hormones (Zakon, 1993). Males produce EODs that are typically greater in amplitude and have longer second phase durations ( $\left.\tau_{\mathrm{P} 2}\right)$ than EODs produced by females. The sexual dimorphisms in EOD occur across multiple dimensions: males enhance the 'masculinity' of their waveform traits during peak breeding hours and in response to social encounters (Franchina and Stoddard, 1998; Hagedorn, 1995; Hagedorn and Zelick, 1989), males display a greater range of EOD modulations in response to challenges than females do in response to the same challenges, and males tend to exhibit larger circadian rhythms in their EOD waveforms than females do (Stoddard et al., 2006a).

These distinctions suggest male EODs may be inherently more plastic than female EODs in both the short-term and intermediate time scales. These sex differences also suggest that, in addition to promoting sexual differentiation, sex steroid hormones may facilitate enhanced waveform modulability and plasticity. Previous studies in multiple weakly electric fish species, including $B$. pinnicaudatus, have shown a clear relationship between androgens and the ability to produce a masculine waveform. Androgen injections or implants reliably masculinize both female and juvenile EODs in all species examined (Bass and Hopkins, 1984; Carlson et al., 2000; Dunlap et al., 1998; Dunlap and Zakon, 1998; Few and Zakon, 2001; Hagedorn and Carr, 1985; Mills and Zakon, 1987; Silva et al., 1999). While the relationship 
between sex steroids and waveform sex differences seems fundamental to communication, it is not known what other influences androgens may exert on the EOD. A great deal of variance exists between weakly electric species in their abilities to alter their waveforms. Not all species are capable of producing the rapid modulations that $B$. pinnicaudatus excels at generating (Goldina et al., 2006). Thus, the role of androgens in facilitating plasticity and modulability in EOD production is not known, yet evidence suggests they may be an important factor in determining the responsiveness of this social signal.

Sex steroids are not the only substances known to act as EOD modulators. Serotonin (5-hydroxytryptamine or 5-HT) is a ubiquitous neurotransmitter known to influence a wide range of physiological and behavioral processes and previous research has shown that 5-HT masculinizes EODs in B. pinnicaudatus (Stoddard et al., 2003). In vivo challenges of intramuscular injections of 5-HT masculinized EODs in males, but direct application of $5 \cdot \mathrm{HT}$ to electrocytes in vitro did not alter the waveform (Markham and Stoddard, 2005; Stoddard et al., 2003). These results imply that 5-HT's effects on EOD waveform observed in vivo are the result of central mechanisms that are mediated by a local modulator in the periphery (Stoddard et al., 2003). The neuroendocrine pathways linking central $5-\mathrm{HT}$ actions and the ensuing waveform modulations have yet to be identified. 
This dissertation consists of a series of experiments designed to investigate the neuroendocrine control of a social communication signal from the brain to the periphery and measuring how the behavior is affected by each manipulation. The goals of the subsequent chapters were to: identify which neurochemicals may be pharmacologically relevant to controlling B. pinnicaudatus EOD plasticity and modulability, (2) identify central-to-peripheral neuroendocrine pathways that regulate EOD production, (3) examine the interactions between relevant pharmacological agents and androgens and, (4) describe how androgens are involved in regulating the expression of the EOD behavior in social situations.

\section{CHAPTER 2}

This chapter conveys the results of experiments designed to identify candidate central-to-peripheral neuroendocrine pathways through which $5^{-}$ HT induces EOD modulations. This study follows research that proved 5-HT induces changes in EOD waveform in $B$. pinnicaudatus in vivo but not in vitro, which indicates intermediate steps between the central 5-HT system and peripheral electrocytes that produce the EOD (Markham and Stoddard, 2005; Stoddard et al., 2003). I tested the hypothesis that the mechanism by which central serotonin masculinizes EOD waveforms is activation of the hypothalamic-pituitary-interrenal (HPI) axis (Norris, 1997, 2000; Sumpter, 1997). The HPI is the teleost analogue of the mammalian hypothalamic- 
pituitary-adrenal (HPA) axis, which is often referred to as the 'stress response axis.'

The HPI controls the mobilization and allocation of energy in response to stressors by controlling levels of glucose (i.e., energy available for work) in the blood. A stressor is fundamentally anything that moves an individual from physiological homeostasis, requiring the animal to respond with circumstance-appropriate behavior(s) (Wendelaar Bonga, 1997). These behaviors often require energy (e.g., flight, fight, communicate, mate, etc.) and they need not be associated with distress; therefore the HPI can be more broadly designated as the "energy regulation axis".

The EOD is an energetically expensive signal and producing enhanced 'masculine' waveforms is particularly costly (Salazar and Stoddard, in prep). It is therefore reasonable to hypothesize that any stimulus that results in modulation or enhancement of the EOD may involve activation of the HPI to provide the requisite energy needed for to produce these changes in waveform. A classic method of HPI/A activation found in many vertebrates, including teleosts, occurs via central 5-HT release (Hoglund et al., 2002; Jorgensen et al., 2001; Van de Kar et al., 2001; Winberg et al., 1997).

Stimulation of the HPI/A by $5-\mathrm{HT}$ is characteristically mediated via two specific $5 \cdot \mathrm{HT}$ receptor types, the $5 \cdot \mathrm{HT}_{1 \mathrm{~A}}$ and the $5 \cdot \mathrm{HT}_{2}$ family of receptors. In teleosts, activating $5 \cdot \mathrm{HT}_{1 \mathrm{~A}}$ and $5 \cdot \mathrm{HT}_{2}$ receptors in the hypothalamus stimulates the nucleus preopticus (NPO) to release 
corticotropin releasing hormone $(\mathrm{CRH})$, which then stimulates production and release of adrenocorticotropic hormone (ACTH) from the pituitary (Metz et al., 2005). The resulting increase in plasma concentrations of ACTH leads to the release of cortisol from interrenal cells. Cortisol stimulates gluconeogenesis which may be the physiological connection linking central 5HT with peripheral EOD modulations.

A recent study demonstrated that challenging $B$. pinnicaudatus with $\mathrm{ACTH}$ induces EOD waveform masculinization both in vivo and in vitro (Markham and Stoddard, 2005). These results provide further support for the hypothesis where central 5-HT causes EOD modulations via activation of the HPI and ACTH release. The lack of data directly connecting the actions of central 5-HT to the actions of ACTH on the electrocytes led me to design the following set of experiments. I challenged fish pharmacologically with intramuscular injections of various $5-\mathrm{HT}_{1 \mathrm{~A}}$ and $5-\mathrm{HT}_{2}$ receptor agonists and antagonists to identify which receptors are effective in eliciting EOD modulation in $B$. pinnicaudatus modulations. I also challenged fish with $\mathrm{CRH}$ to verify that the intermediate steps between the 5-HT and ACTH classically involved in the HPI are able to induce EOD modulations in this fish. These experiments were designed to determine if pharmacologically stimulating each step in the HPI pathway resulted in EOD modulations similar to those observed with 5-HT or ACTH challenges. 
Despite the well-established connection between 5-HT and ACTH in the HPI and evidence that both chemicals are EOD modulators in this fish, there is an alternate viable central-to-peripheral neuroendocrine pathway through which central 5-HT effects could be mediated. Central 5-HT release in the brain can also stimulate the hypothalamic-pituitary-thyroidal (HPT) axis and result in production and release $\alpha-\mathrm{MSH}$. The melanocortin peptide $\alpha-\mathrm{MSH}$ is extremely similar in structure and function to ACTH. Both compounds are produced from proopiomelanocortin, the same precursor molecule, they are structurally similar, and they bind to the same melanocortin receptors (MCRs) (Metz et al., 2006). Although ACTH is currently endorsed as the primary cortisol secretagogue in teleosts, it is unresolved whether $\alpha$-MSH has similar corticotropic effects (Metz et al., 2005).

I therefore also challenged fish with injections of $\alpha-\mathrm{MSH}$ and TRH (an intermediate agent analogous to $\mathrm{CRH}$ ) to determine if these compounds are also able to actuate EOD modulations. Positive results would provide evidence for multiple central-to-peripheral pathways controlling EOD waveform in this species.

\section{CHAPTER 3}

Chapters 3 and 4 describe experiments that investigate androgens' role in regulating EOD plasticity and how androgens interact with relevant pharmacological agents studied in Chapter 2. I tested whether androgens 
are responsible for sexual dimorphisms in both EOD response to stressors and EOD plasticity in response to challenge and environmental conditions.

I implanted female $B$. pinnicaudatus with the non-aromatizable androgen, $5 \alpha$-dihydrotestosterone (DHT) and observed changes in their behavioral responses to pharmacological and social challenges as a result of increased androgen levels. I also measured how increased androgen levels affected female waveforms over time (e.g., changes in the circadian rhythmicity). I used a non-aromatizable androgen to ensure that it was not being converted into estrogens and that any effects I observed could be attributed to the actions of androgens.

Chapter 3 describes the results of the first set of DHT implant experiments in which I investigated: 1) how androgens affect circadian changes in EOD waveform parameters such as daily minima and nightly maxima for both amplitude and duration and, 2) how androgens affected female responses to pharmacological challenges. I pharmacologically challenged females with 5-HT and ACTH to determine how androgens affect an individual's response to these challenges. The results from this experiment address the following: 1) identifying the role of androgens in producing a sexually dimorphic circadian rhythm, 2) investigating how androgens alter response to $5-\mathrm{HT}$ and $\mathrm{ACTH}$ challenge and, 3) investigating how androgens affect EOD plasticity and modulability. 
CHAPTER 4

Chapter 4 details the second set of DHT implant experiments in which I tested the role of androgens in modulating female's EOD response to a social challenge. Encounters with conspecifics result in EOD waveform modulations that communicate information between interacting individuals and are precisely the sort of stimuli that should activate the neurochemical cascades I described earlier.

I socially challenged females with female and male challengers (presented individually on separate days) before and after DHT implants were inserted and recorded their behavior. This experiment allowed me to quantify differences in female responses to intra- and intersexual challengers before DHT was implanted and observe how increased androgen levels changed their responses to each challenger type.

This final set of experiments addresses the question of how changes in neurochemistry directly affect the production of behavior. The results from the experiments described in this dissertation represent an integrative investigation into the control and regulation of a social communication signal. 
CHAPTER 2. PHARMACOLOGICAL CHARACTERIZATION OF SEROTONIN AND MELANOCORTIN RESPONSIVE PATHWAYS THAT REGULATE MASCULINITY OF THE ACTION-POTENTIAL-BASED SOCIAL SIGNALS OF GYMNOTIFORM ELECTRIC FISH

Animals respond to social stressors with a broad array of behavioral and physiological adaptations, often including the development of signals that communicate aggression, dominance, or subordination. The production or modulation of these signals in response to stressors suggests that communication systems should be intimately tied to neuroendocrine systems involved in regulating responses to stress. A stressor is action or event that requires a physiological response to maintain energy balance and physiological competence (Wendelaar Bonga, 1997). The primary neuroendocrine system mediating responses to stressors is the hypothalamicpituitary-adrenal (HPA) axis in mammals, or the homologous hypothalamicpituitary-interrenal (HPI) axis in teleost fish (Norris, 1997, 2000; Sumpter, 1997).

The neuromodulator serotonin $(5-\mathrm{HT})$ has long been associated with promoting behavior appropriate for dominant and/or subordinate individuals within a social group (Edwards and Kravitz, 1997; Simon, 2002). The role of 5-HT in promoting social behavior and the role of HPA/I axis in mediating stress adaptations suggests that social communication signals could be controlled in part through the interaction of the central 5-HT system and the HPA/I axis. The HPA/I axis indeed appears to be regulated by the central serotonergic system in many taxa (Hoglund et al., 2002; Jorgensen et al., 
2001; Van de Kar et al., 2001; Winberg et al., 1997). In teleost fish exposed to stressful conditions, $5-\mathrm{HT}$ activates the HPI axis via hypothalamic $5-\mathrm{HT}_{1 \mathrm{~A}}$ (Hoglund et al., 2002) and 5- $\mathrm{HT}_{2}$ receptors (Van de Kar et al., 2001; Winberg et al., 1997), stimulating release of peptidergic factors from the hypothalamus including corticotropin-releasing factor (CRF) and thyrotropinreleasing hormone (TRH) (Larsen et al., 1998). These hypothalamic peptides stimulate pituitary corticotropes and melanotropes to release into circulation the melanocortin peptides adrenocorticotropic hormone (ACTH) and $\alpha$ melanocyte stimulating hormone $(\alpha-\mathrm{MSH})$, respectively (Rotllant et al., 2000). The HPA/I is best known for mediating release of glucocorticoids in response to stressful stimuli, however the intermediary peptides hormones also regulate behavior and physiology on a broad scale.

The interaction of the central serotonergic system and the HPI axis has been well characterized in teleosts primarily by measuring changes in plasma concentration of target hormones after exposing fish to behavioral or pharmacological challenges. These studies often establish interactions between endocrine systems without assessing the ultimate behavioral consequences of these manipulations. Determining the roles of specific pathways in the regulation of socially relevant behaviors, however, is the key to fully understanding the neuroendocrine control of communication signals. An excellent example is skin darkening in Arctic charr, a response of subordinate individuals that is mediated by activation of the HPI axis. In 
this system, HPI activation elevates circulating levels of both ACTH and $\alpha^{-}$ $\mathrm{MSH}$, with $\alpha-\mathrm{MSH}$ primarily responsible for control of skin darkening (Hoglund et al., 2000).

The electric organ discharge (EOD) of weakly electric gymnotiform fish is a model system particularly well suited for investigating neuroendocrine control of communication signals in response to social stressors (Stoddard et al., 2006b). Specialized excitable cells (electrocytes) in the peripheral electric organ produce the EOD, a signal that is used for navigation and functions also as a dynamic communication signal. EODs are sexually dimorphic in most gymnotiform taxa, the sexes differing in discharge rate and in waveform duration and amplitude (Bass and Zakon, 2005; Zakon, 1993). Social encounters and environmental stressors modulate the EOD waveform by altering the biophysics and discharge waveforms of the electrocytes. The EOD is thus a continuously available signal that responds rapidly to social manipulations, can be measured noninvasively, and directly reflects the biophysical activity of the effector cells. The EOD is an energetically expensive signal and producing enhanced waveforms is particularly costly (Salazar and Stoddard, in preparation). It is therefore reasonable to hypothesize that any stimulus that results in reduction or enhancement of the EOD may involve the HPI to simultaneously regulate the electric waveform and energy available for adaptive social response. Peripheral injections of 5-HT or ACTH elicit EOD waveform modulations comparable to 
those induced by social encounters in the gymnotiform fish Brachyhypopomus pinnicaudatus, but only ACTH acts directly on electrocytes to modify their discharge waveforms (Markham and Stoddard, 2005; Stoddard et al., 2003). These findings suggest that the HPI axis could be responsible for regulating EOD waveform.

Central serotonergic activation of the HPA/HPI is well documented, yet stimulating or blocking specific receptor types often result in contradictory actions on basal ACTH secretion (Welch et al., 1993). The seemingly incongruous role of the same agonist as inhibitor and facilitator can be explained by evidence that serotonergic systems regulate some stressor-related responses and not others (somatosensory vs. emotive vs. physical pain/discomfort) and that different serotonergic pathways are activated by stimulating different receptor types with different results on the HPA/HPI (Jorgensen et al., 1998; Saphier et al., 1995; Welch et al., 1993).

The objective of this study, therefore, was to better characterize the pharmacology of EOD control by signal molecules of the HPI, and in particular to look for opposing actions within the serotonergic system. I used multiple neuroendocrine probes to assess activity along specific steps in the serotonergic and HPI pathways and used changes in the characteristics of a social communication signal as an endpoint. I injected fish with the peptidergic factors $\mathrm{CRF}, \mathrm{TRH}$, and $\alpha \cdot \mathrm{MSH}$ to determine if they also modulate EOD waveforms in vivo, consistent with the hypothesis that melanocortin 
pathways of the hypothalamus and pituitary regulate EOD enhancements. I then sought to determine whether in vivo modulations of EOD waveform by 5-HT are mediated by multiple receptor classes, such as those pharmacologically similar to the mammalian $5 \mathrm{HT}_{1} \mathrm{R}$ and $5 \mathrm{HT}_{2} \mathrm{R}$, and if so, the directionality of those responses.

METHODS

ANIMALS

Adult male Brachyhypopomus pinnicaudatus bred and maintained on Florida International University campus, were randomly collected from breeding pools during 2002-2006 and brought indoors for pharmacological challenge tests. Males were weighed and measured prior to individual placement in recording tanks.

ELECTRIC SIGNAL RECORDING

I recorded EODs with an automated, calibrated recording system previously described in detail (Stoddard et al., 2003). The system automatically records EODs when the fish passes through or sleeps in the geometric center of the tank, and calculates the chosen waveform parameters (described below).

To allow fish to acclimate to their tanks and to measure baseline EODs for each individual, I placed fish individually in recording tanks and collected EOD data for a minimum of 24 -hours before performing any challenge tests. 
Following any challenge trial, the system continued to measure EODs for at least another day, after which fish were returned to their outdoor pools.

\section{Pharmacological Challenges}

Previous investigations determined EOD response to intramuscular injections of $5-\mathrm{HT}$ saturates at $2.5 \mathrm{nMol} \mathrm{g-1}$ body weight and response to ACTH saturates at $25 \mathrm{pMol} \mathrm{g}^{-1}$ (Markham and Stoddard, 2005; Stoddard et al., 2003). I used these figures as the starting point to select doses for serotonergic drugs and peptide hormones. I prepared the injection solutions to produce the desired dose when injected intramuscularly at $1 \mathrm{ul} \mathrm{g}^{-1}$ body weight (bw). All pharmacological compounds were obtained from SigmaAldrich and dissolved in physiological saline described previously (Stoddard et al. 2003). I began with doses estimated to be physiologically active on equivalent mammalian receptors, but if I obtained no effect or an equivocal effect I performed additional injections at higher and lower doses (Figs. 2.22.5).

I used the three partially selective agonists to probe for EOD regulation by the $5 \mathrm{HT}_{2} \mathrm{R}$ family: 2,5-dimethoxy-4-iodoamphetamine (DOI), $\alpha$ methyl-5-hydroxytryptamine ( $\alpha \cdot \mathrm{Me}-5 \cdot \mathrm{HT})$, and 6 -chloro-2- (1-piperazinyl) pyrazine (MK212). The silent $5 \mathrm{HT}_{2 \mathrm{~A}} \mathrm{R}$ antagonist ketanserin was dissolved at $\mathrm{pH} 6.7$, titrated to $\mathrm{pH} 7.2$ with $\mathrm{NaOH}$, and then diluted to a final concentration of $2.5 \mathrm{mM}$. To probe for waveform regulation by the $5 \mathrm{HT}_{1 \mathrm{~A}} \mathrm{R}, \mathrm{I}$ used the selective agonist $8 \cdot{ }^{-}$hydroxy ${ }^{-} \mathrm{di}^{-} n$-propylamino tetralin $(8 \cdot \mathrm{OH}-\mathrm{DPAT})$ 
and the selective $5 \mathrm{HT}_{1 \mathrm{~A}} \mathrm{R}$ antagonist $\mathrm{N}^{-}$[2-[4-(2-methoxyphenyl)-1piperazinyl] ethyl]-N- (2-pyridinyl) cyclohexanecarboxamide trihydrochloride (WAY100635). Table 2.1 shows reported mammalian 5-HT receptor affinities of the serotonergic drugs I used in the experiments characterizing mechanisms of $5 \cdot \mathrm{HT}$ activity. Saline injections $\left(1 \mathrm{ul} \mathrm{g}^{-1} \mathrm{bw}\right)$ served as a control condition for effects of handling and injection. Handling time from capture to replacement in the tank was usually less than one-minute.

DATA ANALYSIS

The EOD pulse of Brachyhypopomus pinnicaudatus is a biphasic sinusoid that varies in amplitude and in the duration of the second phase (Fig. 2.1). I measured amplitude of the EOD waveform peak-to-peak, and duration of the second phase as $\tau_{\mathrm{P} 2}$, the time constant of an inverse exponential function fit to the decay segment of the second phase. Changes in the EOD waveform resulting from my pharmacological challenge trials are superimposed upon circadian cycles in waveform parameters (Franchina and Stoddard, 1998; Stoddard et al., 2003). I therefore mathematically isolated drug-induced changes in these measures as reported previously (Stoddard et al. 2003). This analysis allowed me to extract the changes in EOD amplitude and $\tau_{\mathrm{P} 2}$ that were caused by the challenge trials and not a function of the normal circadian modulations in EOD. Additionally, earlier work showed that responses to $5-\mathrm{HT}$ challenge are closely related to baseline values of an individual's EOD parameters (Stoddard et al., 2003). I therefore quantified 
challenge responses as proportion change relative to baseline: (peak value after injection - baseline value) / baseline value.

Responses to challenge were analyzed for each pharmacological agent tested using Kruskal-Wallis one-way ANOVA tests using dose as the dependent variable and response to saline injection as the control group. Data analysis was generated using SAS software, Version 9.1.3 of the SAS System for Windows, and MATLAB, Version 7.1. Significant omnibus tests $(p<0.05)$ were further analyzed using a pairwise, two-tailed comparison of Kruskal-Wallis mean scores with Bonferroni adjustment (Siegel and Castellan, 1988).

RESULTS

PEPTIDE HORMONES

Intramuscular injection of the hypothalamic releasing hormones CRF and TRH elicited marked increases in EOD amplitude and $\tau_{\mathrm{P} 2}$ compared to control treatments (Fig. 2.2A \& B). Likewise, injection of the melanocortin $\alpha$ MSH increased both EOD parameters significantly (Fig. 2.2C). $5-\mathrm{HT}_{2} \mathrm{R}$ SELECTIVE LIGANDS

Both DOI and $\alpha-\mathrm{Me}-5 \cdot \mathrm{HT}$ increased EOD amplitude and $\tau_{\mathrm{P} 2}$, in a manner like 5-HT injection (Stoddard et al., 2003), but MK212 had no effect (Fig. 2.3A \& B). Results from $\alpha-\mathrm{Me}-5-\mathrm{HT}$ showed some non-linear doseselectivity (Fig. 2.3C) In contrast to the lack of agonists highly selective for individual $5 \mathrm{HT}_{2} \mathrm{R}$ subtypes, the silent antagonist ketanserin is highly 
selective for the $5 \mathrm{HT}_{2 \mathrm{~A}} \mathrm{R}$ over the $5 \mathrm{HT}_{2 \mathrm{~B}} \mathrm{R}$. Therefore, to better assess which of these receptor subtypes is responsible for EOD modulation, I evaluated whether pretreatment with ketanserin would block the effects of a subsequent 5-HT injection. I first injected one group of fish with saline and one group of fish with ketanserin $(2.5 \mathrm{mM})$. Fish in both groups were then given a second injection of 5-HT (2.5 mM) 15-45 minutes later. I found that ketanserin blocked the effects of $5 \cdot \mathrm{HT}$ on $\tau_{\mathrm{P} 2}$. Fish pretreated with ketanserin showed little or no increase in $\tau_{\mathrm{P} 2}$ in response to the $5 \cdot \mathrm{HT}$ injection compared to controls, whereas fish pretreated with saline displayed the typical 5-HT-induced increase in $\tau_{\mathrm{P} 2}$ (Fig. 2.4). These results provide additional evidence that a $5-\mathrm{HT}_{2 \mathrm{~A}}$ receptor mediates EOD modulation, although I cannot conclusively rule out participation by the $5 \cdot \mathrm{HT}_{2 \mathrm{~B}}$ or $5 \mathrm{HT}_{2 \mathrm{C}}$ receptors.

$5-\mathrm{HT}_{1 \mathrm{~A}} \mathrm{R}$ SELECTIVE LIGANDS

To test the possible involvement of $5 \mathrm{HT}_{1 \mathrm{~A}}$ receptors in $\mathrm{EOD}$ waveform modulation, I injected fish with the highly specific $5 \mathrm{HT}_{1 \mathrm{~A}} \mathrm{R}$ agonist $8 \cdot \mathrm{OH}^{-}$ DPAT and the selective $5 \mathrm{HT}_{1 \mathrm{~A}} \mathrm{R}$ antagonist WAY100635. Both EOD amplitude and $\tau_{\mathrm{P} 2}$ decreased in response to 8-OH-DPAT challenges relative to controls (Fig. 2.5A), though amplitude response to the middle dose [0.25 mM] did not differ from the controls.

The silent antagonist WAY100635 increased both amplitude and $\tau_{\mathrm{P} 2}$ at all doses tested (Fig. 2.5B). Taken together, the effects of WAY100635 and 8- 
$\mathrm{OH}-\mathrm{DPAT}$ injections provide strong evidence for the involvement of a $5 \mathrm{HT}_{1 \mathrm{~A}} \mathrm{R}$-like receptor in serotonergic inhibition of EOD waveform. Receptors of the $5 \mathrm{HT}_{1} \mathrm{R}$ family either function as autoreceptors that inhibit activity of serotonergic neurons (Hoyer et al., 2002), or as receptors on post-synaptic cells (for review see Barnes and Sharp, 1999). If the $5 \mathrm{HT}_{1 \mathrm{~A}} \mathrm{R}$ involved in EOD waveform modulations functions as an autoreceptor on the same circuit as the receptor identified by the $5 \mathrm{HT}_{2} \mathrm{R}$ ligands above, then release of EOD inhibition by the $5 \mathrm{HT}_{1 \mathrm{~A}} \mathrm{R}$ antagonist WAY100635 should be blocked by the $5 \mathrm{HT}_{2} \mathrm{R}$ antagonist ketanserin. Conversely, failure to block the effect of WAY100635 with ketanserin would indicate these receptors exist on separate circuits.

I evaluated these hypotheses by pretreating one group of males with ketanserin (or saline for a control), followed by injections of WAY100635 1545 min later. The control group (saline pre-treatment) showed the expected increases in EOD amplitude and $\tau_{\mathrm{P} 2}$ in response to WAY100635 (Fig. 2.6). The fish pretreated with ketanserin showed similar increases in these measures when injected with WAY100635. The failure of ketanserin to block the effects of WAY100635 indicates that EOD modulations are mediated by a $5 \mathrm{HT}_{1 \mathrm{~A}} \mathrm{R}$ on a different circuit than the $5 \mathrm{HT}_{2} \mathrm{R}$, most likely positioned as a postsynaptic receptor rather than a presynaptic autoreceptor. 


\section{DISCUSSION}

The current study demonstrates that $B$. pinnicaudatus possess both $5 \mathrm{HT}_{1 \mathrm{~A}} \mathrm{R}$ and $5 \mathrm{HT}_{2} \mathrm{R}$-like receptors and that these receptor types are implicated in the regulation of rapid EOD modulations in social contexts. The function of the $5 \mathrm{HT}_{2 \mathrm{~A}} \mathrm{R}$-like receptor appears to be the rapid enhancement of the EOD and the effect is likely exerted by increasing plasma levels of melanocortins. I suggest this receptor type may be a mechanism for inducing rapid increases in EOD waveform in response to social challenges or similar stressors. Conversely, the $5 \cdot \mathrm{HT}_{1 \mathrm{~A}}$ appears to inhibit EOD, likely by suppressing release of melanocortins and is a candidate pathway for suppression of the social signal in response to social defeat and physiological stressors. Pharmacologically activating different receptors along the HPI circuit with melanocortin peptides and their secretagogues consistently enhanced the EOD, indicating a role of the HPI in regulating EOD modulations in social contexts.

SEROTONIN RECEPTOR IDENTITY

Activation of $5 \mathrm{HT}_{2 \mathrm{~A}} \mathrm{R}$ has been shown to induce HPA activation via characteristic release of ACTH mediated by $\mathrm{CRF}$ neurons in mammalian PVN (Van de Kar et al., 2001; Winberg et al., 1997) and 5H'T $\mathrm{T}_{2 \mathrm{~A}} \mathrm{R}$ antagonists inhibit increase in plasma ACTH (Saphier et al., 1995). The modulation of EOD waveform by two of the three $5 \mathrm{HT}_{2 \mathrm{~A}} \mathrm{R}$ agonists I tested suggests that a receptor in the $5 \mathrm{HT}_{2} \mathrm{R}$ family is responsible for EOD modulation by $5-\mathrm{HT}$. 
Definitive proof will require molecular methods. Yet the inconsistent effects of these three compounds require further analysis. The $5 \mathrm{HT}_{2} \mathrm{R}$ family includes three receptor subtypes: the $5 \mathrm{HT}_{2 \mathrm{~A}}, 2 \mathrm{~B}$, and ${ }_{2 \mathrm{C}}$ receptors. Although $\alpha^{-}$ Me-5-HT, MK212, and DOI all show preferential affinity to the $5 \mathrm{HT}_{2} \mathrm{R}$ family over other 5HTR families, no currently available $5 \mathrm{HT}_{2} \mathrm{R}$ agonists reliably distinguish between the three subtypes (Ramage, 2005; Van de Kar et al., 2001). Further, binding affinities are reported for mammalian receptor types, and even these vary enough between species (e.g., mice and rats) as to require great caution when speculating about differential receptor subtype affinities in a teleost fish. MK212 generally shows highest affinity for the $5 \mathrm{HT}_{2 \mathrm{~B}} \mathrm{R}$ and $5 \mathrm{HT}_{2 \mathrm{CR}}$ (Hoyer et al., 2002; Smythe et al., 1988), thus the lack of EOD modulation by MK212 suggests that EOD modulation is mediated by a $5 \mathrm{HT}_{2 \mathrm{~A}} \mathrm{R}$, and not by a $5 \mathrm{HT}_{2 \mathrm{~B}} \mathrm{R}$ or $5 \mathrm{HT}_{2 \mathrm{C}}$ receptor. Consistent with this interpretation, pre-treatment with the highly specific $5-\mathrm{HT}_{2 \mathrm{~A}}$ antagonist nullified the effects of 5-HT treatment, providing the strongest evidence that the $5-\mathrm{HT}_{2 \mathrm{~A}}$ is necessary for EOD enhancement in response to $5-\mathrm{HT}$.

The $5 \mathrm{HT}_{1 \mathrm{~A}} \mathrm{R}$ selectivity of $8-\mathrm{OH}-\mathrm{DPAT}$ and WAY100635 are such that I am more confident of the identity of a constitutively active $5 \mathrm{HT}_{1 \mathrm{~A}} \mathrm{R}$ type receptor that modulates EOD amplitude and $\tau_{\mathrm{P} 2}$. These fish reduced their EOD parameters after being injected with the $5 \mathrm{HT}_{1 \mathrm{~A}} \mathrm{R}$ agonist $8-\mathrm{OH}-\mathrm{DPAT}$ and they enhanced their EODs after injections of the silent antagonist WAY100635. These results indicate that a $5 \mathrm{HT}_{1 \mathrm{~A}} \mathrm{R}$-like receptor is present 
and pharmacologically relevant in this species and that it exerts inhibitory control of the EOD.

The silent antagonist WAY100635 caused approximately linear dosedependent enhancement of both EOD parameters however I observed a different pattern by probing with $8-\mathrm{OH}-\mathrm{DPAT}$. Three fish that were given the middle dose $(0.25 \mathrm{mM})$ enhanced their amplitudes and the other three in this group reduced theirs after injection. The effects of this 8-OH-DPAT dose on $\tau_{\mathrm{P} 2}$ were also less inhibitory than either the lower or the higher doses. These results suggest the $5 \mathrm{HT}_{1 \mathrm{~A}} \mathrm{R}$ story may be more complex in this fish than this receptor simply inhibiting release of one melanocortin.

The $5 \mathrm{HT}_{1 \mathrm{~A}} \mathrm{R}$ operates both as a pre-synaptic autoreceptor located on serotonergic neurons and as a post-synaptic receptor on target cells in teleosts (Hoglund et al., 2002). My series of blocking experiments lead me to tentatively propose that the effects I observed in this fish after probing with 8-OH-DPAT and WAY100635 are the result of the actions of a post-synaptic receptor rather than an autoreceptor (Fig. 2.5). I predicted several possible $5 \mathrm{HT}_{1 \mathrm{~A}} \mathrm{R}$ circuits (Fig. 2.7). In model A., the $5 \mathrm{HT}_{1 \mathrm{~A}} \mathrm{R}$ is situated upstream and on the same circuit as the $5 \mathrm{HT}_{2 \mathrm{~A}} \mathrm{R}$. If I block the $5 \mathrm{HT}_{2 \mathrm{~A}} \mathrm{R}$ with ketanserin and follow with a dose of $5 \mathrm{HT}_{1 \mathrm{~A}} \mathrm{R}$ antagonist WAY100635, I would expect to observe no change in EOD. I saw an increase in EOD after this test that was the same as the increases I observed after an independent injection of WAY100635. This signifies that the $5-\mathrm{HT}_{2 \mathrm{~A}} \mathrm{R}$ cannot be downstream and on 
the same circuit as the $5 \mathrm{HT}_{1 \mathrm{~A}} \mathrm{R}$. Model $\mathrm{B}$ predicts that $5 \mathrm{HT}_{2 \mathrm{~A}} \mathrm{R}$ postsynaptic receptors and $5 \mathrm{HT}_{1 \mathrm{~A}} \mathrm{R}$ autoreceptors are located on the same cell. If this model is correct and I block the $5 \mathrm{HT}_{2 \mathrm{~A}} \mathrm{R}$ with ketanserin then stimulate the $5 \mathrm{HT}_{1 \mathrm{~A}} \mathrm{R}$ with $5-\mathrm{HT}$, I would expect to see a decrease in EOD similar to the drop induced by $8-\mathrm{OH}-\mathrm{DPAT}$. I observe no change in the EOD as a result of this test, thus this model is also incorrect. In model $\mathrm{C}$, the $5 \mathrm{HT}_{1 \mathrm{~A}} \mathrm{R}$ is located upstream of a mystery $5 \cdot \mathrm{HT}$ receptor other than a $5 \mathrm{HT}_{2 \mathrm{~A}} \mathrm{R}$. If I probe with ketanserin followed by $5-\mathrm{HT}$, I would expect to see a drop in EOD because the ketanserin would not block the mystery receptor. Ketanserin blocks the 5-HT effect in this test therefore this model cannot be true. The final model I present is the only one I was unable to disprove with my tests. In model D, the $5 \mathrm{HT}_{1 \mathrm{~A}} \mathrm{R}$ is located behind the blood brain barrier and on a circuit separate from the $5 \mathrm{HT}_{2 \mathrm{~A}} \mathrm{R}$, which resides outside the blood brain barrier (e.g., in the pituitary or periventricular organs of the hypothalamus). If this model is correct, peripheral injections of $5 \cdot \mathrm{HT}$ could not reach the $5 \mathrm{HT}_{1 \mathrm{~A}} \mathrm{R}$ but could stimulate the $5 \mathrm{HT}_{2 \mathrm{~A}} \mathrm{R}$. The lack of EOD modulation I observe as a result of the ketanserin followed by WAY100635 test would then be explained by ketanserin reaching and blocking the $5 \mathrm{HT}_{2 \mathrm{~A}} \mathrm{R}$, but the peripheral injection of $5-\mathrm{HT}$ not having an effect because it cannot activate the $5 \mathrm{HT}_{1 \mathrm{~A}} \mathrm{R}$ behind the blood brain barrier.

Evidence that receptor distribution in the brain is limited supports my hypothesis that the $5 \mathrm{HT}_{1 \mathrm{~A}} \mathrm{R}$ is in a distinct location from the $5 \mathrm{HT}_{2 \mathrm{~A}} \mathrm{R}$ (Barnes 
and Sharp, 1999). I propose this model as a guide for future research investigating the placement, distribution, and molecular identity of these different 5-HT receptors in weakly electric fish brains.

Current research is leading to a shift in the paradigm that levels of 5HT and aggression are inversely and linearly related. High levels of 5-HT sometimes accompany high levels of aggression (Korzan et al., 2000; Matter et al., 1998) and a primed serotonergic system may be necessary to enable an individual to produce an appropriate behavioral response in complex social context (Sperry et al., 2005). These findings would help explain the apparent paradox I observe in this fish as a result of 5-HT challenge. If the classical account of the serotonin system as an inhibitor of aggression is accurate and enhancements of the EOD in the presence of conspecifics is aggressive, then the reduction in EOD parameters following activation of the $5 \mathrm{HT}_{1 \mathrm{~A}} \mathrm{R}$ makes perfect sense, but the increase in these parameters following activation of the $5 \mathrm{HT}_{2} \mathrm{R}$ is unexpected. Perhaps both very low and very high levels of serotonergic activity augment the EOD, allowing fish to increase the potency of their communication signal both when dominant (low 5-HT) and when newly challenged (high $5 \cdot \mathrm{HT}$ ).

If aggression modulated through the $5 \mathrm{HT}_{1 \mathrm{~A}} \mathrm{R}$, as some studies suggest (Joppa et al., 1997; Sanchez, 1997; Simon et al., 1998; Sperry et al., 2005), then the autoreceptor and post-synaptic receptor may be one circuit that rapidly inhibits and terminates enhanced EOD response in weakly electric 
fish. Activating the $5 \mathrm{HT}_{1 \mathrm{~A}} \mathrm{R}$ inhibits neuronal firing and decreases $5-\mathrm{HT}$ synthesis (Perreault et al., 2003; Sperry et al., 2005). My data show that activating $5 \mathrm{HT}_{1 \mathrm{~A}} \mathrm{R}$ with $8-\mathrm{OH}-\mathrm{DPAT}$ causes a dampening of both EOD parameters, although I are not yet certain what the detailed social significance of specific patterns of enhancements and reductions in EOD are.

It is likely that there are intricate nuances in the information that EOD modulations send and that the social significance of a rise or fall in EOD is more complicated than linear dominance or subordinacy. Modulations in the EOD, particularly enhancements of $\tau_{\mathrm{P} 2}$, have been proposed to function as mate attracting signals. If enhancing the EOD serves only to attract females, it is not intuitively clear why aggressive behavior channels would regulate this signal.

One possible explanation is that the enhancements of $\tau_{\mathrm{P} 2}$ function in male-male competition instead of, or in addition to, mate attraction or that females favor aggressive males. Alternatively, I favor the idea that the EOD is a multicomponent signal that sends information to different receivers through different aspects of its expression. Because the expression of EOD parameters are intricately tied to each other, it would be easy to see how the mechanisms that control one social signal, e.g., aggression, could be co-opted to regulate another social signal, e.g., mate attraction. On the other hand, it is also possible that this description of control of this plastic and complex signal is simplistic and that other factors interact with the serotonergic 
system to regulate EOD expression. I found that this is certainly the case of the intermediate factors in the central serotonergic-HPI circuit.

\begin{tabular}{|c|c|c|c|c|}
\hline & $5 \cdot \mathrm{HT}_{1 \mathrm{~A}}$ & $5 \cdot \mathrm{HT}_{2 \mathrm{~A}}$ & $5-\mathrm{HT}_{2 \mathrm{~B}}$ & $5 \cdot \mathrm{HT}_{2 \mathrm{C}}$ \\
\hline \multicolumn{5}{|l|}{ Agonist } \\
\hline $5 \cdot \mathrm{HT}$ & $\begin{array}{l}\quad 8.8 \\
\text { (Peroutka } \\
\text { and Howell, } \\
\text { 1994) }\end{array}$ & $\begin{array}{c}8.2 \\
\text { (Peroutka and } \\
\text { Howell, 1994) }\end{array}$ & $\begin{array}{l}\quad 7.6 \\
\text { (Peroutka } \\
\text { and Howell, } \\
\text { 1994) }\end{array}$ & $\begin{array}{l}\quad 8.0 \\
\text { (Peroutka } \\
\text { and } \\
\text { Howell, } \\
\text { 1994) }\end{array}$ \\
\hline 8-OH-DPAT & $\begin{array}{l}\quad 9.2 \\
\text { (Millan et al., } \\
\text { 1992) }\end{array}$ & $\begin{array}{l}\quad 5.2 \\
\text { (Millan et al., } \\
\text { 1992) }\end{array}$ & & $\begin{array}{l}\quad<5 \\
\text { (Millan et } \\
\text { al., 1992) }\end{array}$ \\
\hline DOI & $\begin{array}{l}\quad 5.2 \\
\text { (van } \\
\text { Wijngaarden } \\
\text { et al., 1990) }\end{array}$ & \begin{tabular}{l}
\multicolumn{1}{c}{7.6} \\
(Schechter and \\
Simansky, \\
1988)
\end{tabular} & & \begin{tabular}{l}
\multicolumn{1}{c}{7.0} \\
(Schechter \\
and \\
Simansky, \\
1988)
\end{tabular} \\
\hline MK212 & $\begin{array}{l}\quad 5.3 \\
\text { (Smythe et } \\
\text { al., 1988) }\end{array}$ & $\begin{array}{l}\quad 4.8 \\
\text { (Smythe et al., } \\
\text { 1988) }\end{array}$ & $\begin{array}{c}6.2 \\
\text { (Hoyer et } \\
\text { al., 1994) }\end{array}$ & $\begin{array}{l}\quad 6.2 \\
\text { (Smythe et } \\
\text { al., 1988) }\end{array}$ \\
\hline WAY100635 & $\begin{array}{l}\quad 8.9 \\
\text { (Fletcher et } \\
\text { al., 1996) }\end{array}$ & $\begin{array}{l}\quad<7 \\
\text { (Fletcher et al., } \\
\text { 1996) }\end{array}$ & & $\begin{array}{l}\quad<7 \\
\text { (Fletcher } \\
\text { et al., } \\
\text { 1996) }\end{array}$ \\
\hline Ketanserin & $\begin{array}{c}5.9 \\
\text { (Hoyer, 1989) }\end{array}$ & $\begin{array}{l}\quad 8.7 \\
\text { (Schreiber et } \\
\text { al., 1995) }\end{array}$ & $\begin{array}{c}5.4 \\
\text { (Hoyer et } \\
\text { al., 1994) }\end{array}$ & $\begin{array}{l}\quad 7.2 \\
\text { (Schreiber } \\
\text { et al., } \\
\text { 1995) }\end{array}$ \\
\hline$\alpha-\mathrm{Me}-5-\mathrm{HT}$ & & $\begin{array}{c}6.1 \\
\text { (Baxter et al., } \\
1995)\end{array}$ & $\begin{array}{c}8.4 \\
\text { (Baxter et } \\
\text { al., 1995) }\end{array}$ & $\begin{array}{c}6.2 \\
\text { (Baxter et } \\
\text { al., 1995) } \\
\end{array}$ \\
\hline
\end{tabular}

Table 2.1. Receptor affinities $\left(\mathrm{pK}_{\mathrm{i}} \mathrm{s}\right)$ for serotonergic agents used in this study, following (Barnes and Sharp, 1999; Baxter et al., 1995; Jorgensen et al., 1999). 


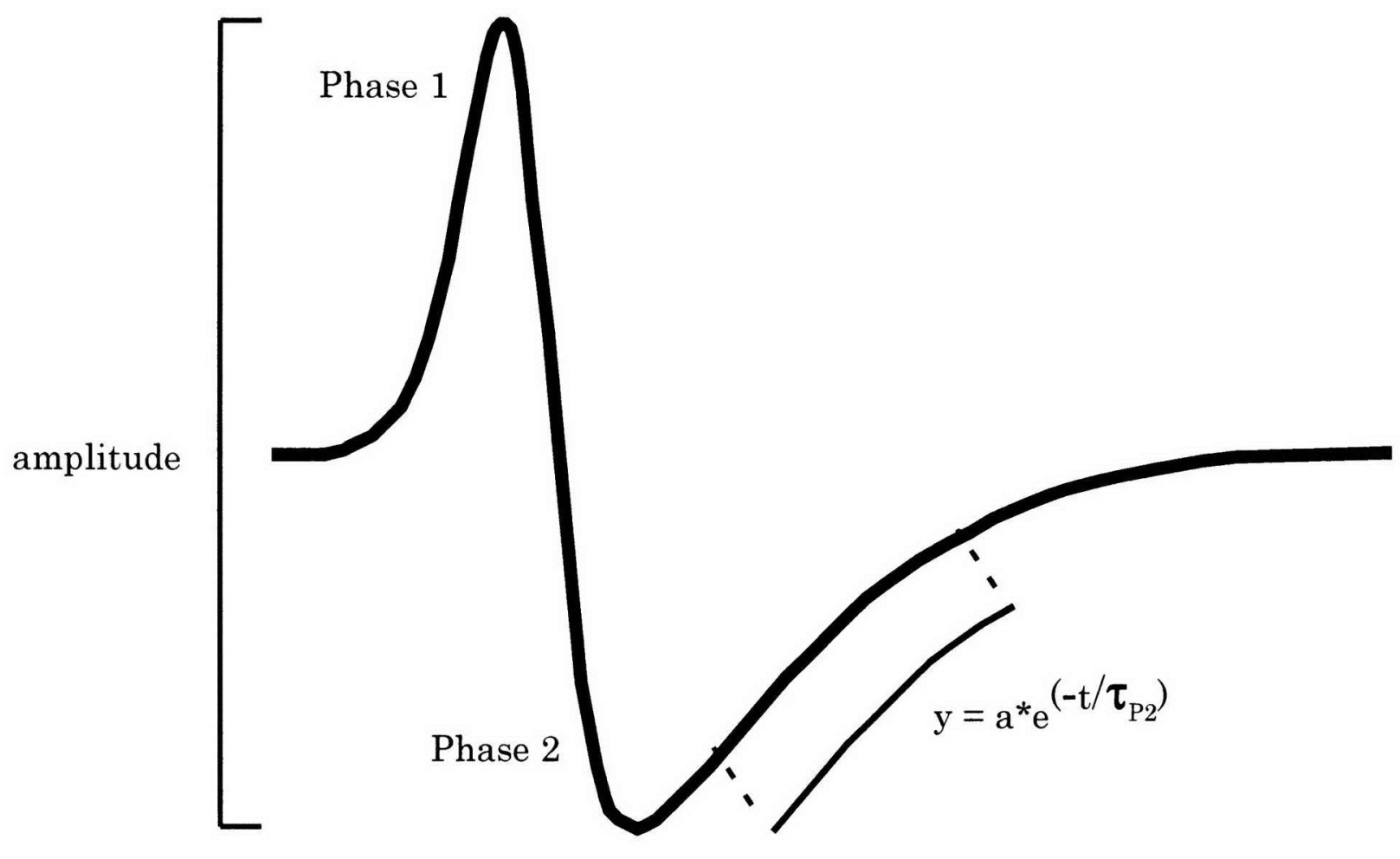

$1 \mathrm{~ms}$

Figure 2.1. Measurement of Brachyhypopomus pinnicaudatus electric organ discharge (EOD) parameters. Amplitude was measured peak-to-peak for the entire waveform. The time constant of repolarization $\left(\tau_{\mathrm{P} 2}\right)$ was estimated by fitting an inverse exponential function fit to the decay segment of phase two. 

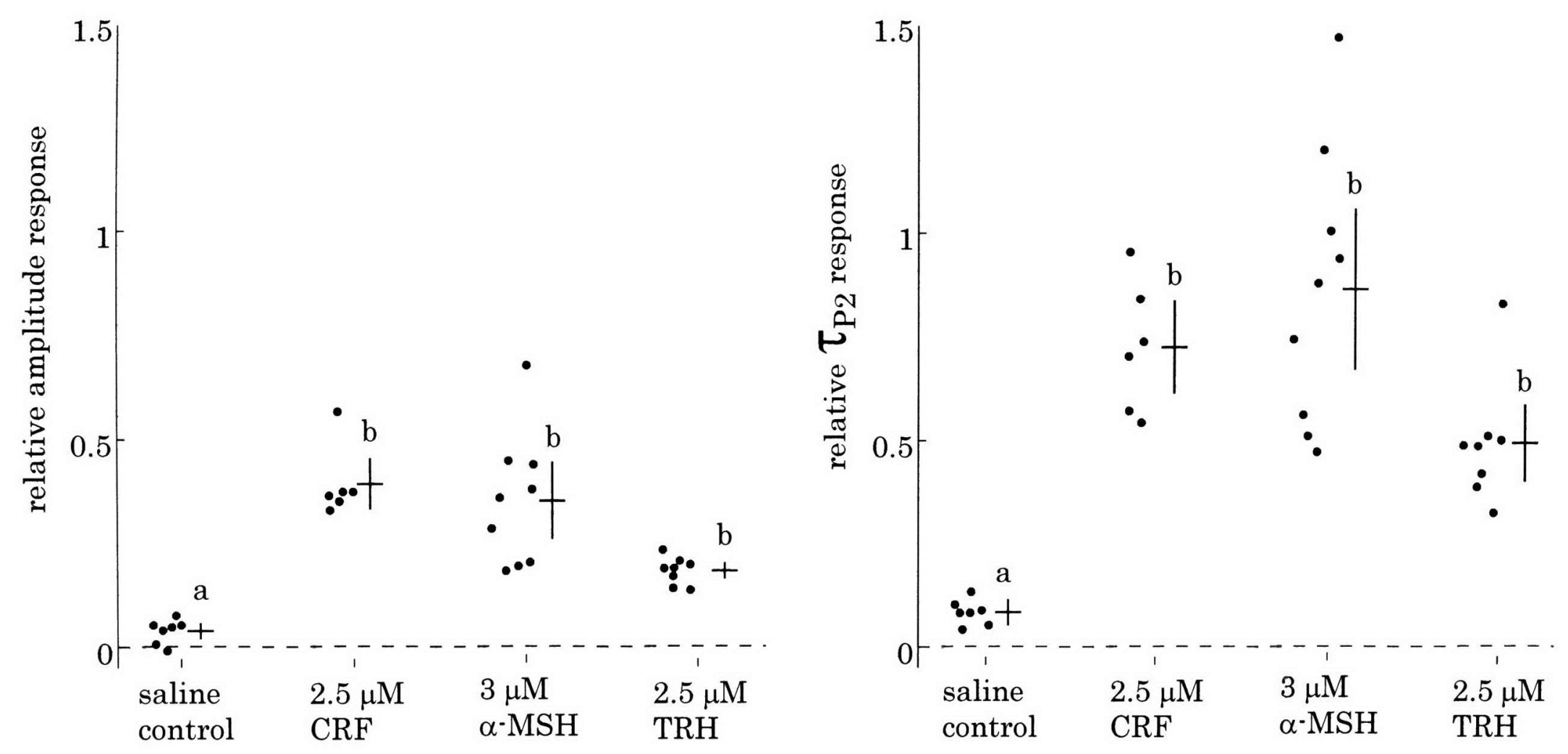

Figure 2.2. Injections of hypothalamic and pituitary hormones modulate EOD waveform. 

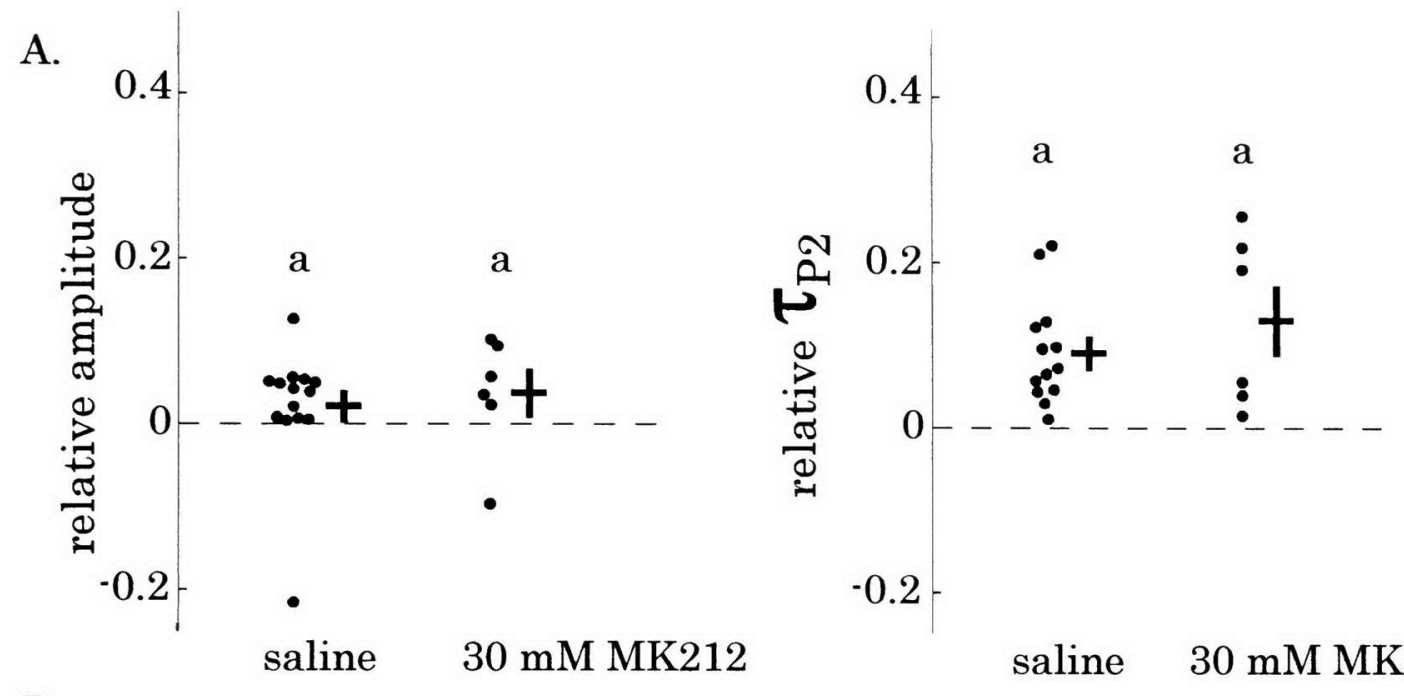

B.

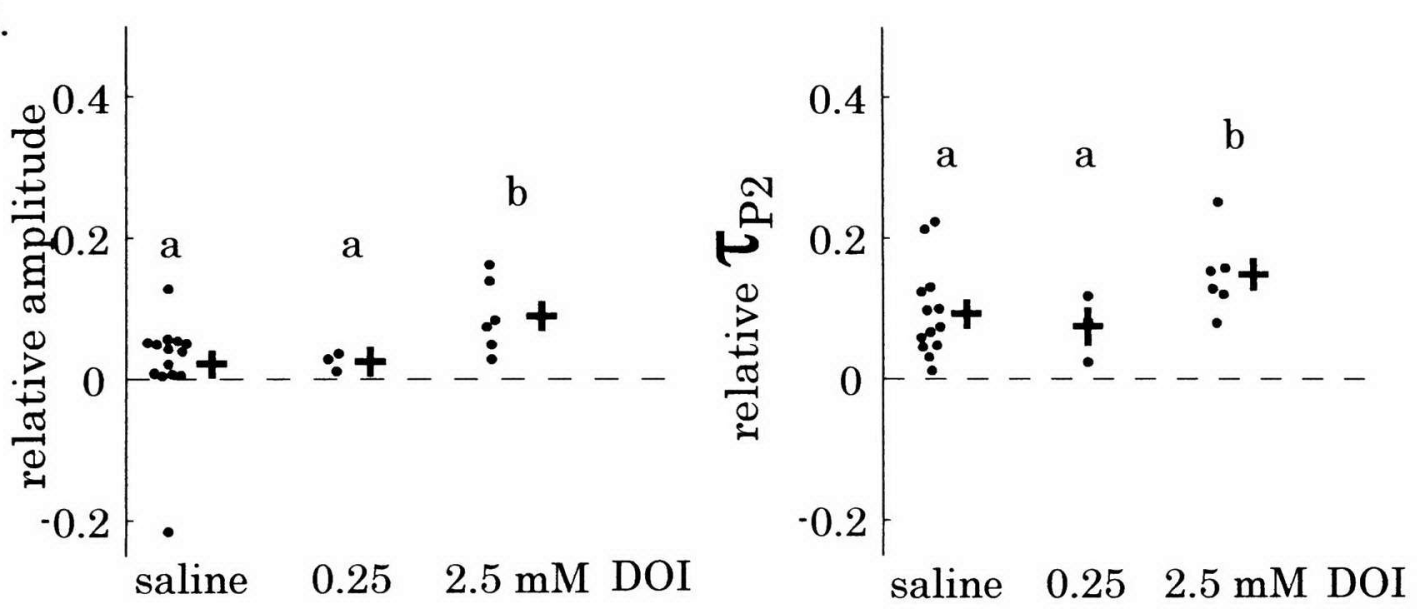
C.

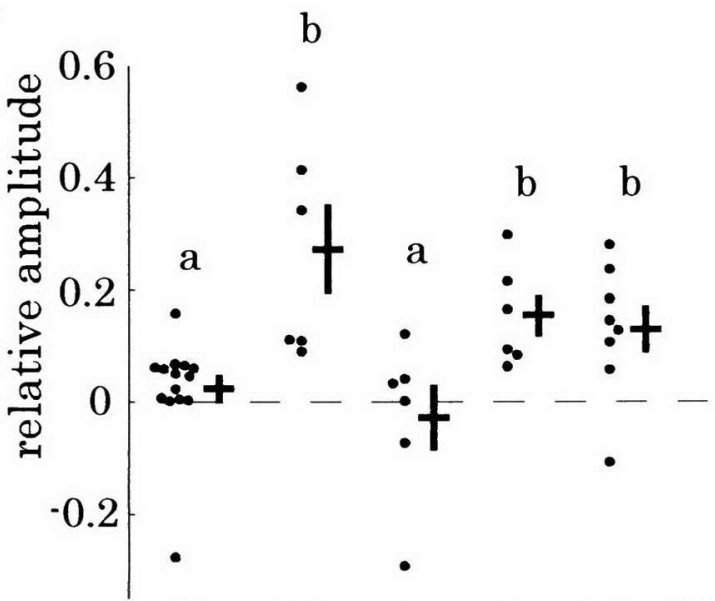

saline $0.25 \quad 2.5 \quad 12.5 \quad 25 \mathrm{mM}$ $\alpha \cdot \mathrm{Me}-5 \cdot \mathrm{HT}$

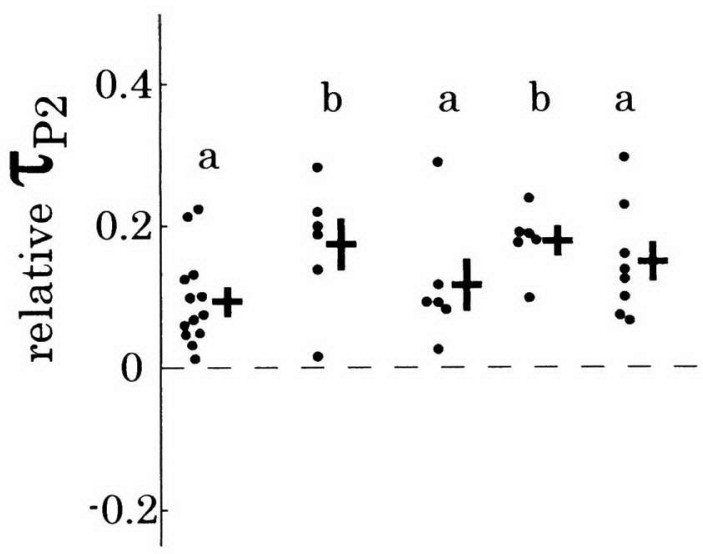

saline $0.252 .512 .525 \mathrm{mM}$ $\alpha \cdot \mathrm{Me}-5 \cdot \mathrm{HT}$

Figure 2.3. Injections of $5-\mathrm{HT}_{2 \mathrm{~A}}$ receptor agonists modulate $\mathrm{EOD} \tau_{\mathrm{P} 2}$, but not amplitude. 

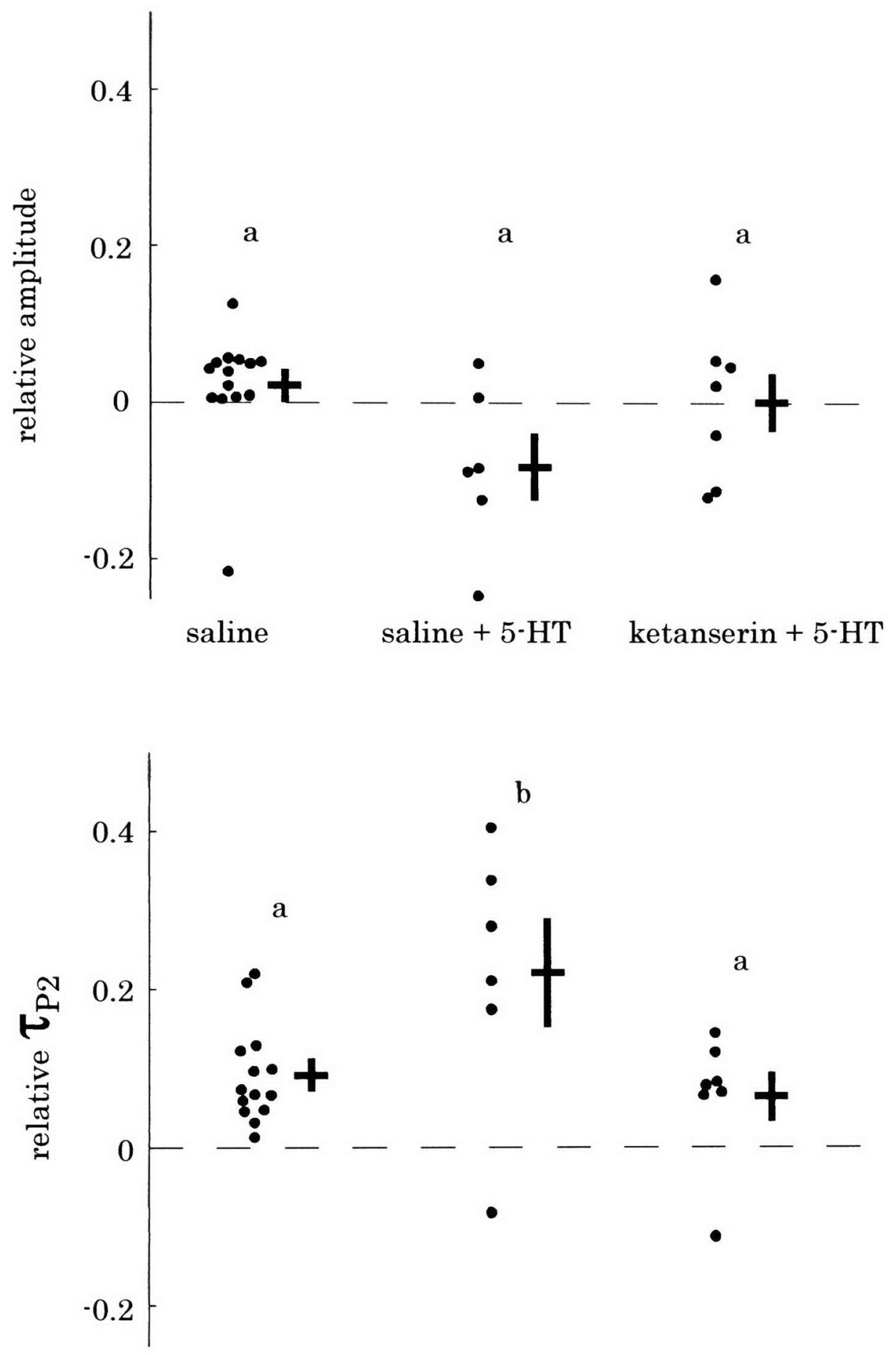

saline saline $+5-\mathrm{HT} \quad$ ketanserin $+5-\mathrm{HT}$

Figure 2.4. Blocking the $5-\mathrm{HT}_{2 \mathrm{~A}}$ receptor with ketanserin inhibits EOD modulations in response to 5 -HT challenge. 
A.

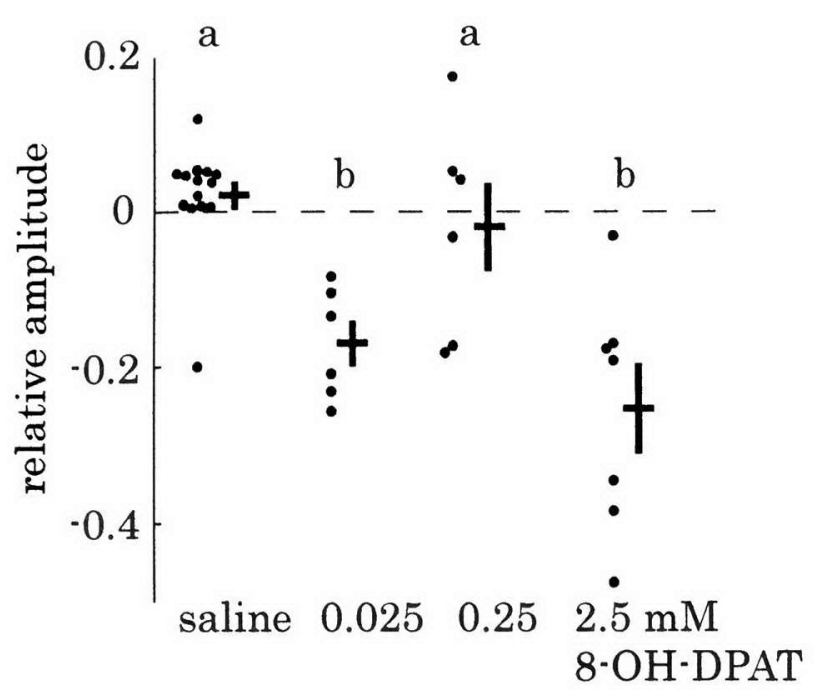

B.

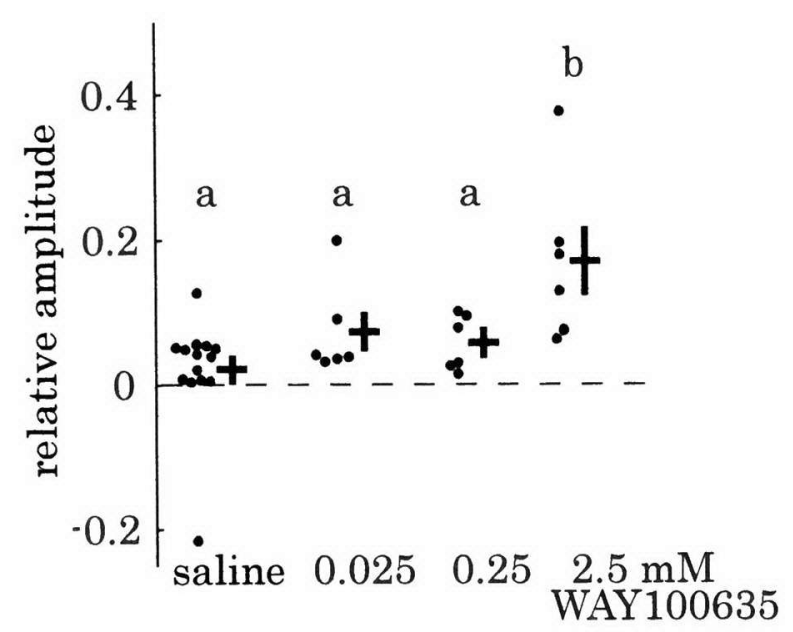

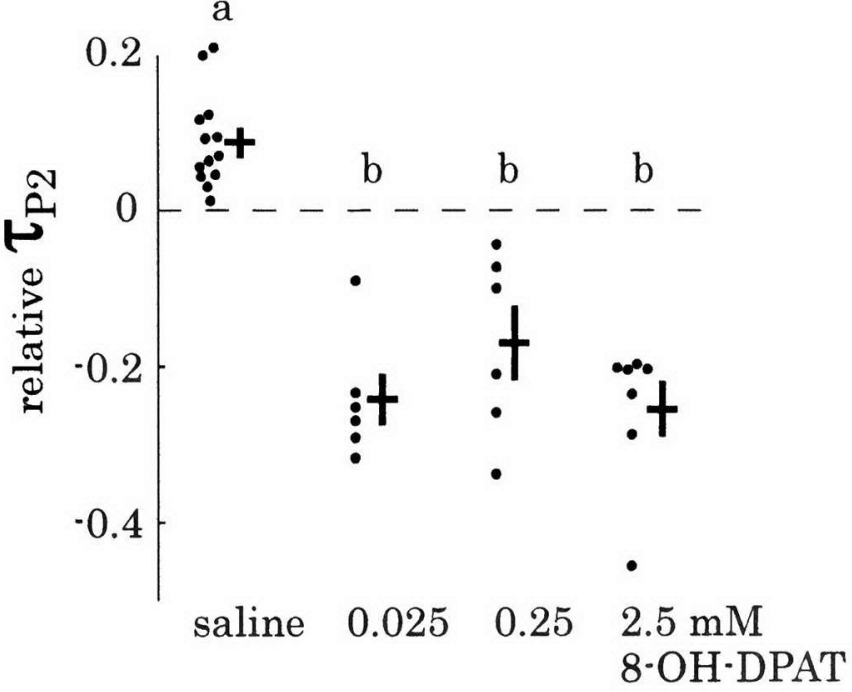

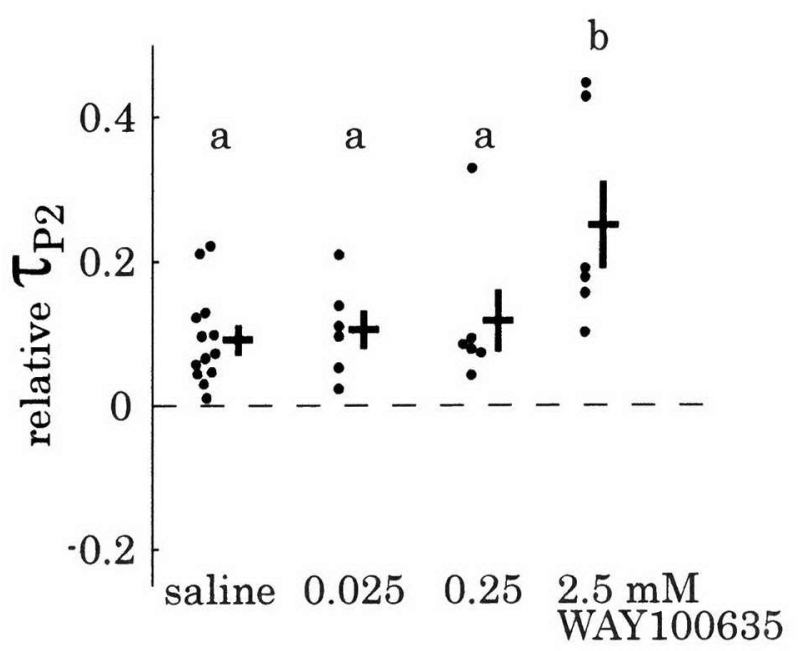

Figure 2.5. Injections of $5 \cdot \mathrm{HT}_{1 \mathrm{~A}}$ receptor agonists and antagonists modulate EOD waveform. 


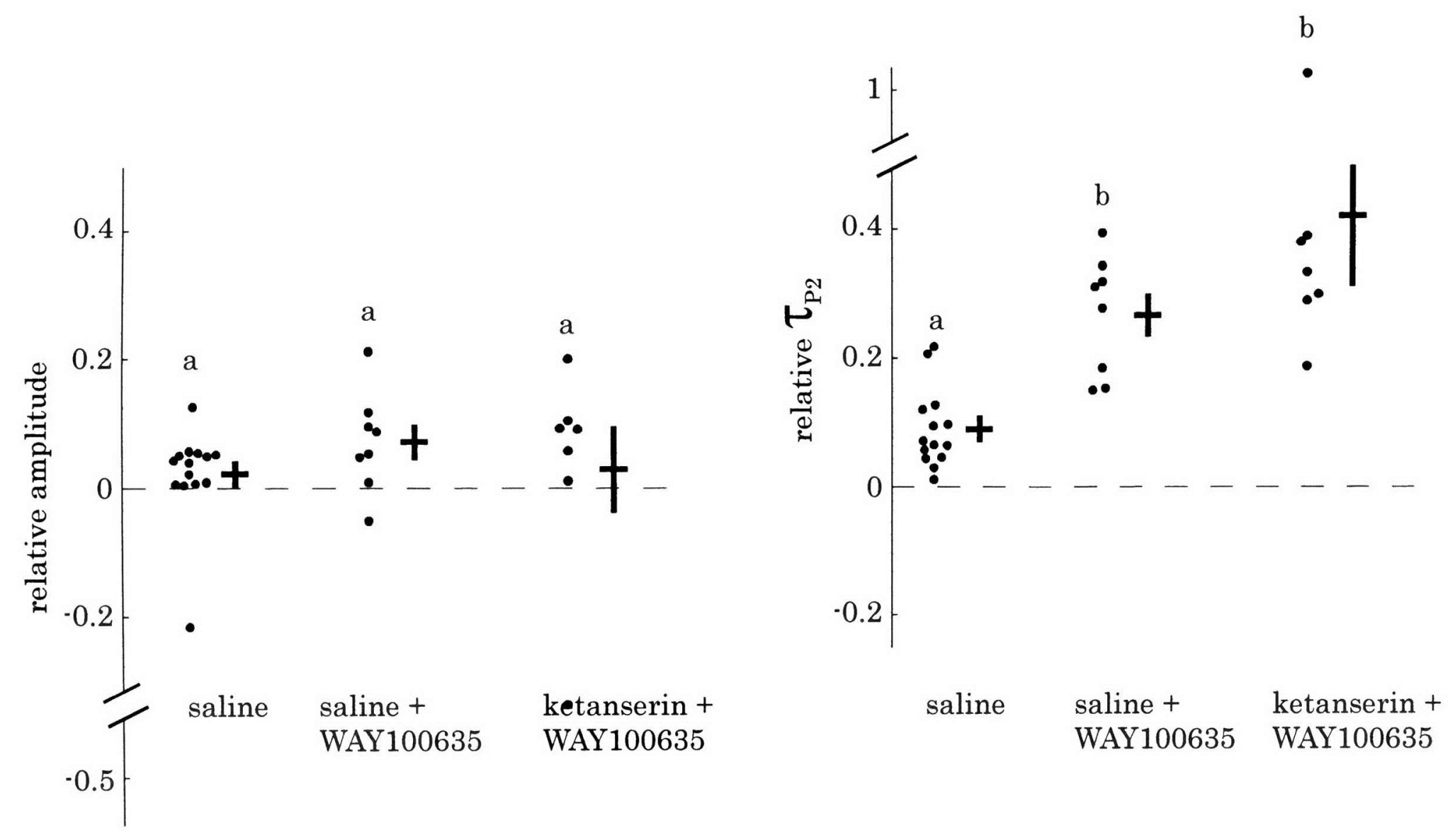

Figure 2.6. Blocking the 5- $\mathrm{HT}_{2 \mathrm{~A}}$ receptor with ketanserin does not inhibit EOD waveform modulation in $\tau_{\mathrm{P} 2}$, but it does inhibit amplitude modulations. 
A.

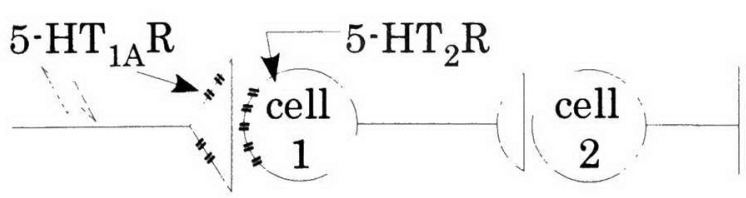

B.

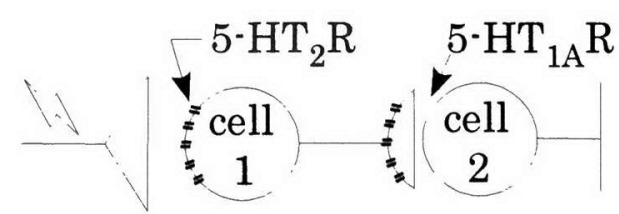

C.

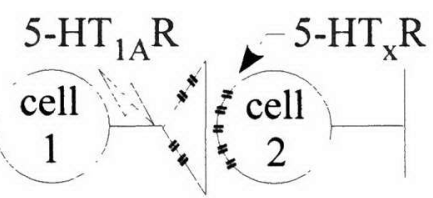

D.

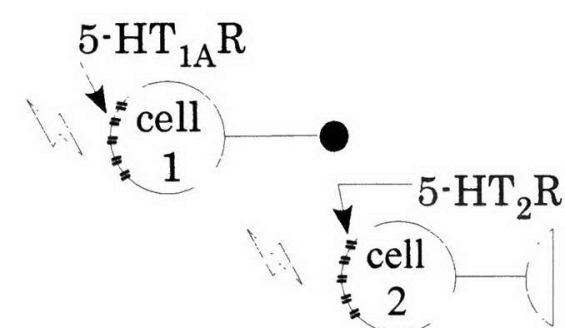

nerve impulse
If model is correct:

Expect $\tau_{\mathrm{p} 2}$ :

block $5 \cdot \mathrm{HT}_{2}$ (ketanserin)

antagonize $5 \cdot \mathrm{HT}_{1 \mathrm{~A}}^{+}(\mathrm{WAY} 100635)$

$\Delta$

$\wedge$

block $5-\mathrm{HT}_{2}$ (ketanserin)

$+$

stimulate $5 \cdot \mathrm{HT}_{1 \mathrm{~A}}(5 \cdot \mathrm{HT})$

block $5 \cdot \mathrm{HT}_{2}$ (ketanserin)

stimulate $5 \cdot \mathrm{HT}_{1 \mathrm{~A}}(5 \cdot \mathrm{HT})$

$\checkmark$

$\triangle$

$\Delta$

block $5 \cdot \mathrm{HT}_{2}$ (ketanserin)

stimulate $5 \cdot \mathrm{HT}_{1 \mathrm{~A}}(5 \cdot \mathrm{HT})$

$\Delta \quad \Delta$

$\Delta \checkmark \uparrow$ no change, decrease, or increase in $\tau_{\mathrm{P} 2}$

Figure 2.7. Models of possible $5-\mathrm{HT}_{1 \mathrm{~A}}$ and $5 \cdot \mathrm{HT}_{2}$ receptor alignments. 
CHAPTER 3. ANDROGENS ENHANCE PERIPHERAL RESPONSE TO MELANOCORTINS BUT SHOW LITTLE EFFECT ON CENTRAL CIRCADIAN RHYTHM GENERATION

Steroid hormones are known to masculinize or feminize central and peripheral structures depending on which hormones are introduced, the sex and developmental stage of the individuals exposed, and which neuroendocrine pathways are activated (Brenowitz and Lent, 2002; Herfeld and Moller, 1998; Lund et al., 2006). Studies investigating the role of heterologous steroids in masculinizing or feminizing behavior and morphology across diverse taxa are extensive and have greatly increased my understanding of the interactions between hormones and sexually dimorphic behaviors (revs. Cooke, et al., 1998; Staub and De Beer, 1997). While the role of sex steroids in promoting sexual differentiation is well documented, what function these hormones may have in potentiating behavioral plasticity is not as well understood. Among teleosts, the electric communication systems of gymnotiform electric fish are excellent models to further investigate the roles of steroid hormones in potentiating sexually dimorphic behavioral plasticity.

Gymnotiform fishes produce weak electric organ discharges (EODs) for electrolocation and electrocommunication (Bullock and Heiligenberg, 1986; Hopkins, 1999a). Waveforms are species-specific and often sexually dimorphic, where males typically produce EODs larger in amplitude and duration than do females or juveniles. The development of sexually dimorphic EODs is controlled by sex steroids (Zakon, 2000). In addition, in 
species with sexually dimorphic EODs, female and juvenile electric fish waveforms can be masculinized by introducing exogenous androgens via injection or implantation (Bass, 1986; Bass and Hopkins, 1983; Franchina, 1997; Hagedorn and Carr, 1985; Hopkins et al., 1990; Meyer et al., 1987; Meyer et al., 1984). Earlier studies investigating the effects of steroid hormones on EOD waveform have focused on electrophysiology of electrocytes, changes in EOD waveform, measured after days (Few and Zakon, 2001) or weeks (Hagedorn and Carr, 1985; Meyer, 1983; Mills and Zakon, 1991). These studies provide snap shot accounts of how steroids modify EOD waveform and behavior before and after exogenous hormones are introduced, but none have constantly monitored the whole fish EOD to determine how these hormones affect waveform parameters such as daily minima, nightly maxima, and the magnitude of circadian swing over the intermediate time scale.

EOD waveforms also show sexually dimorphic plasticity in modulability along the intermediate timescale (minutes to hours), with males showing more exaggerated changes in EOD waveform under both natural and experimental conditions than females. For example, male Brachyhypopomus pinnicaudatus display circadian rhythms with greater magnitudes and they respond more dynamically to stressors and social manipulations than females do (Franchina et al., 2001; Franchina and Stoddard, 1998; Markham and Stoddard, 2005; Stoddard et al., 2006a). 
Males also modulate their EODs in response to pharmacological challenges, both in vivo and in vitro (Markham and Stoddard, 2005; Stoddard et al., 2003).

Two such substances that alter EOD plasticity are serotonin and adrenocorticotropic hormone. Serotonin $(5-\mathrm{HT})$ appears to regulate EOD waveform masculinity indirectly via central action, probably in the hypothalamus and/or pituitary (Markham and Stoddard, 2005; Stoddard, 2006; Stoddard et al., 2003). Melanocortin peptides such as adrenocorticotropic hormone (ACTH) modulate EOD waveform masculinity by direct action on electrocytes (Markham and Stoddard, 2005). Peripheral injections of $5 \cdot \mathrm{HT}$ or $\mathrm{ACTH}$ induce rapid EOD modulations in electric fish and can be used to specifically target either the central or peripheral pathways regulating EOD waveform modulations (Markham and Stoddard, 2005; Stoddard et al., 2003).

I can use melanocortins and serotonin to probe where in the neuromuscular system sex steroids are producing sexual dimorphisms in the EOD. This experiment was designed to examine how female responses to pharmacological challenge compare to male responses and to examine how androgens alter female capacity to modulate their EOD waveforms. Here I use androgen implants to address two specific questions in the gymnotiform fish, B. pinnicaudatus: (1) Is EOD plasticity and/or modulability androgen- 
dependent? (2) If so, do androgens enhance plasticity in the central pathway or in the periphery?

METHODS

EXPERIMENTAL DESIGN

I designed this experiment to measure the role androgens play in modulating individual female's EOD waveforms taking into account interindividual variations in EOD amplitude, duration, and the magnitude of the circadian changes in these waveform parameters. I used the following experimental protocol to address this variability: for each individual I recorded baseline data, pharmacologically challenged with 5-HT and ACTH injections, inserted androgen implants, and then re-challenged with 5-HT and ACTH.

This design allowed me to compare pre-implant to post-implant EOD waveform characters and challenge responses within each individual, thereby eliminating inter-individual differences as a source of variance when comparing across groups. By comparing pre- and post-implant responses to challenges using one drug known to act centrally and one peripherally, I are able to probe the site(s) of DHT action.

SUBJECTS AND MEASUREMENT SYSTEM

B. pinnicaudatus (Hopkins, 1991), feathertail knifefish or 'pinnis', are nocturnal South American gymnotiform fish that produce a species-specific, biphasic EOD. They display prominent sexual dimorphism in the duration of 
the second phase of their waveforms, which I parameterize with the timeconstant of repolarization, or $\tau_{\mathrm{P} 2}$. Males normally have a larger $\tau_{\mathrm{P} 2}$ than females and males, more than females, further enhance this parameter during the first few hours after dusk when most of the breeding activity occurs (Franchina et al., 2001; Franchina and Stoddard, 1998; Hagedorn, 1995; Kawasaki and Heiligenberg, 1989; Silva et al., 1999; Stoddard et al., 2006a). The EOD waveform parameters analyzed in this study include peak-

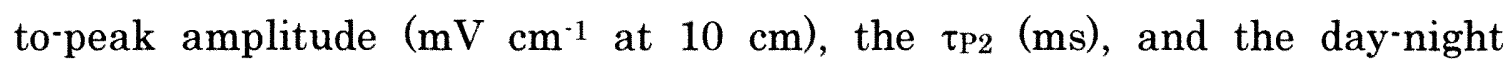
changes, or swing, in amplitude and $\tau_{\mathrm{P} 2}$ calibrated by methods in Franchina et al. (2001)(Fig. 2.1).

A large breeding colony of $B$. pinnicaudatus is maintained at Florida International University in Miami, Florida. Fish are kept in 450-1 outdoor stock pools (dimensions: $185 \times 95 \times 26 \mathrm{~cm}$ ) covered with water hyacinth (Eichhornia crassipes) and fed live oligochaete "blackworms" ad libitum. Experimental groups composed of three to eight females were tested using fish randomly sampled from the outdoor stock pools. The female subjects were brought indoors and held individually in 284-1 automated measurement tanks $(120 \times 44 \times 44 \mathrm{~cm})$ for the whole of each experimental run. Fish were weighed and measured for total length (TL) and length to end of anal fin (LEA) before being placed into recording tanks where they were fed oligochaete blackworms ad libitum under consistent photoperiod (12L: 12D) and temperature $\left(28^{\circ} \mathrm{C} \pm 1^{\circ} \mathrm{C}\right)$ throughout the course of each experiment. 
This study was completed using a total of 52 females tested in 11 experimental groups from January 2003 through December 2005.

IMPLANT FABRICATION

I implanted fish with the non-aromatizable androgen, $5 \alpha^{-}$ dihydrotestosterone (DHT) at doses of $0.03 \mathrm{mg}, 0.1 \mathrm{mg}, 0.3 \mathrm{mg}$, or $1.0 \mathrm{mg} 10$ $\mathrm{g}^{-1}$ body weight (bw). Implant doses were randomly assigned to individuals across experiments until I had minimum sample sizes of 6 females per DHT dose.

I chose the non-aromatizable androgen DHT to ensure any changes I observed in female EODs were the result of androgenic activity and to follow protocols used in previous research to provide comparable results (e.g., Few and Zakon, 2001; Hagedorn and Carr, 1985). There are some indications that DHT is an endogenous androgen in weakly electric fishes, although this has yet to be quantified (Sperry and Thomas, 1999; Zakon et al., 1991). In addition, recent studies have identified at least two distinct nuclear androgen receptors in teleosts (Elsaesser et al., 1989). The peripheral androgen receptor has higher affinity (and thus specificity) for DHT than testosterone or 11 -ketotestosterone $(11-\mathrm{KT})$. These findings suggest that by using DHT, and investigating the changes induced by multiple implant doses, I can attempt to target the periphery over the CNS without resorting to localized implants (e.g., Few and Zakon, 2001). 
DHT implants were made using Dow silicone mixed with DHT crystals following methods of Elsaesser et al.(1989; 2003). Silicone and DHT were combined 3:2 and the mix was extruded through a 20-gauge needle onto a piece of weigh paper in thin straight lines, which were allowed to cure for approximately one week. A sample of plain silicone was weighed and placed next to the implants to provide an estimate of solvent evaporation. After one week, the plain silicone sample was reweighed to calculate mass lost through evaporation. I then applied that evaporation percentage to the DHT implants and recalculated the ratio of silicone to DHT to 2.43:1. I reweighed test fish on the day implants were administered then weighed and cut custom implants to the appropriate size to deliver the randomly assigned dose of DHT to each female.

HORMONE ANALYSIS

Levels of DHT released from my implants were determined by radioimmunoassay (RIA) at Yerkes National Primate Research Center at Emory University. I sampled the levels of DHT released from the implants in two ways. First, I implanted females $(\mathrm{n}=2)$ with $1.0 \mathrm{mg} 10 \mathrm{~g}^{-1}$ implants, observed changes in EOD nightly maximums until the DHT peak effect reached a plateau, then drew blood from those females for RIA analysis. Second, I cut one implant each for the two high doses of DHT I used in this study, sized for a $20 \mathrm{~g}$ fish. I placed the implants in Eppendorf tubes with 20 $\mathrm{ml}$ of physiological saline (equivalent to a $20^{-\mathrm{g}}$ fish) and placed them on a 
shaker set to $10 \mathrm{rpm}$ to mimic blood flow within a fish. I stored the samples in the same room as the recording tanks to mimic the conditions focal fish were held in $\left(28^{\circ} \mathrm{C} \pm 1^{\circ} \mathrm{C}\right)$. I drew $500 \mu \mathrm{l}$ samples from each sample at precise intervals to measure the release rate of the implants over time. Saline and serum samples were then sent to Yerkes National Primate Research Center at Emory University to be assayed for concentrations of DHT.

BASELINE DATA

Females were held indoors without manipulation for up to three days to acclimatize them to their new tanks and allow me to collect baseline EOD waveform data for each individual. I recorded calibrated EODs run from freely swimming females around the clock at intervals of $\sim 1 \mathrm{~min}$ for the entirety of each experiment using an automated system described in detail elsewhere (Franchina and Stoddard, 1998; Stoddard et al., 2006a). Female EOD amplitude $\left(\mathrm{mV} \mathrm{cm}^{-1}\right)$ and $\tau_{\mathrm{P} 2}(\mathrm{~ms})$ daily minima and nightly maxima were collected by extracting representative EOD values after she had acclimatized to the data-collection tanks and before any experimental manipulations were performed (Fig. 3.1.). These values were used to characterize each female's baseline EOD waveform characters as well as to calculate differences between minimum and maximum values, which constitute the magnitude of the circadian swing in amplitude and $\tau_{\mathrm{P} 2}$. 
ANALYSIS OF CIRCADIAN RHYTHM MAGNITUDES

EOD amplitude and $\tau_{\mathrm{P} 2}$ vary with circadian rhythms that free-run under constant light or constant dark (Franchina et al., 2001). One of my main goals for this experiment was to determine if androgens masculinize central and/or peripheral plasticity in the intermediate time scale over days, parallel to socially-induced changes (Stoddard et al., 2003). An earlier study showed that an individual's waveform baseline values predict the magnitude of response to 5-HT challenge (Stoddard et al., 2003). Here I describe circadian rhythm oscillation both in terms of absolute magnitude ("absolute swing" = nightly maximum - daily minimum $)$, and magnitude relative to the daytime baseline ("relative swing" = [nightly maximum - daily minimum] / daily minimum). I selected representative day and night points for each individual from the cycle before the implant and from the cycle two days after the implant. I also collected circadian data from 17 males in 2002 and 2003 to compare to pre- and post-DHT implant female circadian rhythms to determine if implants had enhanced circadian oscillation.

Pharmacological CHALlEnges

I challenged the females with serotonin (5-HT; 5-hydroxytryptamine creatinine sulfate complex, Sigma-Aldrich) and adrenocorticotropic hormone (synthetic porcine ACTH, Sigma-Aldrich) to determine how androgens affect plasticity of EOD modulability at the central and peripheral levels. Challenges consisted of intramuscular injections of 5-HT and ACTH given in 
random order on separate days once baseline data had been collected for each individual. 5-HT concentrations were $2.5 \mathrm{mM}(2.5 \mu \mathrm{M} \mathrm{g} \cdot 1)$ and ACTH concentrations were $25.0 \mu \mathrm{M}\left(25.0 \mathrm{nM} \mathrm{g}^{-1}\right)$, each injected at a volume of $1 \mu \mathrm{lg}$ ${ }^{1} \mathrm{BW}$. Females were injected between 1000 and 1500 hours and their EODs were continuously monitored.

Once the pharmacological challenges were completed, I inserted the DHT implants customized for each individual female. To insert the implants, fish were deeply anesthetized with 2 -phenoxy ethanol $\left(750 \mu \mathrm{l}^{-1}\right)$ then placed on their right side. I removed two scales ventral to the lateral line then punctured the abdomen between two ribs using an 18-gauge needle to create a lane for the DHT implants. I inserted the implants, sealed the incision site with surgical glue and returned the fish to their tanks. The implant procedure took less than 5 minutes and all fish recovered quickly.

EOD magnitude took 3-7 days to plateau after DHT implantation, after which I repeated the 5-HT and ACTH challenges described above, again on separate days and in random order. Once the DHT effect had peaked and before pharmacology challenges were repeated, I calculated the post-implant magnitude of circadian rhythm oscillation using representative minimum and maximum values for amplitude and $\tau_{\mathrm{P} 2}$ taken from a single 24 -hour period. I then compared the post-implant swing by dose (= relative swing) as well as calculating the difference between pre- and post-implant swing amplitude and $\tau_{\mathrm{P} 2}$ (= relative swing changes). Relative swing is a 
determination of how concentration of DHT affects the magnitude of circadian swing without removing inter-individual variations in EOD, while relative swing change removes inter-female variance by characterizing each female's post-implant swing relative to her pre-implant circadian swing.

To measure the effects of pharmacological challenges, I estimated the circadian oscillation and subtracted it from the data records using methods described in detail elsewhere (Siegel and Castellan, 1988). I assessed DHT effects by measuring post-DHT implant responses to challenge for (= relative response to challenge) amplitude and $\tau_{\mathrm{P} 2}$ as well as comparing the difference between pre-implant and post-implant responses to challenge within individuals (= relative change in response to challenge).

Female EOD data were compared to male data collected from separate experiments where males were either challenged in the same manner or where circadian data had been collected. Data were analyzed using KruskalWallis one-way ANOVA tests using DHT implant dose as the dependent variable. Significant omnibus tests $(\mathrm{p}<0.05)$ were further analyzed using a pairwise, two-tailed comparison of Kruskal-Wallis mean scores with Bonferroni adjustment (Dunlap et al., 1998).

RESULTS

DHT ASSAY RESULTS

The pattern of release of DHT into saline was consistent between the two doses of implant I tested (data not shown). I therefore extrapolated what 
the DHT concentrations would have been in the blood of females receiving the lower three doses of DHT using the average value of the two blood samples assayed. I compared my estimates to previous analysis of androgens present in two other species of weakly electric fish (Table 3.1.) (Dunlap et al., 1998). Provided that the androgen profiles are similar between two species of Apternotus and B. pinnicaudatus, I determined that females who received the highest implant dose received supra-physiological levels of androgens. Preliminary data from studies currently underway in Dr. Stoddard's

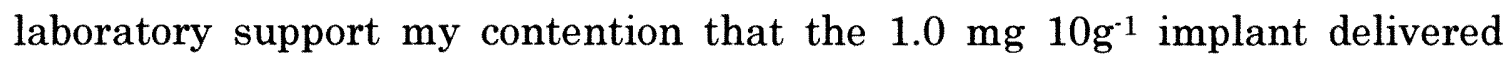
supra-physiological doses on androgens to females (VL Salazar unpubl data). Due to the inherent variability in androgen profiles between even closely related species, I refrain from concluding that the concentrations of DHT that the lower three implant doses are within physiological ranges for this particular species until this can be confirmed with hormonal assays.

EFFECT OF IMPLANT DOSE ON MAGNITUDE OF FEMALE EOD CIRCADIAN RHYTHM SWING

I observed dramatic changes in EOD waveforms after DHT implants were in place, particularly in females that received the highest dose of DHT. The implants produced no change in EOD amplitude but dramatically increased $\tau_{\mathrm{P} 2}$ starting the first night after implants were in place. The baseline rose, as did the nightly peaks and the absolute swing (Fig. 3.1.). 
Females that received the highest dose showed the largest $\tau_{\mathrm{P} 2}$ absolute swing (= nightly maximum - daily minimum).

There were no differences in magnitude of relative circadian swing in either amplitude $(\mathrm{H}=0.27)$ or $\tau_{\mathrm{P} 2}(\mathrm{H}=0.58)$ between any of the groups before DHT implants were placed. I found differences in the magnitude of postimplant amplitude swing between the different doses, but not in $\tau_{\mathrm{P} 2}$ swing (Fig. 3.2A). Amplitude swings were greater in females that were given 1.0 mg $10 \mathrm{~g}^{-1}$ DHT implants than they were in females in the other groups once the implants had reached their peak effect. I did not, however, observe this distinction between the dose groups when I compared the individual's postimplant circadian swing to her pre-implant values. The differences between the results of the relative swing and change in relative swing comparisons are most likely due to values from two females with large post-implants swings influencing the statistical analysis. The change in relative swing eliminates inter-female variability, and thus is a more reliable measure of DHT effects.

I found no differences in the magnitude of relative change in circadian swing or in post-implant relative swing in $\tau_{\mathrm{P} 2}$ (Fig. 3.2B). These results seem counterintuitive to the data presented in Figure 3.1 that clearly demonstrate marked enhancements in EOD $\tau_{\mathrm{P} 2}$ parameters. The marked DHT-induced increases in absolute values of $\tau_{\mathrm{P} 2}$ are not apparent in the relative measures (i.e., (peak - baseline) / baseline)) because both the daily minima and nightly 
maxima used to calculate relative swing increased. Comparing absolute to relative changes in each waveform parameter individually illustrate that while DHT increased the height and width of the envelope, the relative proportion of peak to baseline did not change as a result of the exogenous androgens.

Lastly, I compared the magnitudes of relative circadian swing of unmanipulated females, DHT females, and males to determine if the highest dose of implants shifted female circadian rhythms toward male-like rhythms (Fig. 3.3).

I found no differences between the three groups in magnitude of relative amplitude swing, but males and DHT females displayed greater relative $\tau_{\mathrm{P} 2}$ swing than unmanipulated females did.

EFFECTS OF DHT DOSE ON FEMALE RESPONSE TO PHARMACOLOGICAL CHALLENGES

My analysis of post-implant challenge responses by DHT dose are reported in Table 3.2 and significant pairs are identified in Figure 3.4.

Both female amplitude and $\tau_{\mathrm{P} 2}$ response to 5-HT challenge increased with increasing doses of DHT, with the two largest dose groups showing the greatest response to challenge (Fig. 3.5.). I found a similar trend in response to ACTH challenge, and EOD amplitude and $\tau_{\mathrm{P} 2}$ of females receiving the highest dose showed the greatest increase (Fig. 3.6.). Comparing within individuals, only the change in $\tau_{\mathrm{P} 2}$ response to ACTH challenge was 
significantly greater following DHT implant. I compared pharmacological challenge responses from females (low dose), DHT-females (high dose), and males to determine how DHT had masculinized female responses to $5 \cdot \mathrm{HT}$ and ACTH (Table 3.3.) (Fig. 3.6.). DHT female response to 5-HT challenge was indistinguishable from male response for both EOD amplitude and $\tau_{\mathrm{P} 2}$. The same pattern was present for EOD amplitude response to ACTH challenge. Responses of DHT females were greater than responses of females to the same challenges in some cases, even when males and females responses were indistinguishable. Response to ACTH challenge of $\tau_{\mathrm{P} 2}$ in DHT females was supra-enhanced to the point of exceeding normal male responses to the same challenge.

\section{Discussion}

CHANGES IN THE INTERMEDIATE TIME SCALE

The effect of DHT on the EOD waveforms of females was more pronounced for $\tau_{\mathrm{P} 2}$ than for amplitude, even though both parameters are sexually dimorphic and even though both are enhanced in minutes by the actions of serotonin and melanocortins. For $\tau_{\mathrm{P} 2}, \mathrm{DHT}$ induced increases in daily minima, and even greater increases in nightly maxima, resulting in greater magnitude of circadian oscillations/cycles. EOD amplitude however did not increase as a result of the DHT implants. One possible explanation for this discrepancy between $\tau_{\mathrm{P} 2}$ and amplitude response could be that the high dose of DHT that I used may not be a saturating dose to adequately 
masculinize amplitude cyclicity. However, DHT concentrations in the blood sampled from implanted females and from my saline-leaching experiment were an order of magnitude higher than physiological levels of androgens previously reported in two species of weakly electric fishes (Sperry and Thomas, 2000). Therefore, I think it unlikely that the dose I used was insufficient to induce an effect.

Another hypothesis for why DHT produced little change in EOD amplitude was low affinity for DHT by the type of androgen receptor(s) that control waveform and circadian cyclicity. A reasonable hypothesis is that androgen receptors in the brain control the magnitude of amplitude cycling via a different pathway than receptors that control EOD $\tau_{\mathrm{P} 2}$ cyclicity. This hypothesis is supported by recent discovery of at least two distinct nuclear androgen receptors in teleosts (Sperry and Thomas, 1999, 2000). These receptors, $A R 1$ and $A R 2$, exhibit different tissue distributions and binding affinity characteristics for natural and synthetic androgens (Stoddard et al., 2003). AR2 has a greater binding affinity for DHT than $\mathrm{T}$ or $11-\mathrm{KT}$, whereas AR1 is more specific for $\mathrm{T}$ than $11-\mathrm{KT}$ or DHT. AR1 is most abundant in brain tissues whereas $\mathrm{AR2}$ is more abundant in peripheral tissues such as the gonads. If androgen receptors of gymnotiforms show similar distributions and affinities as the other teleosts, the differential binding affinities of AR1 and AR2 suggest my DHT implants could have activated peripheral AR2 more than central AR1 types. A corollary hypothesis is that 
testosterone binds to androgen receptors in the brain to masculinize the circadian rhythms in EOD amplitude seen in males, and thus DHT was the wrong androgen to induce amplitude cyclicity in females. Despite the likely differences in AR effect that my implants had, I doubt this corollary hypothesis because the supra-physiological levels of DHT released by my highest implant dose should have compensated for differences in receptor affinities and yet still did not induce change in amplitude cycling. For now, the proximate mechanism(s) controlling circadian modulation of EOD amplitude remains a mystery; if androgen receptors are involved in the differential control of amplitude and $\tau_{\mathrm{P} 2}$ cycling, they appear to be only part of the story.

\section{ChaNGES IN EOD MODULABILITY}

Previous research has indicated that serotonin acts centrally to regulate the EOD waveform, possibly at the level of the hypothalamus or pituitary (Markham and Stoddard, 2005; Stoddard et al., 2003; Stoddard et al., 2006b). Because individual electrocytes do not respond to 5-HT challenge in vitro, challenging fish with serotonin injections provides insight into the periphery's responsiveness to central control of EOD waveform modulation.

On average, serotonin injections slightly reduced EOD amplitudes of un-manipulated females. At the highest two doses, DHT implants reversed this effect, causing mean EOD amplitude to increase. Females that were given the two lower doses of DHT showed no response to $5 \cdot \mathrm{HT}$ challenge on 
average, although the responses were variable. Though responses from the high DHT dose females were not statistically different than males, they were higher than low DHT dose females. This inherent variability in amplitude response to 5-HT challenge is not surprising, because males also tend to exhibit highly varied responses in EOD amplitude to 5-HT challenge (Bethea et al., 2002).

The $\tau_{\mathrm{P} 2}$ response of DHT-treated females to $5 \cdot \mathrm{HT}$ challenge followed the same trend as amplitude responses. The highest DHT dose group showed the greatest $\tau_{\mathrm{P} 2}$ response to $5-\mathrm{HT}$ challenge post-implant, while the changes within individuals were identical across all four DHT doses. This variation in consistency suggests that while the $\tau_{\mathrm{P} 2}$ response to $5-\mathrm{HT}$ challenge is influenced by androgens, the effect is subject to high inter-individual variability. The $\tau_{\mathrm{P} 2}$ response of high dose females was, however, masculinized and comparable to male $\tau_{\mathrm{P} 2}$ responses. Thus electrocytes in males and in DHT-treated females are more responsive to central control of EOD modulations than female electrocytes are.

Another possible explanation for the relative lackluster effect of DHT on 5 -HT challenge response may be found in understanding how steroidal milieu affects 5-HT system functioning. Estrogens have been shown to decrease 5-HT release, reduce the number of 5-HT receptor binding sites, reduces the efficacy of 5-HT agonists on neuronal firing rate and release of $\mathrm{ACTH}$ and corticosterone, down regulate 5-HT autoreceptor 
activity/expression, increase and decrease 5-HT receptor densities in different areas of the brain, and alter behavioral response to activating different classes of $5 \cdot \mathrm{HT}$ receptors (for review see Markham and Stoddard, 2005). Although a hormonal profile for $B$. pinnicaudatus is not currently available, it is reasonable to postulate that females have higher levels of circulating estrogens than males and that these hormones may interfere with responses to 5 -HT challenge.

ChANGES IN RESPONSE TO MELANOCORTINS

ACTH challenges allow me to determine the capacity of the electrocytes to augment EOD amplitude and $\tau_{\mathrm{P} 2}$, since previous work has shown that this pituitary melanocortin can induce EOD modulations via direct action on the electrocytes (Dunlap et al., 1998). High dose DHT female amplitude responses to ACTH challenge were the same as male responses, exceeding responses normally displayed by un-manipulated and low DHT dose females. An interesting distinction from the enhancement I observed in $5-\mathrm{HT}$ responses of females receiving different doses of $\mathrm{DHT}$, the high dose DHT females produced supra-masculine responses to ACTH for both amplitude and $\tau_{\mathrm{P} 2}$. These supra-responses exceeded normal male responses to ACTH challenge and suggest that androgens increase the capacity to respond to melanocortins. The finding that male and female EOD $\tau_{P 2}$ responses to ACTH challenge are normally indistinguishable and that DHT causes treated females to produce a response that greatly exceeds male 
response suggests that DHT is operating on the level of the electrocytes. This supra-enhancement may be due to DHT activating more or different melanocortin receptors, which in turn alters modulability due to ACTH challenge. Alternately or additionally, DHT might act anywhere farther downstream of the melanocortin receptor, including $2^{\text {nd }}$ messenger machinery, or the ion channels that make the EOD.

Another important distinction between responses to ACTH and 5-HT is that male and female ACTH challenge responses in both EOD amplitude and $\tau_{\mathrm{P} 2}$ do not differ statistically under normal (non-implant) conditions, whereas males typically show a greater response to 5-HT in both EOD parameters than do non-implanted females. This dichotomy suggests that circulating levels of androgens may in part control electrocyte capacity to respond to ACTH challenge, but because females have lower levels of the biologically relevant androgen than males do, their responses to ACTH challenge are also lower. This level of responsiveness in the periphery appears to be plastic and modulated, in part by melanocortin peptides. The responses to 5-HT challenge did not show the extreme increases due to DHT levels that responses to ACTH did. This difference between effects of 5-HT and ACTH suggests that DHT acted peripherally to increase the response of electrocytes to melanocortins, while its effects on central mechanism appeared less dramatic. Particularly interesting, DHT caused EOD amplitude of females to rise in response to $5 \cdot \mathrm{HT}$, whereas before DHT implants, EOD amplitude 
frequently fell. DHT may have reversed central inhibitory effects of $5 \cdot \mathrm{HT}$, or it may have increased peripheral responsiveness to the point where it swamped central inhibitory effects.

While these pharmacological challenges demonstrate that DHT alters the electrocyte's capacity to modulate in response to challenge, the changes seen in female EOD circadian rhythmicity provide insights into how androgens operate in the brain to mediate EOD waveform plasticity. The lack of DHT influence on female amplitude daily minima and nightly maxima suggests their brain was not masculinized to produce male-like circadian rhythmicity, even though their responses to challenge demonstrate that the periphery is capable of producing such cycling. Increased magnitude of circadian cycling was, however, observed in DHT female EOD $\tau_{\mathrm{P} 2}$, which leads to additional questions as to why DHT affected waveform amplitude and $\tau_{\mathrm{P} 2}$ so differently. One possibility is that DHT was not as effective at stimulating androgen receptors in the brain as it was in the periphery. Alternatively, these results may imply that the two different teleost androgen receptors may differ in the role they play in EOD modulability. Another explanation is that the implants did not produce a pulsatile release of DHT, which may be a temporal requirement for amplitude cycling or that another hormone is involved. 


\section{SUMMARY}

My experiments with DHT implants in female $B$. pinnicaudatus clearly demonstrate that androgens increase EOD waveform plasticity and responsiveness to pharmacological challenges. Females increased their responses to both 5-HT and $\mathrm{ACTH}$ challenge, usually with the highest implant dose producing the greatest effects. These results imply that increased levels of circulating androgens enhance the electrocyte's capacity to show an enhanced response to other neurotransmitters and hormones.

The lack of effect of DHT on EOD amplitude swing suggests that $\tau_{\mathrm{P} 2}$ and amplitude are at least partially regulated by separate mechanisms. My pharmacological challenges with probes known to affect different levels of the nervous system gave me a partial answer to my second question of whether androgenic effects are central or peripheral. The dramatic challenge responses to ACTH clearly show that the periphery is altered by androgens. The results for whether androgens affect the central control of EOD modulations are not as clear.

I did observe slight changes in response to 5 -HT challenge, relative to the changes that ACTH challenges produced. Although I know that 5-HT likely mediates EOD modulations above the level of the electrocyte, it is still possible that any increases I observed in response to $5-\mathrm{HT}$ were indirect effects (e.g., changes of downstream effectors) rather than direct action of androgens on the central nervous system. In addition, other steroid such as 
estrogen, may have affected the response to androgen implants. Androgens are apparently largely responsible for the sexual dimorphisms I observe in EOD circadian modulations and in responses to challenge. The molecular mechanisms by which androgens are able to exert these influences should provide informative areas of research in the future.

\begin{tabular}{|c|c|c|c|c|}
\hline androgen & $\begin{array}{c}\text { A Apternotus } \\
\text { albifrons }\end{array}$ & q & $\begin{array}{l}\text { O Apternotus } \\
\text { leptorhynchus }\end{array}$ & q \\
\hline $\left.11-\mathrm{KT}^{(\mathrm{ng} \mathrm{ml}}{ }^{-1}\right)$ & $6.12 \pm 1.22$ & $\begin{array}{c}0.82 \pm \\
0.12 \\
\end{array}$ & $5.33 \pm 1.74$ & $\begin{array}{c}0.89 \pm \\
0.25 \\
\end{array}$ \\
\hline $\mathrm{T}\left(\mathrm{ng} \mathrm{ml} \mathrm{m}^{-1}\right)$ & $8.45 \pm 3.21$ & $\begin{array}{c}4.21 \pm \\
4.1 \\
\end{array}$ & $10.6 \pm 2.41$ & $\begin{array}{c}12.2 \pm \\
3.11 \\
\end{array}$ \\
\hline \multicolumn{5}{|l|}{$\begin{array}{l}\uparrow \text { values reported in } \\
\text { Dunlap et al. (1998) }\end{array}$} \\
\hline & $\begin{array}{c}\hat{\jmath} \& \text { 우 } \\
\text { Eigenmannia } \\
\text { virescens } \\
\end{array}$ & & & \\
\hline 11-KT (ng ml-1) & $0.97 \pm 0.26$ & & & \\
\hline $\mathrm{T}\left(\mathrm{ng} \mathrm{ml} \mathrm{l}^{-1}\right)$ & $1.27 \pm 0.41$ & & & \\
\hline \multicolumn{5}{|l|}{$\begin{array}{c}\uparrow \text { values reported in } \\
\text { Dunlap \& Zakon } \\
(1988) \\
\end{array}$} \\
\hline $\begin{array}{c}\text { B. pinnicaudatus } \\
\text { implant dose this } \\
\text { study }\end{array}$ & $1.0 \mathrm{mg} / 10 \mathrm{~g}$ & $\begin{array}{c}0.3 \\
\mathrm{mg} / 10 \mathrm{~g}\end{array}$ & $0.1 \mathrm{mg} / 10 \mathrm{~g}$ & $\begin{array}{c}0.03 \\
\mathrm{mg} / 10 \mathrm{~g}\end{array}$ \\
\hline $\begin{array}{l}\left.\text { DHT (ng ml }{ }^{-1}\right) \\
{ }^{*} \mathrm{RIA} \text { reported } \\
\text { concentrations } \\
{ }^{*} \text { estimated } \\
\text { concentrations }\end{array}$ & $95.35^{*}$ & $28.61^{* *}$ & $9.54^{* *}$ & $2.86^{* *}$ \\
\hline
\end{tabular}

Table 3.1 Androgen profiles in weakly electric fishes. Androgen levels found in plasma of three species of weakly electric fishes and concentration of DHT released by implants in the current study. $(*)$ The concentration reported for 
$1.0 \mathrm{mg} 10 \mathrm{~g}^{-1}$ implants was determined by radioimmunoassay by Yerkes

National Primate Research Center. (**) Values were calculated by

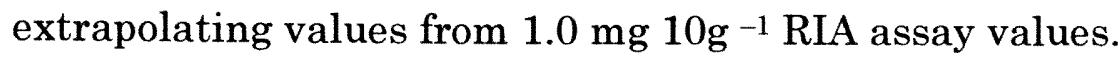

\begin{tabular}{|l|c|c|}
\hline & Amplitude & $\tau$ P2 \\
\hline $\begin{array}{l}\text { Relative swing post } \\
\text { implant }\end{array}$ & $\mathrm{p}=0.002$ & $\mathrm{p}=0.13$ \\
\hline $\begin{array}{l}\text { Change in relative } \\
\text { swing }\end{array}$ & $\mathrm{p}=0.38$ & $\mathrm{p}=0.08$ \\
\hline
\end{tabular}

Table 3.2 Kruskal-Wallis p-values of effect of DHT implants on female EOD circadian oscillations

\begin{tabular}{|l|c|c|}
\hline & Amplitude & $\tau_{\mathrm{P} 2}$ \\
\hline $5-\mathrm{HT}$ & $\mathrm{p}=0.08$ & $\mathrm{p}=0.03$ \\
\hline ACTH & $\mathrm{p}=0.001$ & $\mathrm{p}=0.006$ \\
\hline
\end{tabular}

Table 3.3 Kruskal-Wallis p-values of effect of DHT implants on relative response to pharmacological challenge.

EOD parameters increased in response to pharmacological challenge after DHT implant (p-values from Kruskal-Wallis test). In general, responses to ACTH are more statistically robust than responses to 5-HT.

\begin{tabular}{|l|c|c|}
\hline & Amplitude & $\tau_{\mathrm{P} 2}$ \\
\hline $5 \cdot \mathrm{HT}$ & $\mathrm{p}=0.06$ & $\mathrm{p}=0.23$ \\
\hline $\mathrm{ACTH}$ & $\mathrm{p}=0.007$ & $\mathrm{p}=0.006$ \\
\hline
\end{tabular}

Table 3.4 Kruskal-Wallis p-values of effect of DHT implants on changes in relative response to pharmacological challenge. 
Using each female as her own control (pre-vs. post-implant) only responses to ACTH were significantly increased by DHT implants ( $\mathrm{p}$-values from Kruskal-Wallis test).

\begin{tabular}{|l|c|c|}
\hline & Amplitude & $\tau_{\mathrm{P} 2}$ \\
\hline $5-\mathrm{HT}$ & $\mathrm{p}=0.005$ & $\mathrm{p}=0.01$ \\
\hline ACTH & $\mathrm{p}=0.002$ & $\mathrm{p}=0.003$ \\
\hline
\end{tabular}

Table 3.5. Kruskal-Wallis p-values of effect of DHT implants on relative female, DHT-female, and male responses to pharmacological challenge. Comparison of EOD changes in response to 5-HT and ACTH in the lowest DHT dose females, the highest DHT dose females, and males found significant group differences in both parameters. (p-values from KruskalWallis test). 

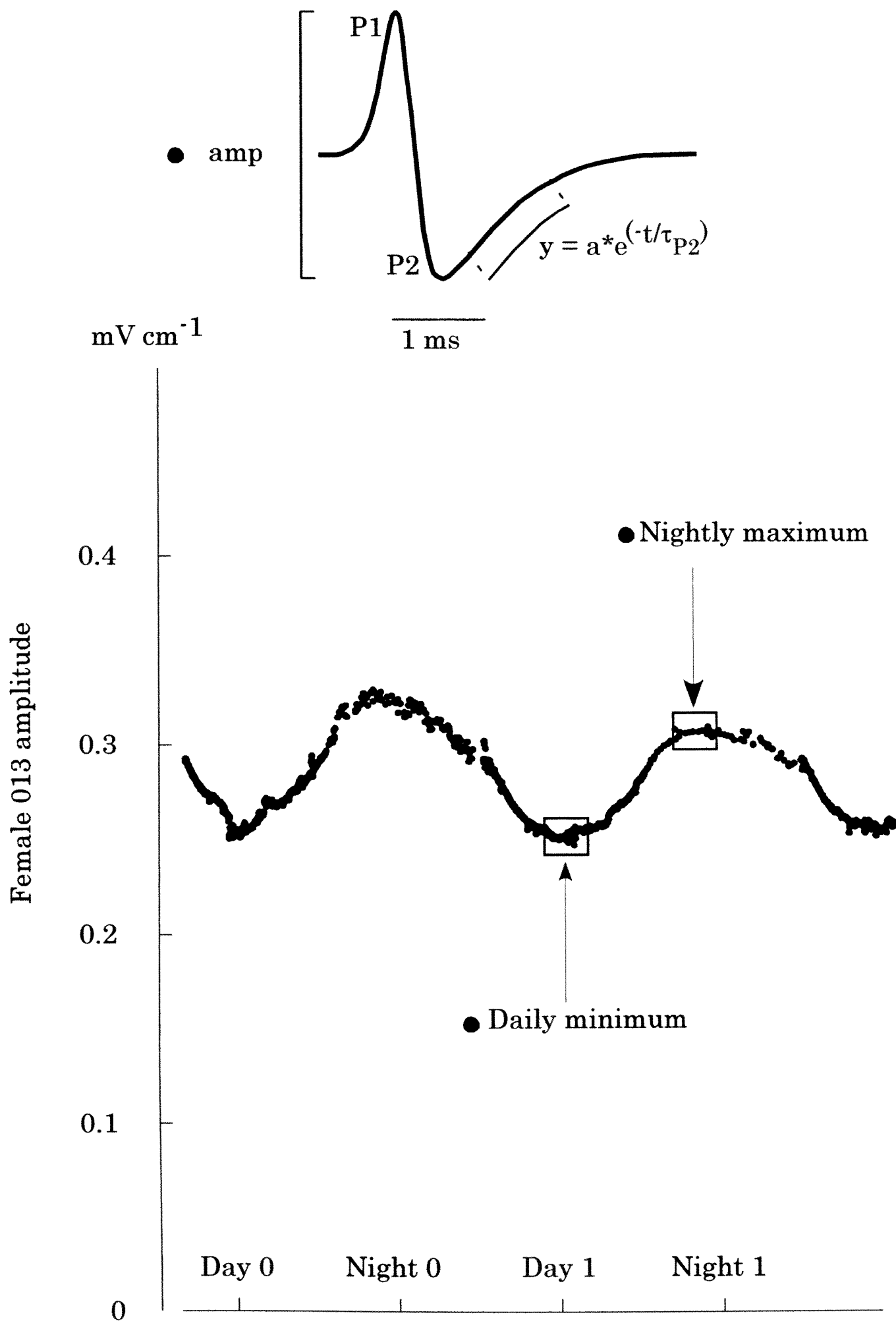

Figure 3.1. Single EOD waveform and 48-hours worth of EODs from one female Brachyhypopomus pinnicaudatus. 
A.
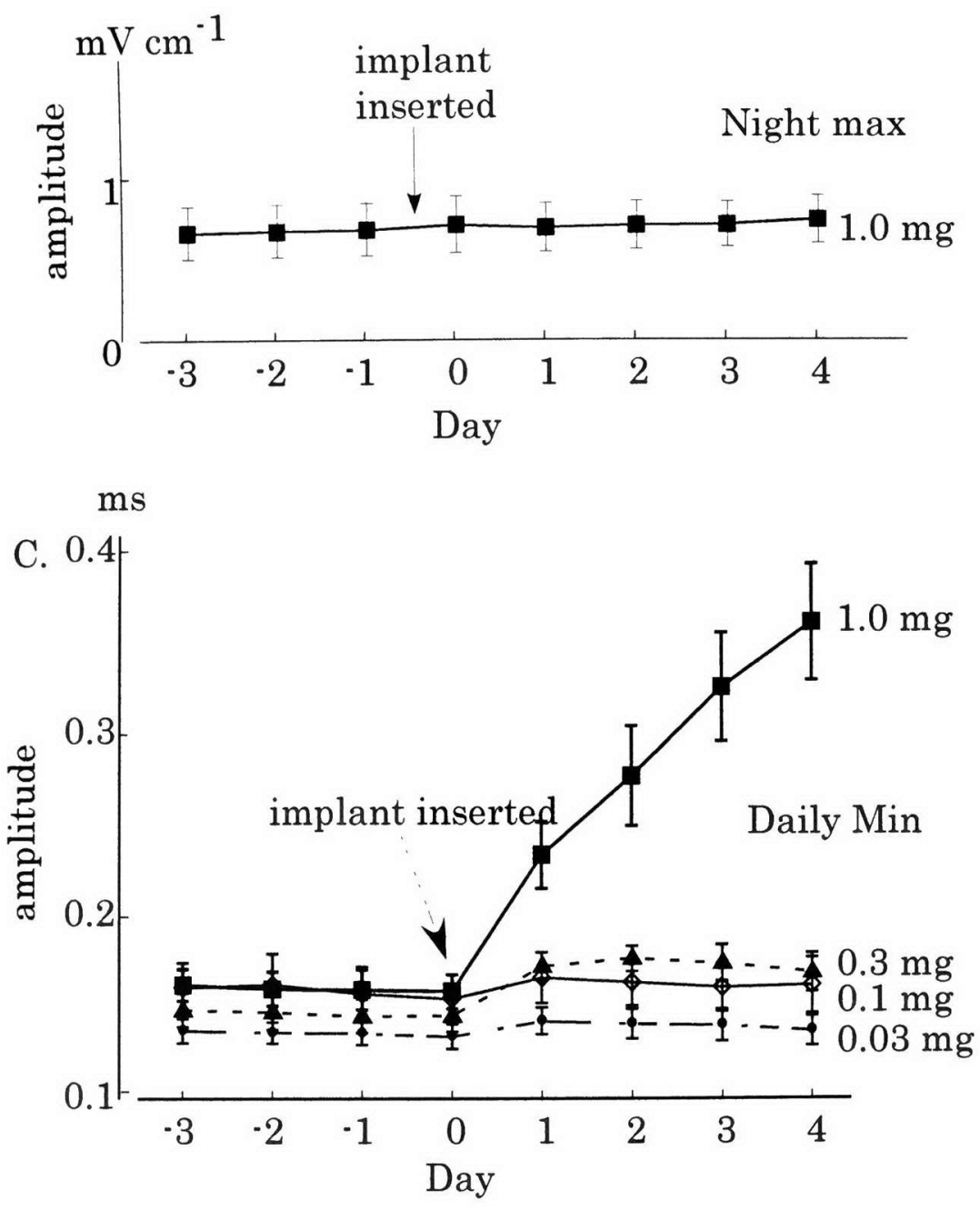

Figure 3.2. Absolute effect of DHT on EOD waveform.

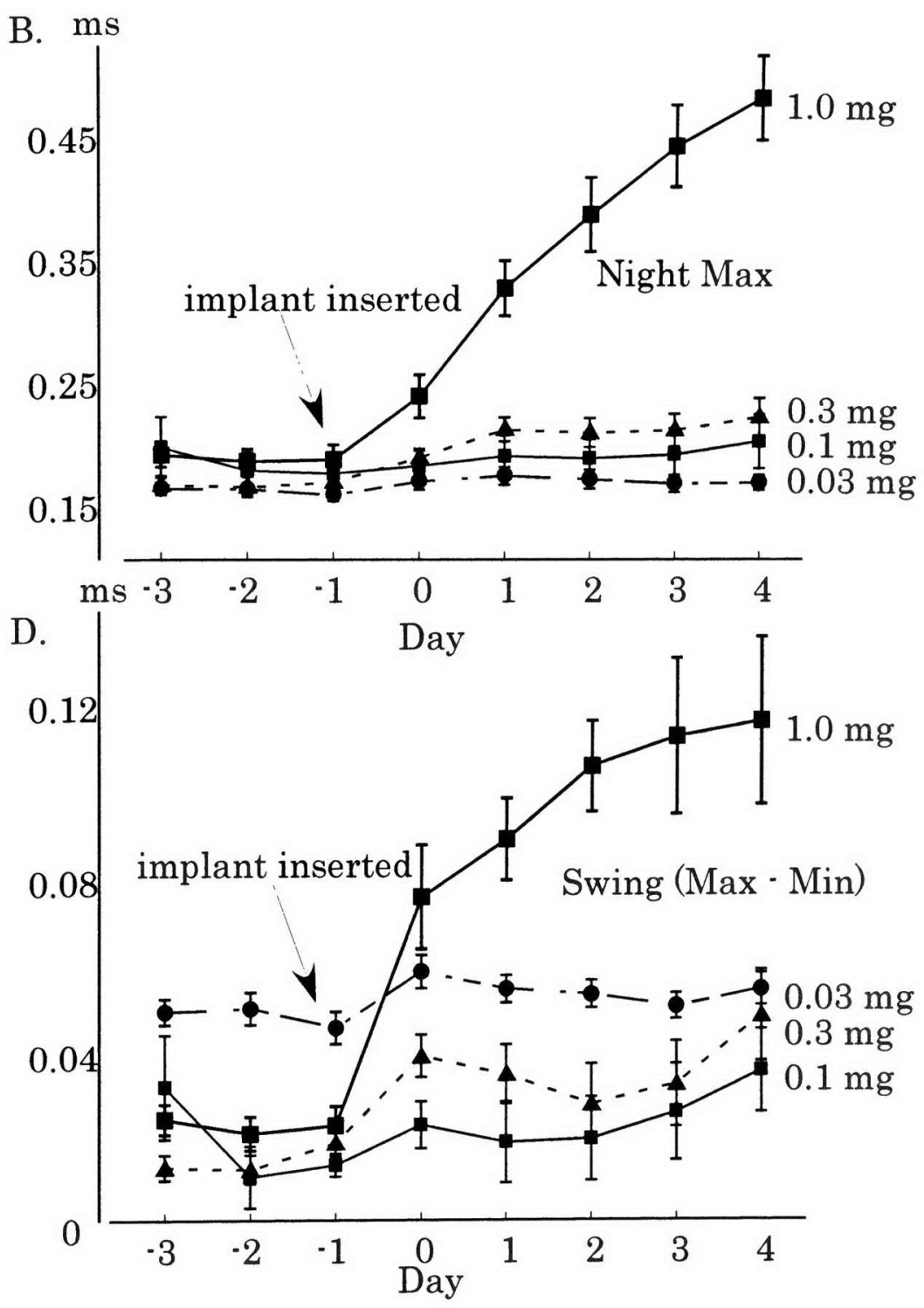


A.
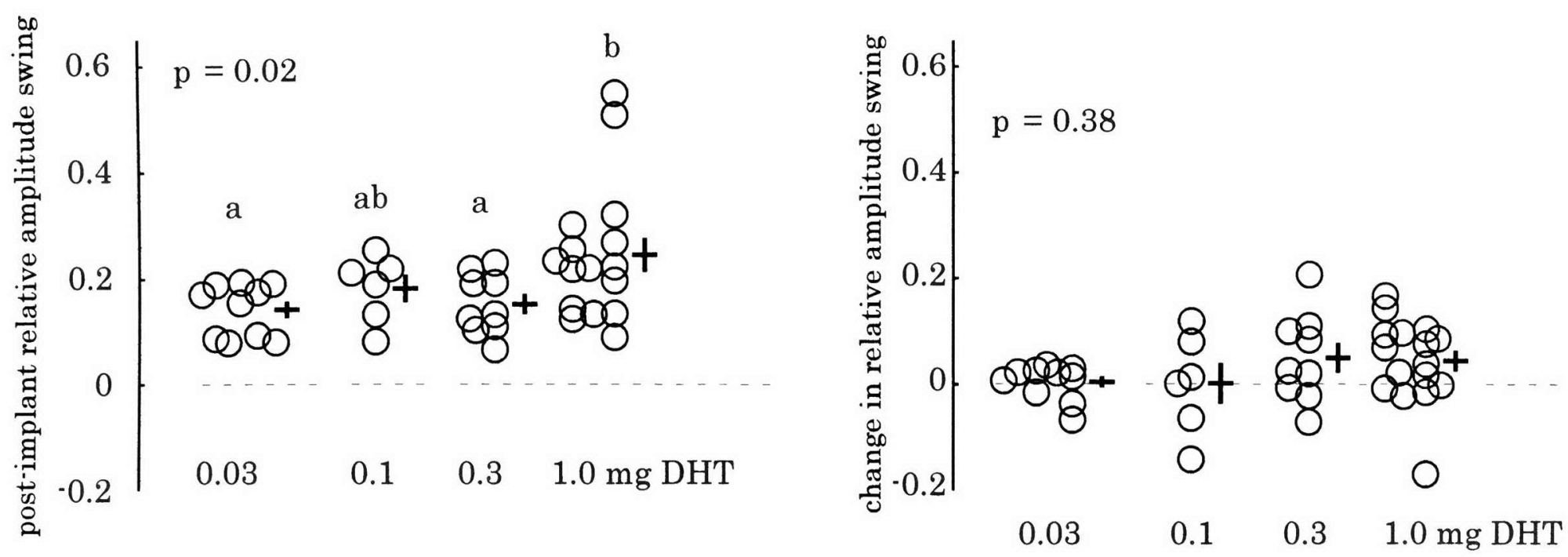

B.
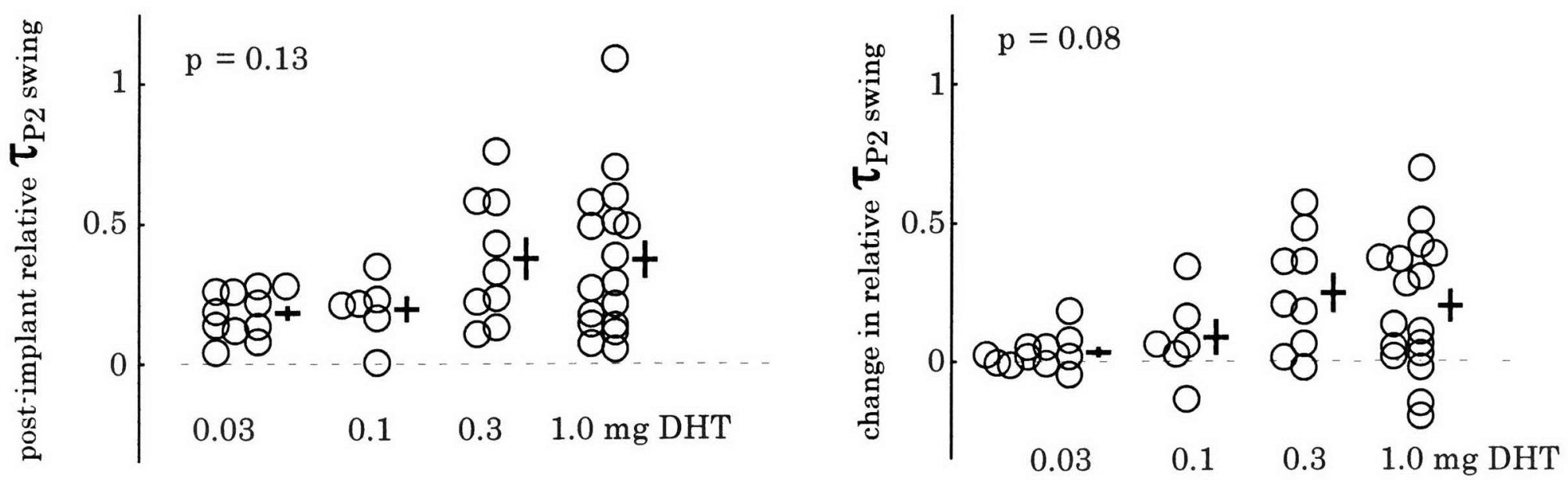

Figure 3.3. Effects of DHT implant dose on female EOD circadian oscillations. 

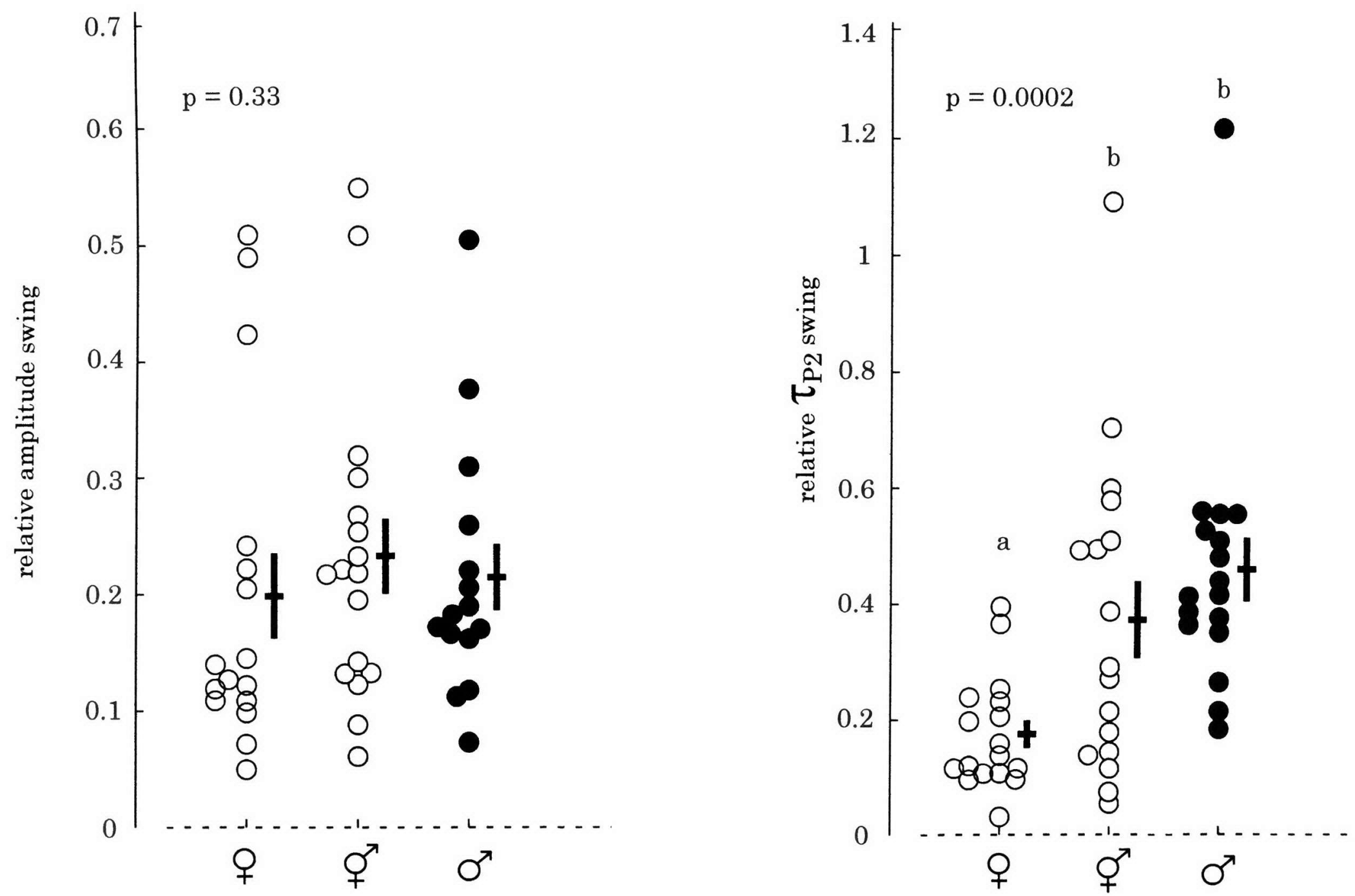

Figure 3.4. Comparison of female, DHT-female, and male EOD circadian oscillations. 

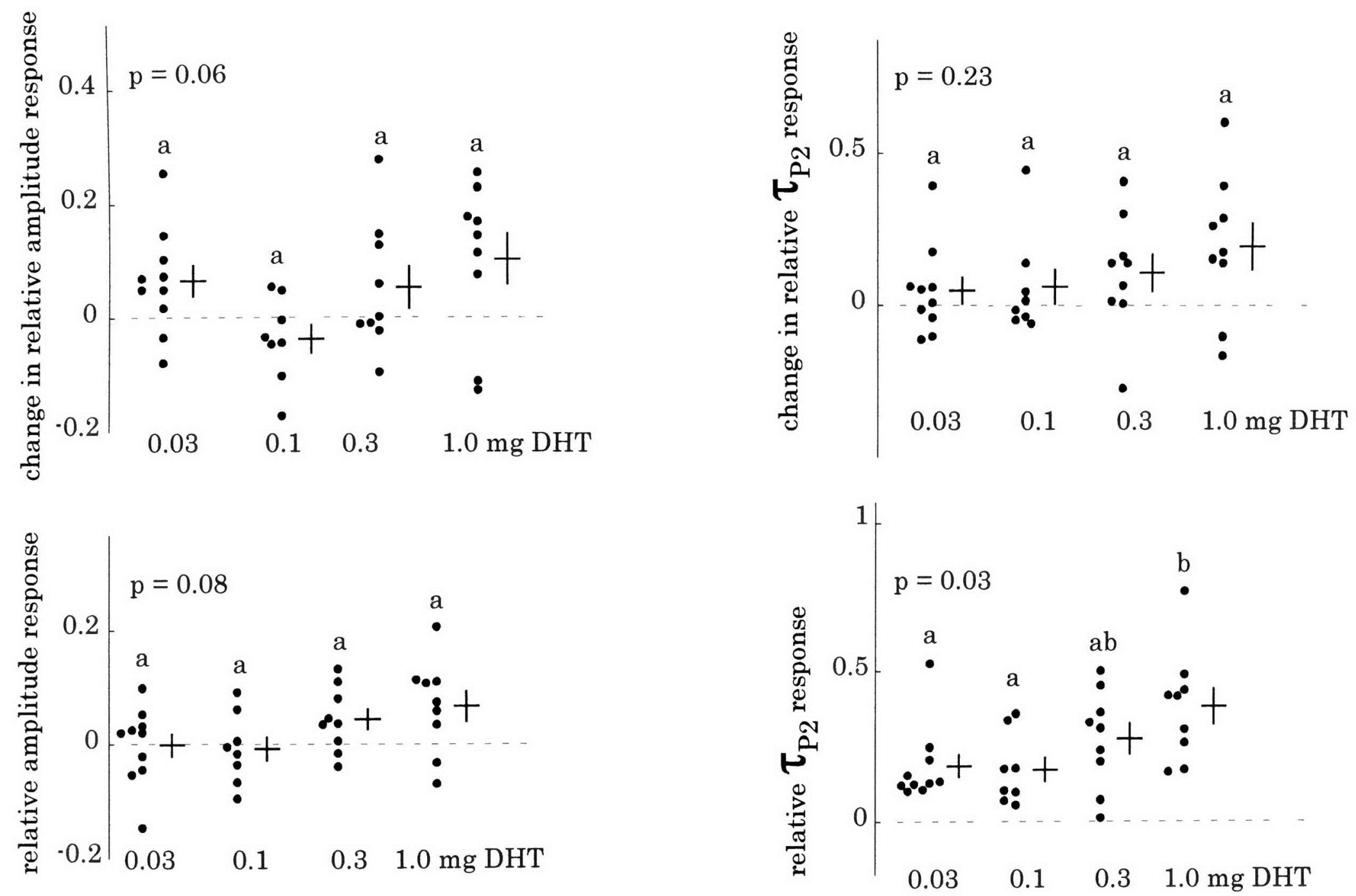

Figure 3.5. Effects of DHT implants on female responses to 5-HT challenge. 

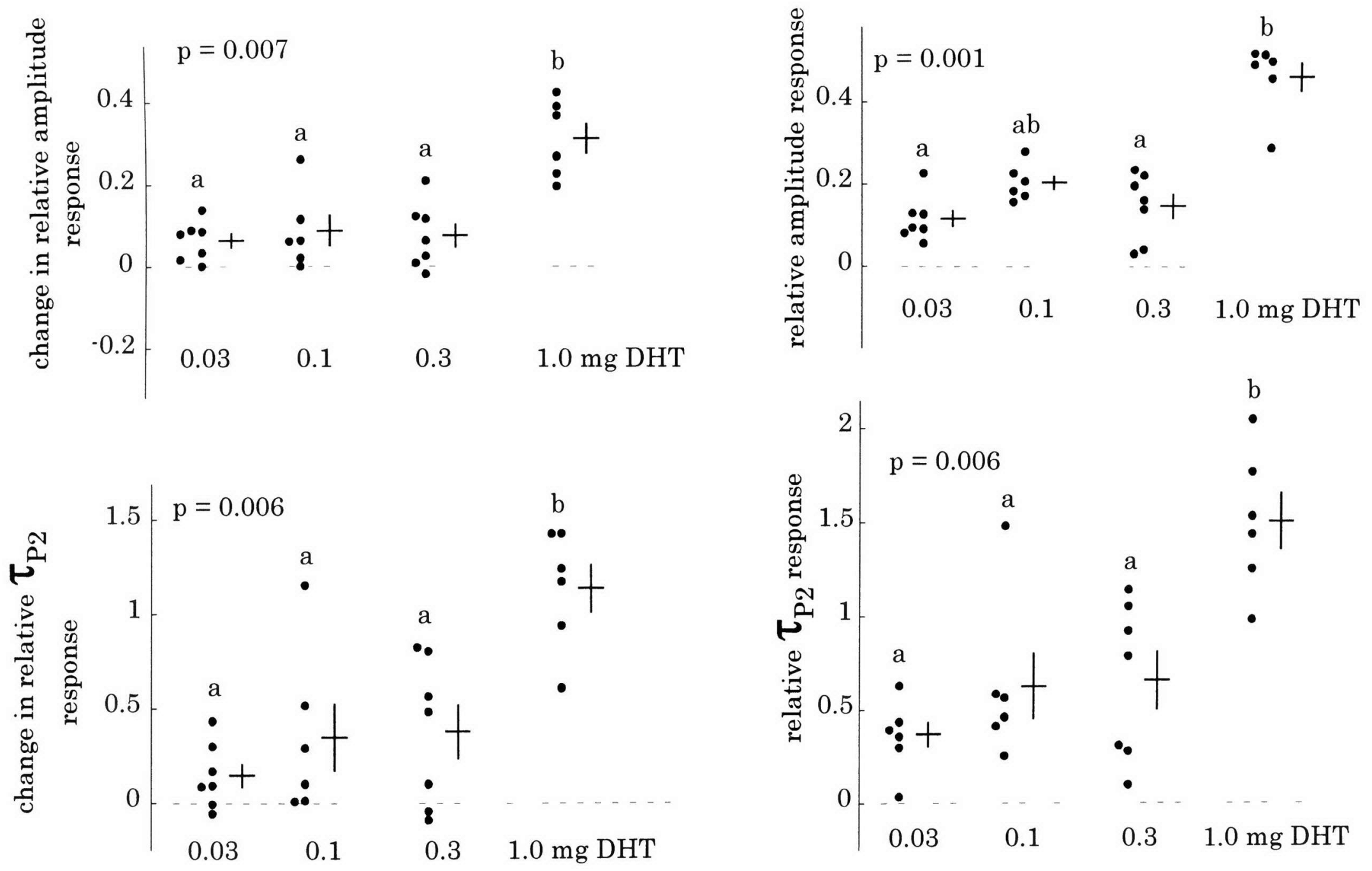

Figure 3.6. Effects of DHT on female responses to ACTH chal lenge. 

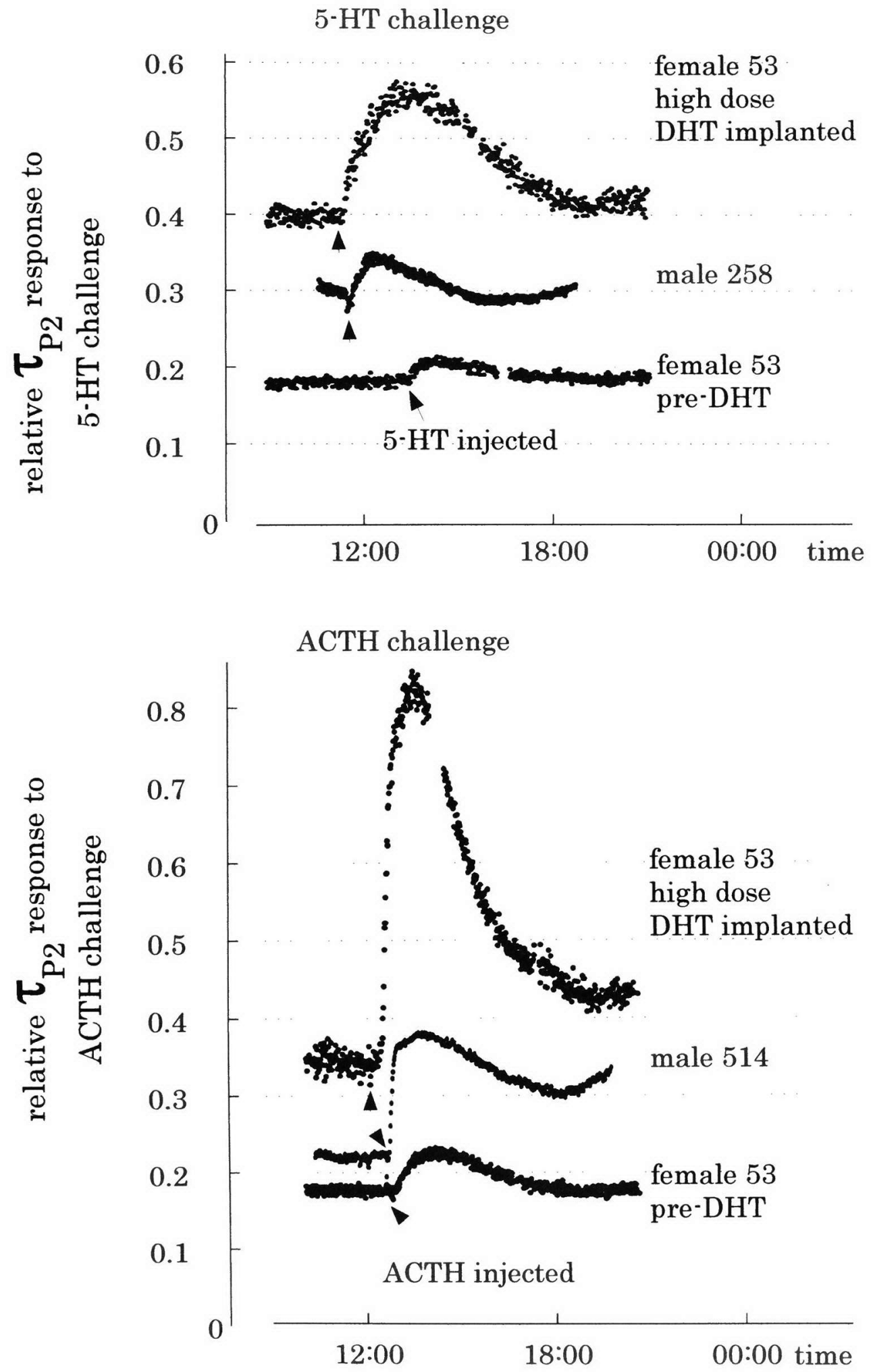

Figure 3.7. Example of effects of DHT on responses to pharmacological challenge with 5-HT and ACTH. 
A.
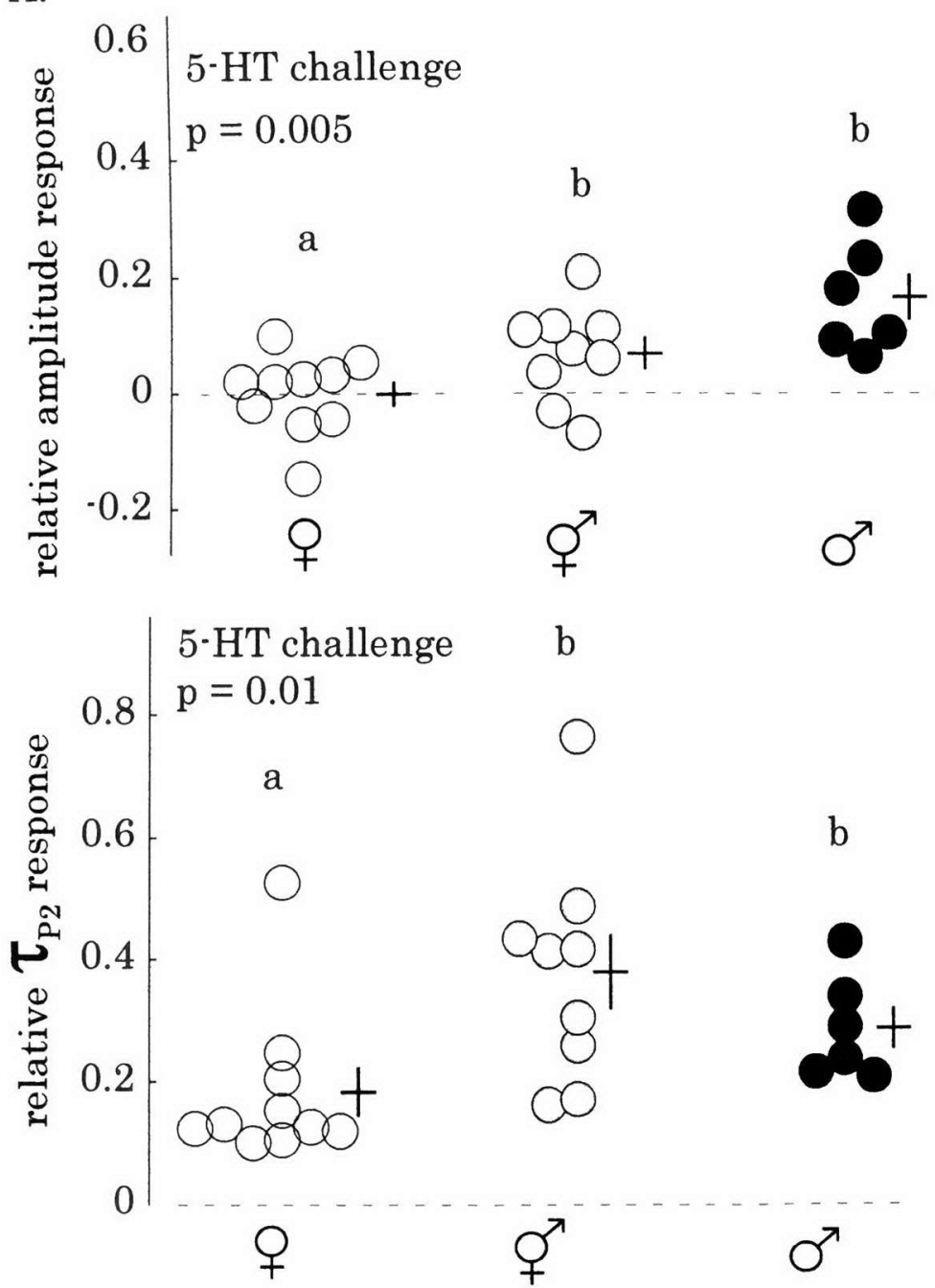

B.
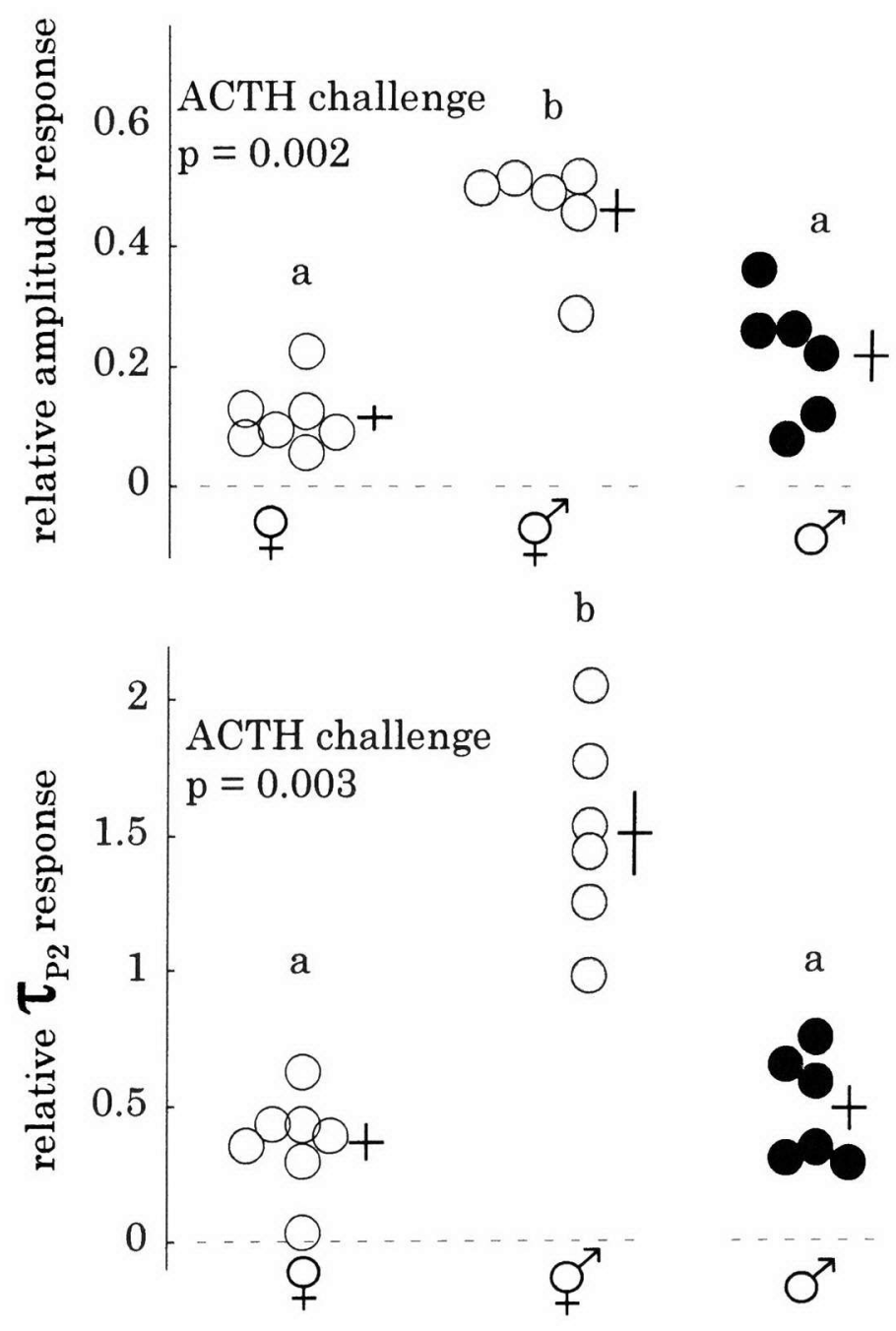

Figure 3.8. Comparison of female, DHT-implanted female, and male re sponses to challenge. 
CHAPTER 4. ANDROGENS ENHANCE RESPONSIVENESS TO SOCIAL CHALLENGE BUT DO NOT INDUCE SEX-SPECIFIC BEHAVIOR TOWARD CONSPECIFICS USING A FORCED SOCIAL CHALLENGE PROTOCOL

Females and males often differ in their responses to social encounters with conspecifics and these dimorphisms are often the behavioral accompaniment to a species' reproductive system (Andersson, 1994; Crews and Silver, 1985). Sex differences in behavior are usually attributed to the actions of gonadal steroid hormones. Typically, androgens are credited for generating male-typical behavior and estrogens for female-typical behaviors (Goy and McEwen, 1980; Kelley, 1988; Kime, 1993; Oliveira et al., 2005). Recent studies with teleosts argue that gonadal steroids, androgens in particular, may be more efficient at masculinizing morphologies than the expression of behavior (Breder and Rosen, 1966; Lee and Bass, 2005; Oliveira et al., 2001b).

Teleosts are the most species rich vertebrate taxa and they display the widest diversity and greatest plasticity in reproductive behaviors among vertebrates (Borg, 1994). At least five different androgens (testosterone (T), 11-ketotestosterone $\quad\left(11-\mathrm{KT}^{\prime}\right), \quad 11$-ketoandrostenedione $\quad(11-\mathrm{KA}), \quad 11 \beta^{-}$ hydroxytestosterone $(11 \beta-\mathrm{OHT})$, and $11 \beta$-hydroxyandrostenedione $\quad\left(11^{-}\right.$ OHA4)) have been measured in teleosts; their presence and relative concentrations vary interspecifically, intersexually, and intrasexually (in species that exhibit sexual polymorphisms) such that there is no 'typical' association between a particular hormone and a specific behavior (for 
comprehensive reviews see Kime, 1993; Lissman, 1958). This diversity in androgen profiles and androgenic control of behavior among species indicates that teleosts have much to offer comparative studies investigating the roles of sex steroids in producing specific behaviors.

Within the teleosts, gymnotiform electric fish have been particularly well studied in regard to the relationships between steroid hormones and behavior. Gymnotiforms of South America, along with the mormyrids of Africa, are unique among teleosts in producing a weak electric discharge for navigation and communication (Bennett, 1961; Bennett, 1971; Hopkins, 1983). The electric organ discharge (EOD) is produced by specialized cells, or electrocytes, that collectively make up the electric organ (EO) (Zakon, 1996). Waveforms are species specific and sexual dimorphisms in EOD traits are common, often occurring in the duration of the waveform and/or in EOD frequency (Hopkins, 1999b; Zakon et al., 1991). Evidence that androgens enhance EOD characters in weakly electric fishes is reviewed elsewhere (Bass and Zakon, 2005; Hopkins et al., 1990; Zakon, 1993, 2000).

Males in the genus Brachyhypopomus (formerly Hypopomus) typically produce biphasic EOD waveforms with longer second phase durations than females produce (Hagedorn and Carr, 1985). Injections or implants of the non-aromatizable androgen 5 $\alpha$-dihydrotestosterone (DHT) extend EOD duration in males, females, and juveniles (Dulka and Maler, 1994; Silva et al., 1999). Fish in the genus Apternotus produce rapid EOD modulations in 
response to social stimuli, behaviors known as chirps. The tendency to produce chirps in response to simulated electronic stimuli is characteristically male; addition of testosterone (T) or DHT leads to enhancement of this behavior (Dulka et al., 1995; Meyer, 1983). Gonadectomy feminizes the EOD frequency and duration of male Sternopygus macrurus (Gymnotiformes: Sternopygidae) EODs, and concomitantly enhances female EOD frequencies (Meyer, 1983).

All of the available data indicate that treatment with the androgens $\mathrm{T}$, 11-KT or DHT enhances EOD waveform and frequency, that plasma levels of $\mathrm{T}$ and 11-KT are correlated with enhanced waveforms, and that estradiol $\left(\mathrm{E}_{2}\right)$ induces female-like waveforms in at least some weakly electric fishes (Dulka and Maler, 1994; Mills and Zakon, 1987; Zakon, 1996; Zakon et al., 1991). A causal link between gonadal hormones and expression of socially-behavior in electric fish interacting with other individuals has not been shown.

Earlier studies have quantified androgen-induced changes in electrocyte morphology, waveform frequency and shape, and an individual's response to artificial stimuli rather than interactions with another individual (Dulka et al., 1995; Hagedorn and Heiligenberg, 1985; Zakon, 1996). I know of no published studies to date that examine whether androgens modify behavioral responses of electric fish, using a methodology that combines androgen treatment with social challenges from live conspecifics that interact with focal individuals. This question is particularly relevant given that 
modulations in EOD waveform are communication signals purportedly evolved for use during social interactions, particularly reproductive interactions, and their expression is under gonadal hormone control (Bass and Hopkins, 1983; Bass et al., 1986; Hagedorn and Carr, 1985; Hagedorn and Heiligenberg, 1985; Hopkins, 1974, 1991; Landsman, 1991). In this experiment I examine the role of androgens in modulating EOD waveform plasticity and response to social encounters in the weakly electric fish, Brachyhypopomus pinnicaudatus (Hopkins et al., 1990).

B. pinnicaudatus, the feather-tail knifefish or 'pinni', is a nocturnal South American gymnotiform fish that produces a sinusoidal biphasic EOD with prominent sexual dimorphism in the duration of the second phase (Franchina and Stoddard, 1998). Males modulate duration of the second phase $\left(\tau_{\mathrm{P} 2}\right)$ on a circadian rhythm such that this waveform parameter is greatest during the peak breeding hours (Silva et al., 1999; Stoddard et al., 2006a). This sexual dimorphism in EOD modulation is thought to be biologically significant and used either in male-male competition for mates or to signal attractiveness to females (Franchina et al., 2001; Franchina and Stoddard, 1998; Hagedorn, 1986, 1995; Kawasaki and Heiligenberg, 1989). Previous studies have also shown that males differentially respond to conspecific social stimuli based on sex of the stimulus fish, suggesting sexrelated differences in the expression of social behaviors are also biologically relevant (Franchina et al., 2001). 
Social isolation leads to diminished EOD amplitude and $\tau_{\mathrm{P} 2}$ in male $B$. pinnicaudatus, but these waveform traits can be restored to pre-isolation levels by the addition of a conspecific stimulus fish. Amplitude and $\tau_{\mathrm{P} 2}$ both increase during social stimulation, but the speed of each response depends of the sex of the stimulus fish: amplitude increases more quickly in the presence of males than females (Franchina and Stoddard, 1998). Females also modulate their waveforms, however these modulations are produced less consistently and are smaller in magnitude than male-typical modulations (Goldina et al., 2006; Hagedorn, 1995; Silva et al., 1999; Stoddard et al., 2006a). Based on these sexual dimorphisms in EOD modulation and in expression of behavior toward conspecifics, I predicted that androgens are a likely mechanism controlling sex differences in EOD expression. To understand the role of waveform modulation in social behavior it would be useful to compare male and female behaviors under similar circumstances.

My goal for this study was to examine hormonal control of sexually dimorphic behavior in a species of gymnotiform that has apparently evolved the most plastic signal compared to other taxa (Dunlap et al., 1998) to further understanding of hormonal control of this behavior. Weakly electric fishes are excellent model systems for exploring these questions because they appear to have undergone rapid evolutionary changes in the production and neuroendocrine control of their EOD waveforms (Stoddard et al., 2003). The specific issues I sought to address were to: (1) document behaviors of male 
and female $B$. pinnicaudatus in response to social challenge by male and female fish and (2) determine if androgens alter the behavior of females in response to these challenges.

\section{METHODS}

\section{EXPERIMENTAL DESIGN}

Previous studies have indicated that response of this species to challenge is associated with an individual's baseline EOD parameters (Hagedorn and Carr, 1985). For all analyses presented within this paper, I calculated an individual's response to challenge by calculating relative change [(peak - baseline) / baseline] to reduce inter-individual variance in waveforms unrelated to social challenge. I accounted for inter-individual variance in female EODs using the following experimental protocol: I recorded baseline data for each individual, presented male and female challengers, inserted androgen implants, re-administered social challenges, and calculated the change in relative response to social challenge (= postimplant relative response - pre-implant relative response). This protocol allowed me to use each female as her own control and thereby eliminate inter-individual differences as a source of variance when analyzing responses to challenge between implant dose groups.

\section{ANIMALS AND MEASUREMENT SYSTEM}

A large breeding colony of $B$. pinnicaudatus is maintained on Florida International University grounds in Miami, Florida. Fish are kept in 450-1 
outdoor stock pools (dimensions: $185 \times 95 \times 26 \mathrm{~cm}$ ) covered with water hyacinth (Eichhornia crassipes) and fed live oligochaete "blackworms" ad libitum. Experimental groups $(\mathrm{n}=3-8$ females) were tested using randomly sampled fish collected from the outdoor stock pools. Focal females were brought indoors and held individually in 284-1 automated measurement tanks $(120 \times 44 \times 44 \mathrm{~cm})$ for the whole of each experimental trial. Fish were weighed and measured for total length (TL) before being placed into recording tanks where they were fed oligochaete blackworms ad libitum under constant photoperiod (12L: 12D) and temperature $\left(28{ }^{\circ} \mathrm{C} \pm 1{ }^{\circ} \mathrm{C}\right)$ throughout each trial. This study was completed using a total of 52 focal females tested in 11 experimental groups from January 2003 through December 2005.

\section{IMPLANT FABRICATION}

I implanted focal females with $5 \alpha$-dihydrotestosterone (DHT) at doses of $0.03 \mathrm{mg}, 0.1 \mathrm{mg}, 0.3 \mathrm{mg}$, or $1.0 \mathrm{mg} 10 \mathrm{~g}^{-1}$ body weight (bw). Implant doses were randomly assigned to individuals across experiments until I had minimum sample sizes of 6 females per DHT dose.

I chose the non-aromatizable androgen DHT to ensure any changes I observed in female EODs were the result of androgenic activity and to follow protocols used in previous research to provide comparable results (Allee et al., 2007; Few and Zakon, 2001). DHT implants were made using Dow silicone mixed with DHT crystals using a method described in detail 
previously (Elsaesser et al., 1989) and following earlier protocols (e.g. Few and Zakon, 2001; Franchina and Stoddard, 1998). I sent frozen serum samples to Yerkes National Primate Research Center at Emory University, Atlanta Georgia for radioimmunoassay to determine DHT concentrations delivered by my implants . The results suggest that at their peak effect, my 4 implant doses delivered approximately $95.35,28.61,9.54$, and $2.86 \mathrm{ng} \mathrm{ml}-1$ of DHT, respectively.

\section{Challenges}

Females were acclimated to the indoor recording tanks without intrusion for up to three days during which I collected baseline EOD waveform data for each individual. I recorded calibrated EODs from freely swimming females around the clock at intervals of $\sim 1$ min for the entirety of each trial using an automated system described in detail previously (Franchina and Stoddard, 1998; Stoddard et al., 2003). I measured EOD peak-to-peak amplitude $\left(\mathrm{mV} \mathrm{cm} \mathrm{cm}^{-1}\right.$ measured at $10 \mathrm{~cm}$ as described in (Hagedorn and Zelick, 1989)), $\tau_{\mathrm{P} 2}$ (ms), and the day-night changes, or swing, in amplitude and $\tau_{\mathrm{P} 2}$. I measure $\tau_{\mathrm{P} 2}$ as the time constant of the exponential decay of the second phase of the EOD (Fig. 4.1.).

In captivity, gymnotiform electric fish readily hide in narrow tubes and males in particular are noted for defending their hiding tubes against intruders (Hopkins, 1991). To determine how androgens change behavior directed toward conspecifics in competitive social situations, I challenged 
each female by introducing a sexually mature male or female into her hiding tube. Challengers were randomly sampled from outdoor stock pools immediately prior to a social challenge and their weights and lengths recorded. I took advantage of the ceramic tubes in the center of the tanks in the automated data collection system to create these forced social encounters.

I compelled focal females to interact with their challengers by confining pairs in the ceramic hiding tubes located in the center of each recording tank. I blocked one end of the tube with polyester filter fiber while the focal female was inside the tube, then gently guided the challenger into the tube by hand, and blocked the second opening with more filter fiber. I continued to record EODs from each tank throughout each social challenge. After challengers had been in the tubes with the focal females for 45 minutes, I unblocked both ends of the tube and removed the challenger. Challengers were then returned to their outdoor pools and I continued to collect data from the focal females.

I paired challengers with focal females randomly with regard to size to reduce potential covariation between relative size and female response to challenge. $B$. pinnicaudatus are easily sexed due to dimorphic tail morphologies (Hopkins et al., 1990; Siegel and Castellan, 1988); so distinguishing between focal females and male challengers was unambiguous. Differentiating between focal females and their female challengers was occasionally difficult, particularly when the pair did not 
differ greatly in size and/or when there were no distinguishing characteristics available to differentiate between the two females. For any dyads where there was uncertainty in the focal female identity after the conclusion of the challenge, both females were re-weighed and measured to ensure the correct female remained in the tank.

I also tested focal males $(n=6)$ with both male and female challengers using the same experimental protocols. This provided data on male responses to the same $\mathrm{SC}$ and allowed me to make direct comparisons between female, DHT-implanted female, and male responses to social challenge.

I organized the response to challenge data two ways for statistical analysis. First, I subtracted an individual's pre-implant response from her post-implant response to challenge to measure the effect of $\mathrm{DHT}$ on behavior. Thus I used each female as her own control to further reduce inter-individual variance in EOD waveform not related to the social challenges. The second way I characterized the effect of DHT on response to challenge was to compare only the post-implant female responses between the different implant dose groups to determine effect of dose on female behaviors.

I analyzed all data using Kruskal-Wallis tests using sex of challenger as the dependent variable. I report the Kruskal-Wallis test statistic $(\mathrm{H})$ and $\mathrm{p}^{-v}$ alues for all tests (H, p-value). Data analysis was generated using SAS software, Version 9.1.3 of the SAS System for Windows and Matlab, Version 
7.1, The MathWorks, Inc. Significant omnibus tests $(\mathrm{p}<0.05)$ were further analyzed using a pairwise, two-tailed comparison of Kruskal-Wallis mean scores with Bonferroni adjustment (Lee and Bass, 2005).

\section{RESULTS}

FEMALE SOCIAL BEHAVIOR

Prior to receiving DHT implants, females enhanced their EOD $\tau_{\mathrm{P} 2}$ by approximately $20 \%$ in response to both female and male social challengers. In contrast, their amplitude increased less than $3 \%$ on average and frequently decreased after social challenge (Table 4.1.). I analyzed pre-implant female response to challenge for both female and male challengers and found no differences in either amplitude or $\tau_{\mathrm{P} 2}$ response. To avoid confusion between challenge type and EOD waveform parameter measured, all Kruskal-Wallis $p^{-}$values are provided in the figures. When significant differences were found between groups, different letters designate pairs that differed from each other.

\section{EFFECTS OF DHT}

Females that were implanted with the highest dose of DHT began to develop secondary sexual characteristics within one week of implantation. Their tails broadened and became feathered at the tip, more closely resembling male tail morphology than female tails (Fig. 4.2.). I did not quantify these changes further. 
FEMAle CHALlenge

DHT implants increased the magnitude of EOD augmentation following female challenge. Pre- and post-implant difference in female amplitude $(\mathrm{H}=9.1, \mathrm{p}=0.03)$ and $\tau_{\mathrm{P} 2}(\mathrm{H}=16.01, \mathrm{p}=0.001)$ response to challenge was greatest in females implanted with the two high doses of DHT. The postimplant amplitude $(\mathrm{H}=18.5, \mathrm{p}=0.0004)$ and $\tau_{\mathrm{P} 2}(\mathrm{H}=17.21, \mathrm{p}=0.0006)$ responses were greatest in the group that received the highest DHT dose (Fig. 4.3.).

MALE CHALLENGE

Androgen implants also increased the magnitude of female responses to male challengers. Females in the three highest implant dose groups showed a larger increase in response to challenge in their EOD amplitude $(\mathrm{H}=8.3, \mathrm{p}=0.04)$ and $\tau_{\mathrm{P} 2}$ responses $(\mathrm{H}=7.8, \mathrm{p}=0.05)$ to male challenge than females implanted with the lowest dose of DHT did. The post-implant female amplitude $(\mathrm{H}=12.9, \mathrm{p}=0.005)$ and $\tau_{\mathrm{P} 2}(\mathrm{H}=11.4, \mathrm{p}=0.01)$ responses followed a similar trend (Fig. 4.4.).

Both the change in response to male challenge and the post-implant responses to male challenge appeared to show an approximately linear effect of DHT dose on amplitude and $\tau_{\mathrm{P} 2}$ response (Figs. 4.3 and 4.4.). The variability in female responses to both challenge types was greatest in $\tau_{\mathrm{P} 2}$ compared to amplitude, and was greatest at the highest DHT implant doses. 
This effect was particularly noticeable in the $\tau_{\mathrm{P} 2}$ responses to male challengers.

FEMALE RESPONSE COMPARED TO MALE RESPONSE

I found no differences between male and female responses to challenge in either inter- or intrasexual challenges (Fig. 4.5.). DHT female responses to both types of social challenge were much greater for both EOD amplitude and $\tau_{\text {P2 }}$ compared to male and female responses (female challenge: amplitude $\mathrm{H}=19.8, \mathrm{p}<0.0001 ; \tau_{\mathrm{P} 2} \mathrm{H}=26.1, \mathrm{p}<0.0001 ;$ male challenge: amplitude $\mathrm{H}=20.9$, $\mathrm{p}<0.0001$ and; $\left.\tau_{\mathrm{P} 2} \mathrm{H}=19.5, \mathrm{p}<0.0001\right)$. Treatment with DHT clearly resulted in exaggerated female response to challenge for both waveform parameters. WAVEFORM CHANGES

Among all fish tested, $\tau_{\mathrm{P} 2}$ responses to social challenge were greater than amplitude responses and my social challenge paradigm revealed no significant differences in male and female behaviors toward intrasexual or intersexual challengers (Table 4.1.). The only distinction I observed when I compared female, male, and DHT female behaviors was that prior to implantation with DHT, females often reduced their amplitudes in response to both female and male challengers (Figs. 4.3 and 4.4.). While the mean change in amplitude was positive, female amplitude responses to social challenges were highly variable with some females decreasing their amplitudes in response to challenges. In contrast to EOD amplitude, no females decreased $\tau_{\mathrm{P} 2}$ after social encounter. Females were the only group I 
tested that showed a decrease in an EOD parameter over the time course of an hour, and then, only in EOD amplitude following social challenge.

Discussion

Evidence suggests that androgens may be more efficient at masculinizing morphology or exaggerating existing traits rather than inducing the expression of masculine behaviors, per se (Allee et al., 2007; Oliveira et al., 2001a; Oliveira et al., 2001b). Results from my experiments tend to support this proposal. I found evidence that androgens affect behavioral change in weakly electric fish by altering electrocyte capacity to respond to challenges but do not modify the pattern of behavior expressed towards conspecifics.

In a companion study, I examined the effects of androgens on the plasticity and responsiveness of female electrocytes and their capacity to modulate in response to pharmacological challenges with serotonin and ACTH (Franchina et al., 2001). I found that introducing androgens leads to an increased female responsiveness to pharmacological challenge and augments the magnitude of female response to challenge. While measuring response to ACTH challenge informs me about the mechanistic capacity of electrocytes to generate an enhanced social signal, measuring response to social challenge addresses the higher-level question of how steroid hormones influence the expression of social behavior. A previous study in which $B$. pinnicaudatus interacted freely through a mesh divider revealed that males 
produce larger modulations of EOD waveform in response to males than females (Stoddard, 2006). Unexpectedly, the current study found no such sex differences in response to forced social challenges. The percentage of change in amplitude and $\tau_{\mathrm{P} 2}$ were the same in both sexes and neither sex responded differentially to inter- versus intrasexual encounters. Nonetheless, addition of DHT resulted in striking exaggeration of female responses to encounters with either sex.

Instead of uncovering sexual dimorphisms in response to forced social challenge, I appeared to uncover a general increase in responsiveness and/or in sensitivity to social stimuli due to androgens and a paradox in male and female expression of behavior. Both the female change in response to challenge and the post-implant response to challenge increases were related to implant dose, which supports my interpretation that androgens facilitate level of responsiveness rather than orchestrating a suite of male-typical social behaviors. This leaves confusion as to why I found no differences in expression of behavior toward the two sexes, given that previous studies demonstrated these differences exist.

One possible explanation for this discrepancy could be that my forced social challenge paradigm simulates a different sort of social encounter than one created when fish interact at will through a plastic screen. I employed forced encounters (i.e. fish in the same hiding tube) rather than unforced encounters based on previous data showing that this protocol reliably elicits 
rapid EOD modulations. If the challenges are unforced, then fish do not begin to interact and change their EODs until nightfall (VL Salazar, unpubl. data, in Narins and Capranica, 1980). The two sexes appear to elicit different magnitudes of response in these two experimental paradigms. I observed qualitative differences in focal female behavior toward female versus male challengers that statistical analysis did not capture. Focal females were more likely to rush out of their hiding tubes as a female challenger was being put into the tube than they were when males were being put in. Females tended to leave the hiding tubes faster than males did when the tubes were unblocked at the end of a challenge and it was common for either or both females to exhibit signs of physical damage (e.g. cuts, scrapes) following female challenge. This tended not to be the case with male challengers.

Females seemed to readily share their tubes with males and signs of agonistic interactions were rare after male challenges. It is possible that these fish simply became stressed by being locked in their tubes and any differences in reaction toward females and males were anomalous; but this seems unlikely. I often encounter pinnis that take a long time to settle into their tanks after being brought indoors. I have found that one of the best ways to calm these fish down and encourage them to stay inside the tubes so I can collect data is to block one end of the tube with this fiber. Pinnis appear to welcome having this material to burrow in to, perhaps because it mimics 
plant roots in which pinnis normally seek refuge. These observations lead me to suspect that the differences I observed in female reaction to other females are indicative of real differences in behavior toward conspecifics and should be investigated further. Evidence supporting female-female agonistic interactions exists in electric fish. In the congener $B$. brevirostris, female dyads have been found to fight more aggressively for exclusive use of a shelter tube than do male dyads (W.G.R. Crampton, pers. com.).

The goal of this study was to measure how androgens modify behavioral responses and I wanted to eliminate as much non-challenge specific inter-individual variability as possible. Interpreting absolute versus relative changes in EOD waveform provides information on different aspects of biologically relevant traits in this fish. Relative measures of EOD waveform allow me to compare changes in an individual's capacity to respond to a specific challenge based on a particular treatment (e.g. DHT versus control). Comparing relative data standardizes my measures of responses to challenges and eliminates the inter-individual variability in EOD caused by social context. Yet the variability I controlled in the present experiments may be precisely the variability that explains the social significance of an individual's capacity to respond, the trait I measured here. Studies currently underway in Dr. Stoddard's laboratory are investigating just this question of how social context alters EOD expression and how it leads to different patterns of waveform modulations. The results from the present study 
complement these investigations by addressing the mechanisms that may underlie this social regulation of the EOD.

The fact that males and females show the same relative responses to forced social challenges suggests that the physiological mechanisms underlying modulations of the EOD in response to social encounters may be the same in both sexes. The fact that introducing androgens resulted in exaggeration of responses suggests that my implants altered the physiological machinery involved in producing waveform modulations, i.e. I altered the electrocyte's capacity to respond to challenge.

Because I only found changes in the magnitude of response and not in the pattern of response to different sexed challengers, this seems to indicate that the mechanisms controlling the expression of social behaviors in different contexts are not androgen dependent. The results from my study lead to interesting questions that must be addressed before I can fully understand the hormonal control of EOD modulations in pinnis. I need to address the lack of information available regarding the biological relevance of EOD modulations before I can fully interpret the results of this and other studies on the role of androgens in affecting EOD modulations. Do rapid modulations in $\mathrm{t}$ signal aggressive intent? What types of female-female interactions exist and when are they displayed? Why do I see such disparate responses to social challenge in the $\tau_{\mathrm{P} 2}$ and amplitude waveform parameters? 
It is tempting to speculate that the EOD is a complex, multicomponent signal comparable to the coqui call of Puerto Rican tree frogs Eleutherodactylus coqui (Backwell and Passmore, 1996), fiddler crab waves (Gibson, 1996; Pope, 2000), grouse-calls (Scheuber et al., 2003a), and cricket chirps (Kelley, 1988; Scheuber et al., 2003b). If the EOD was a complex signal, it might be possible that $\tau_{\mathrm{P} 2}$ and amplitude broadcast different information about the signaler and that they are aimed at different receivers. If males compete for females or actively attract females, then courtship is a characteristic male behavior (Hagedorn and Heiligenberg, 1985). The role of EOD modulations characteristic of males in $B$. pinnicaudatus have putatively been assigned as mate attraction although this has yet to be demonstrated experimentally (Hagedorn, 1988; Hopkins et al., 1990; Kawasaki and Heiligenberg, 1989; Silva et al., 1999; Stoddard, 2002; Wilhelmi et al., 1955). Curtis and Stoddard (2003) demonstrated that females chose longer males when given the choice between two males of unequal size. Research currently being conducted on male-male interactions suggests that intrasexual variations in behavioral response to social challenge are present in $B$. pinnicaudatus and that male-male competition is a relevant social interaction (VL Salazar, unpubl obs). Likewise Crampton's observations suggest female-female competition can be extremely intense (W.G.R. Crampton, pers. com.). 
Additionally, my results tentatively eliminate androgens as the proximate hormonal modulators of expression of social behavior in pinnis. Future work should address what other factors may regulate social behavior. A good place to start would be to look at whether pinni EODs are modified by introduction of AVT. Research has shown that this neuropeptide is involved in the expression of reproductive behaviors in teleosts and is an unexplored avenue in electric fish (Foran and Bass, 1998; Godwin et al., 2000; Goodson and Bass, 2000a, b, 2001; Grober and Sunobe, 1996; Knight et al., 1990; Macey et al., 1974; Oliveira et al., 2005; Ota et al., 1999; Pickford and Strecker, 1977; Zakon et al., 1991).

\section{SUMMARY}

The exaggerated responses exhibited by DHT females combined with the evidence that males and females do not differ in their responses to my behavioral challenge imply that other factors are involved in regulating EOD waveform modulations in social contexts. Zakon et al. (2001) suggest this may also be true for Sternopygus. They found that high plasma concentrations of androgens always coincided with production of dominant male EODs, but the masculinity of EODs was more variable when androgen levels were low. They proposed that androgens might have the foremost role in producing masculine EODs, but that other factors may be important when androgen levels are low. 
The differential responses based on sex of the stimulus fish that observed might not be androgen dependent. Because I saw no change in the patterns of behavioral expression that females displayed toward either males or to females, and because no changes in responsiveness of $\tau_{\mathrm{P} 2}$ and amplitude were found, it appears that the immediate control of social signal enhancement may not be androgen dependent in $B$. pinnicaudatus. The ability to develop masculine electrocytes and to maintain a level of responsiveness to stimuli does appear to be androgen dependent; however the production of socially relevant behaviors using these enhanced structures appears to be dependent on other factors. 


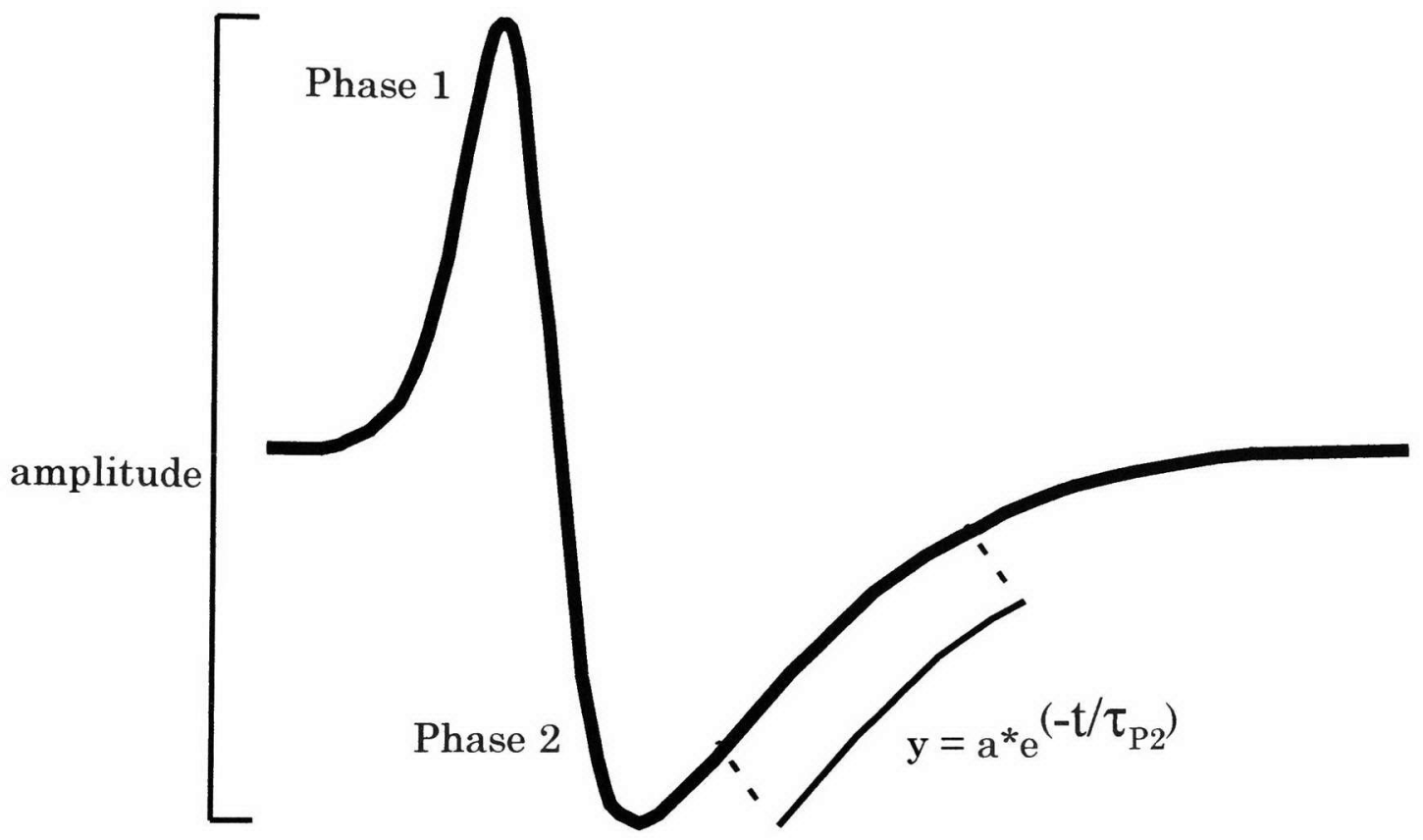

$1 \mathrm{~ms}$

Figure 4.1. Measurement of Brachyhypopomus pinnicaudatus electric organ discharge (EOD) parameters. Amplitude was measured peak-topeak for the entire waveform. The time constant of repolarization $\left(\tau_{\mathrm{P} 2}\right)$ was estimated by fitting an inverse exponential function fit to the decay segment of phase two.

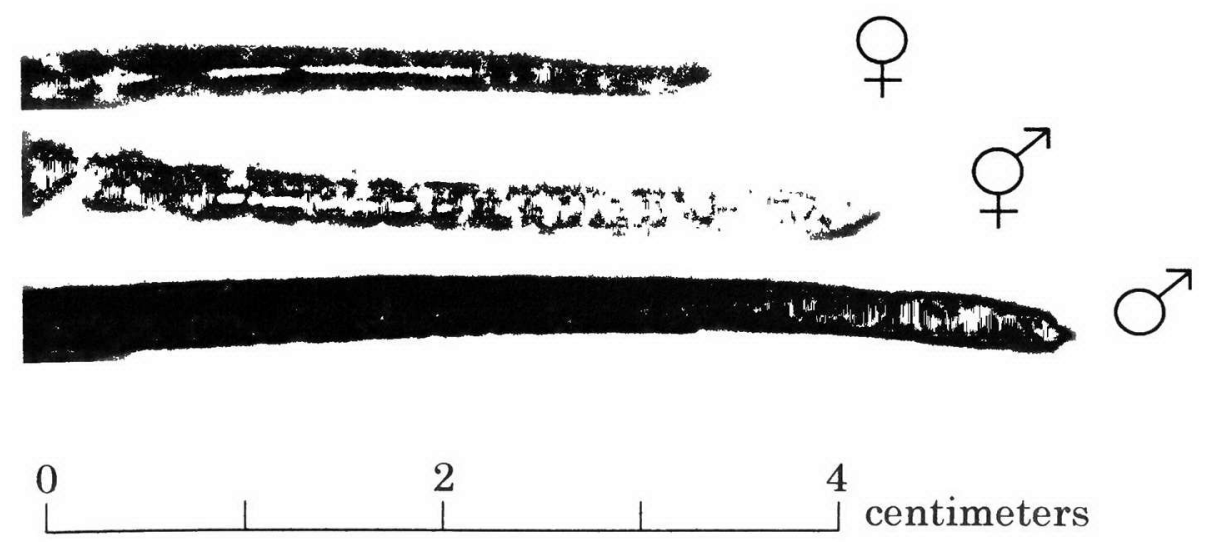

Figure 4.2. Implanting DHT causes females to develop secondary sexual characteristics. 
A.

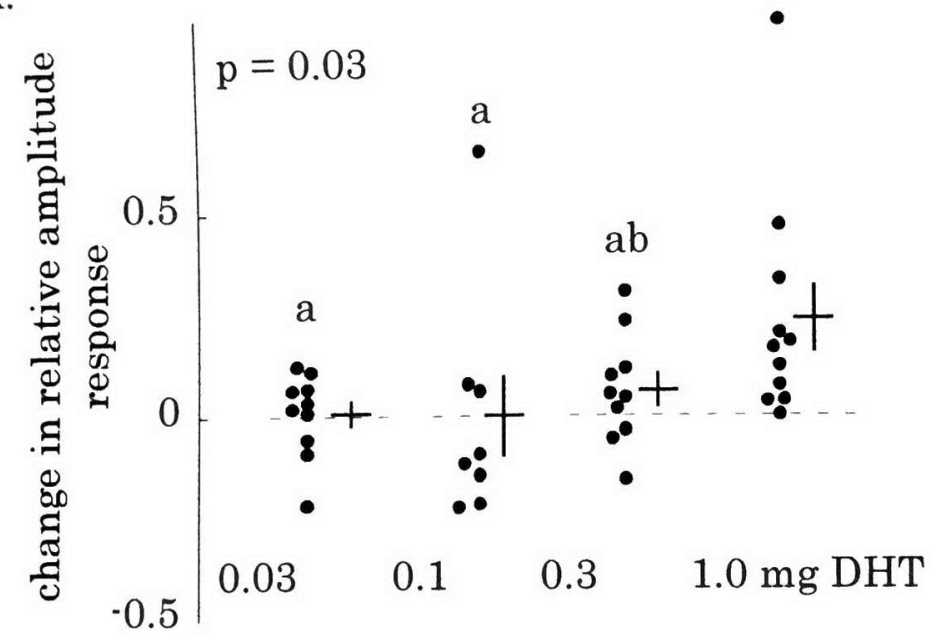

C.

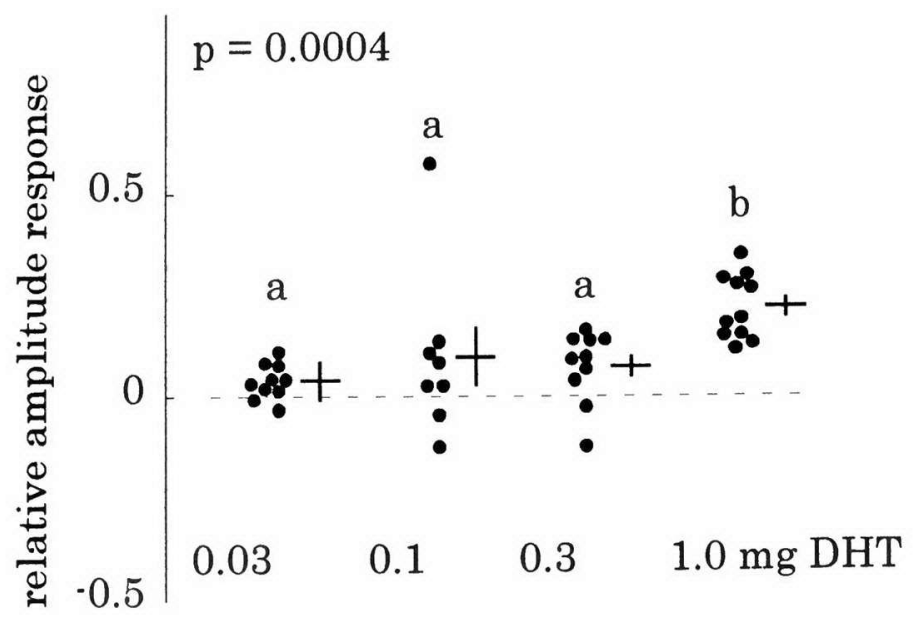

B.

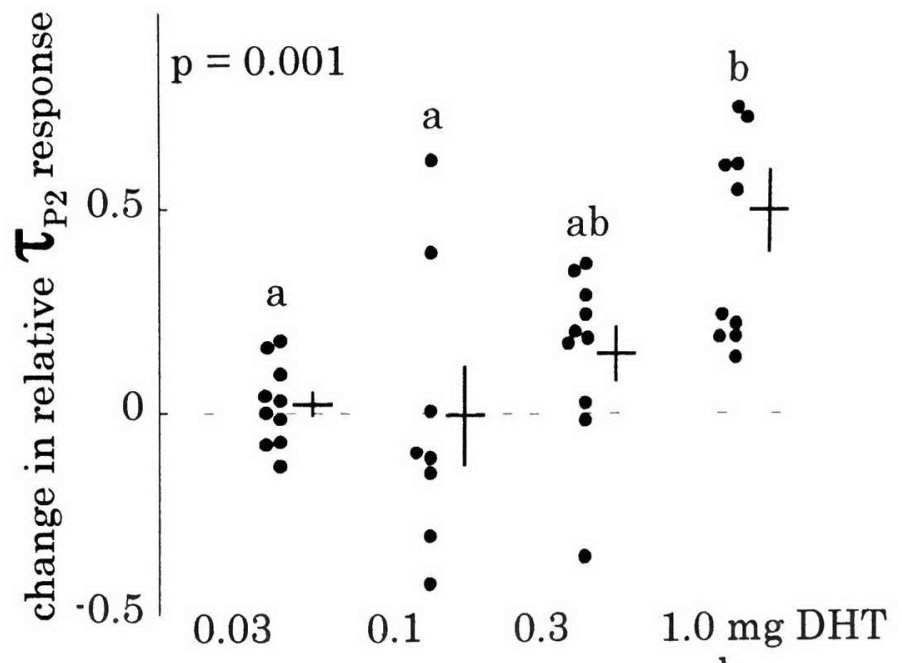

D.

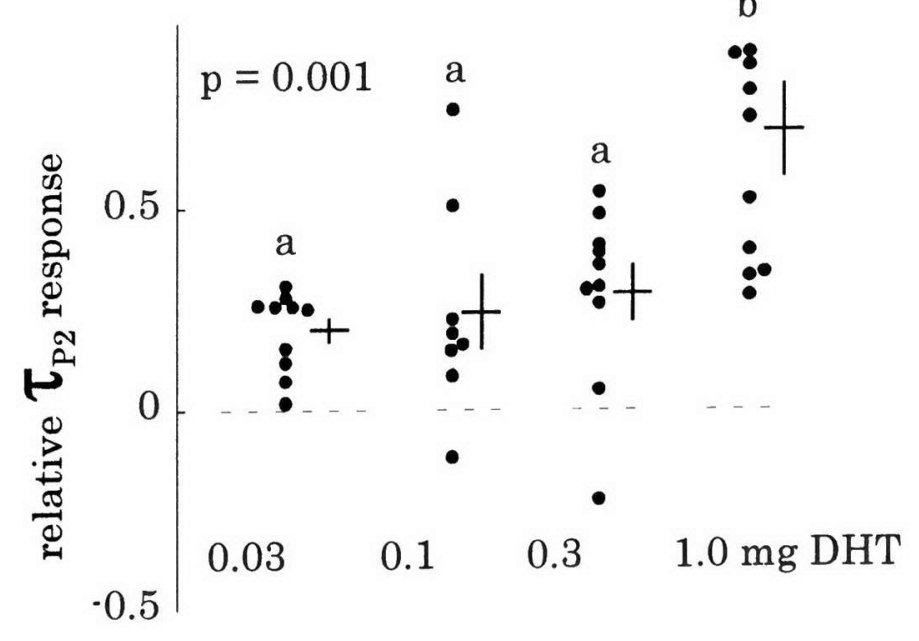

Figure 4.3. Effect of DHT implants on female responses to female challenge. 


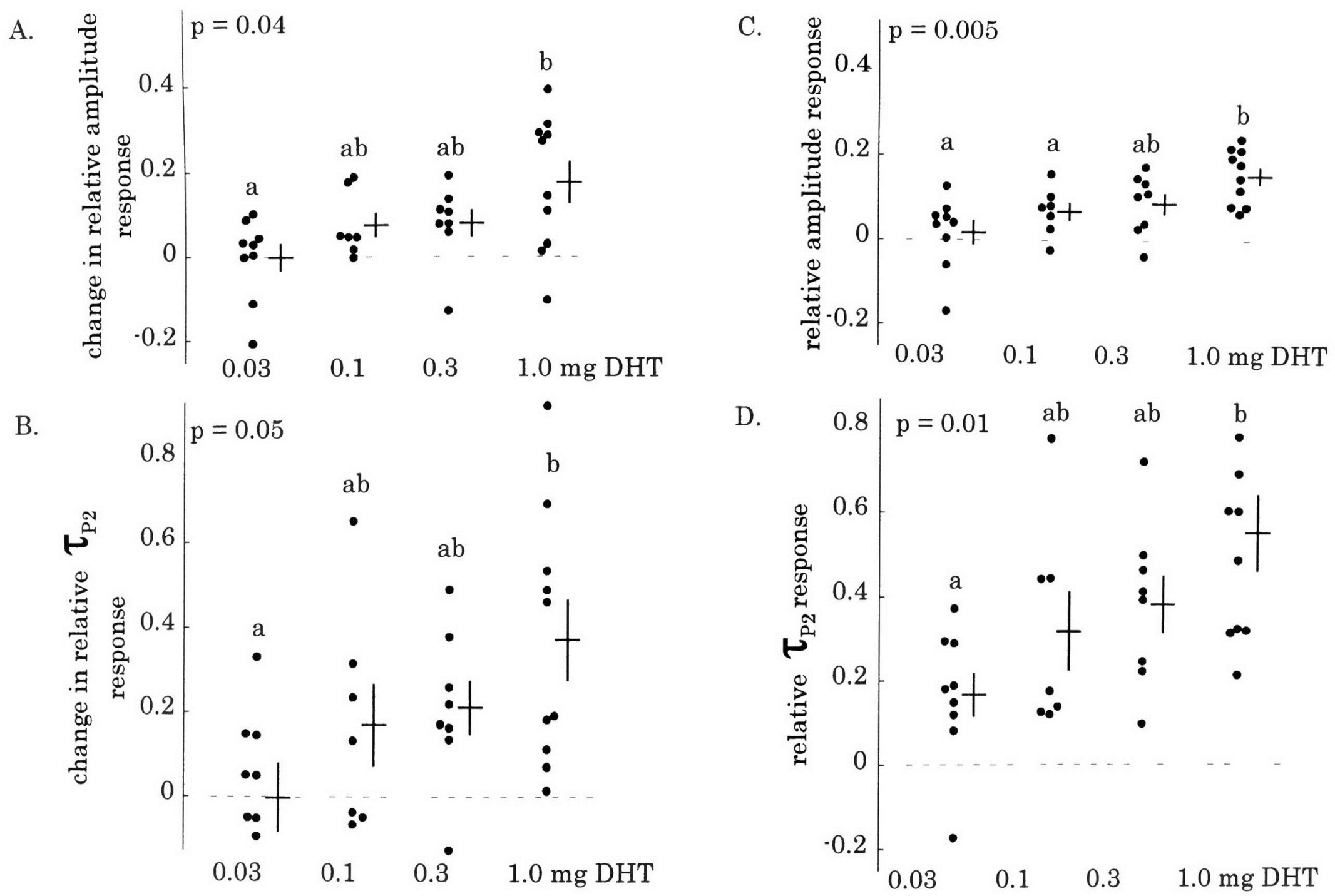

Figure 4.4. Effect of DHT implants on female responses to male challenge. 
A.

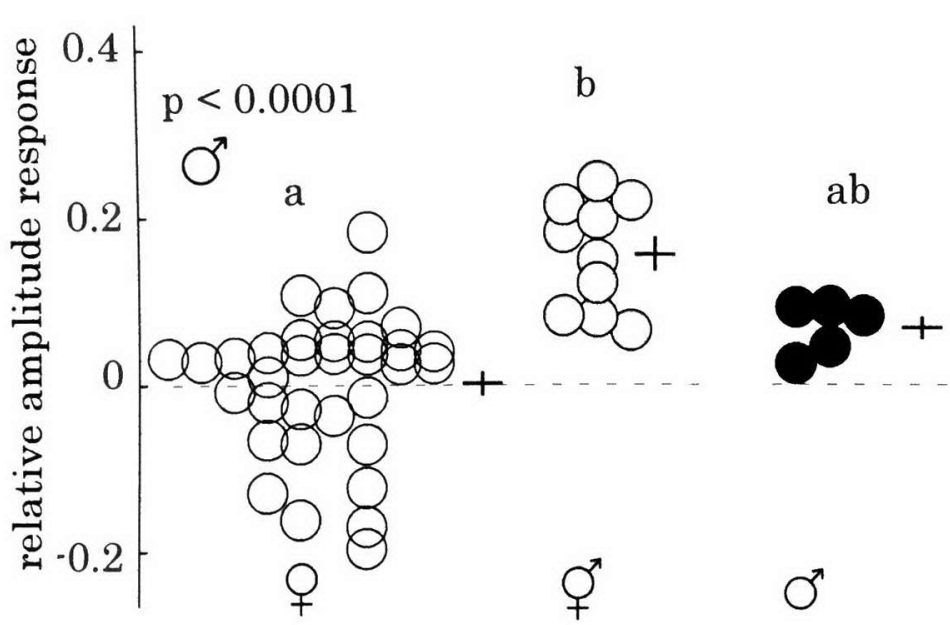

C.

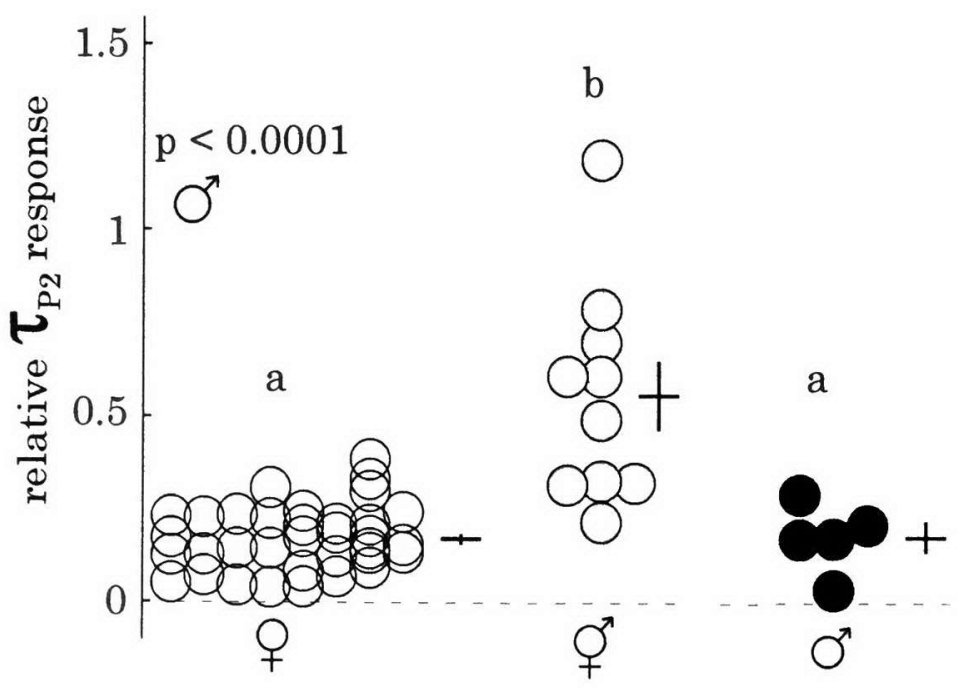

B.

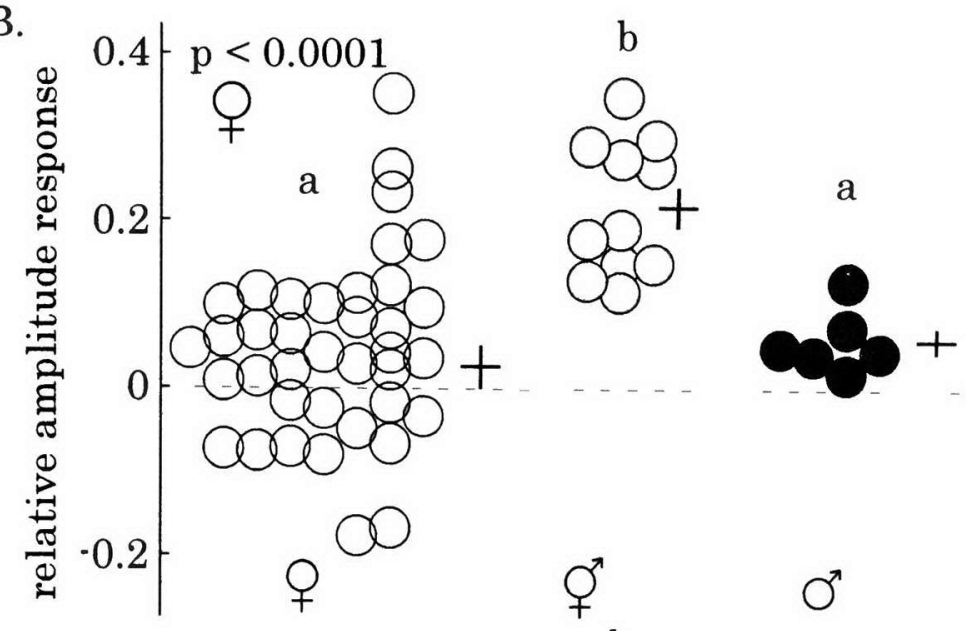

D.

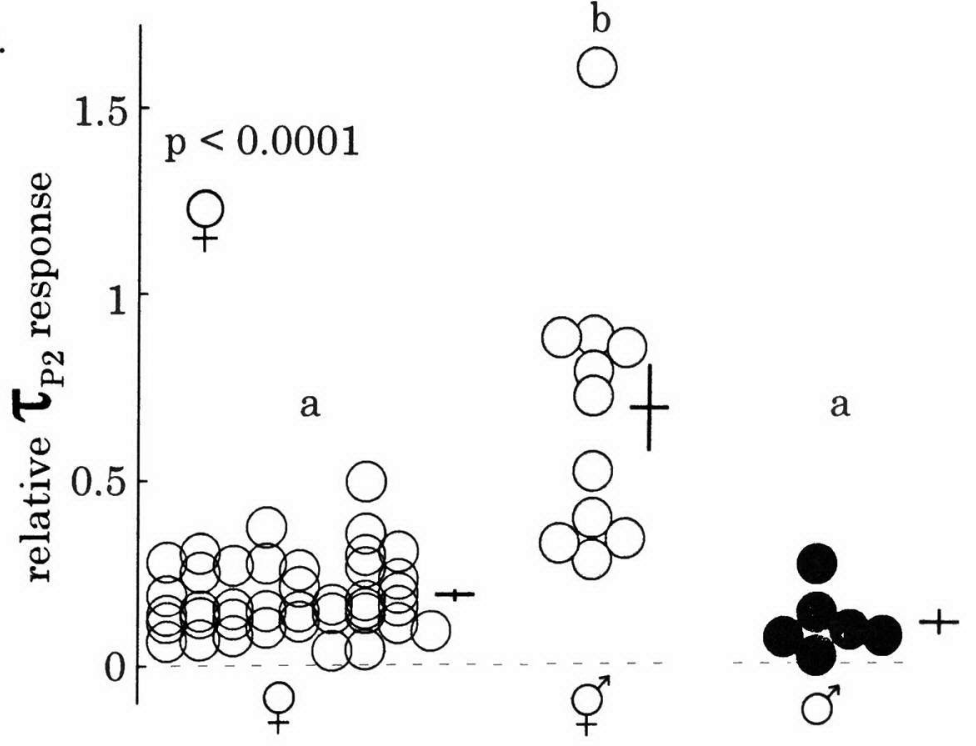

Figure 4.5. Comparison of female, DHT-implanted female, and male responses to social challenge. 


\section{LITERATURE CITED}

2000. The American Heritage dictionary of the English language. Houghton Mifflin, Boston.

Allee, S.J., Markham, M.R.,Stoddard, P.K., 2007. Androgens enhance peripheral response to melanocortins but show little effect on central circadian rhythm generation. Horm. Behav.

Andersson, M.B., 1994. Sexual selection. Princeton University Press, Princeton, N.J.

Backwell, P.R.Y.,Passmore, N.I., 1996. Time constraints and multiple choice criteria in the sampling behaviour and mate choice of the fiddler crab, Uca annulipes. Behav. Ecol. Sociobiol. 38, 407-416.

Barnes, N.M.,Sharp, T., 1999. A review of central 5-HT receptors and their function. Neuropharmacology. 38, 1083-1152.

Bass, A.H., 1986. A hormone-sensitive communication system in an electric fish. J. Neurobiol. 17, 131-156.

Bass, A.H.,Hopkins, C.D., 1983. Hormonal control of sexual differentiation: changes in electric organ discharge waveform. Science. 220, 971-974.

Bass, A.H.,Hopkins, C.D., 1984. Shifts in frequency tuning of electroreceptors in androgen-treated mormyrid fish. J. Comp. Physiol. A. 155, 713-724.

Bass, A.H., Segil, N.,Kelley, D.B., 1986. Androgen binding in the brain and electric organ of a mormyrid fish. J. Comp. Physiol. A. 159, 535-544.

Bass, A.H.,Zakon, H.H., 2005. Sonic and electric fish: at the crossroads of neuroethology and behavioral neuroendocrinology. Horm. Behav. 48, 360-372.

Baxter, G., Kennett, G., Blaney, F.,Blackburn, T., 1995. 5-HT2 receptor subtypes: a family re-united? Trends Pharmacol. Sci. 16, 105-110.

Bennett, M., 1961. Modes of operation of electric organs. Ann. N. Y. Acad. Sci. 94, 458-509.

Bennett, M.V.L., Electric organs. In: Hoar, W.S., Randall, D.J., Eds.), Fish Physiol. Academic Press, New York, 1971, pp. 347-491. 
Bethea, C.L., Lu, N.Z.,Streicher, J.M., 2002. Diverse actions of ovarian steroids in the serotonin neural system. Front. Neuroendocrinol. 23, $41-100$.

Borg, B., 1994. Androgens in teleost fishes. Comp. Biochem. Physiol. 109C, 219-245.

Breder, C.M.J.,Rosen, D.E., 1966. Modes of reproduction in fishes. Natural History Press, New York.

Brenowitz, E.A.,Lent, K., 2002. Act locally and think globally: intracerebral testosterone implants induce seasonal-like growth of adult avian song circuits. Proc. Natl. Acad. Sci. U. S. A. 99, 12421-12426.

Bullock, T.H.,Heiligenberg, W., 1986. Electroreception. Wiley, New York.

Carlson, B.A., Hopkins, C.D.,Thomas, P., 2000. Androgen correlates of socially induced changes in the electric organ discharge waveform of a mormyrid fish. Horm. Behav. 38, 177-186.

Crews, D.,Silver, R., Reproductive physiology and behavior interactions in nonmammalian vertebrates. In: Adler, N., et al., Eds.), Reproduction. Plenum, New York, 1985, pp. 101-182.

Dulka, J.G.,Maler, L., 1994. Testosterone Modulates Female Chirping Behavior In The Weakly Electric Fish, Apteronotus leptorhynchus. J. Comp. Physiol. A. 174, 331-343.

Dulka, J.G., Maler, L.,Ellis, W., 1995. Androgen-Induced Changes In Electrocommunicatory Behavior Are Correlated With Changes In Substance P-Like Immunoreactivity In The Brain Of The Electric Fish Apteronotus leptorhynchus. J. Neurosci. 15, 1879-1890.

Dunlap, K.D., Thomas, P.,Zakon, H.H., 1998. Diversity of sexual dimorphism in electrocommunication signals and its androgen regulation in a genus of electric fish, Apteronotus. J. Comp. Physiol. A. 183, 77-86.

Dunlap, K.D.,Zakon, H.H., 1998. Behavioral actions of androgens and androgen receptor expression in the electrocommunication system of an electric fish, Eigenmannia virescens. Horm. Behav. 34, 30-38.

Edwards, D.H.,Kravitz, E.A., 1997. Serotonin, social status and aggression. Curr. Opin. Neurobiol. 7, 812. 
Elsaesser, F., Hayashi, S., Parvizi, N.,Ellendorff, F., 1989. In vitro characterization of secretion rates from silastic micropellets containing estradiol. Steroids. 54, 159-168.

Few, W.P.,Zakon, H.H., 2001. Androgens alter electric organ discharge pulse duration despite stability in electric organ discharge frequency. Horm. Behav. 40, 434-442.

Fletcher, A., Forster, E.A., Bill, D.J., Brown, G., Cliffe, I.A., Hartley, J.E., Jones, D.E., McLenachan, A., Stanhope, K.J., Critchley, D.J., Childs, K.J., Middlefell, V.C., Lanfumey, L., Corradetti, R., Laporte, A.M., Gozlan, H., Hamon, M.,Dourish, C.T., 1996. Electrophysiological, biochemical, neurohormonal and behavioural studies with WAY100635 , a potent, selective and silent $5 \cdot \mathrm{HT}_{1 \mathrm{~A}}$ receptor antagonist. Behav. Brain Res. 73, 337-353.

Foran, C.M.,Bass, A.H., 1998. Preoptic AVT immunoreactive neurons of a teleost fish with alternative reproductive tactics. Gen. Comp. Endocrinol. 111, 271-282.

Franchina, C.R., 1997. Ontogeny of the electric organ discharge and the electric organ in the weakly electric pulse fish Brachyhypopomus pinnicaudatus (Hypopomidae, Gymnotiformes). J. Comp. Physiol. A. $181,111-119$.

Franchina, C.R., Salazar, V.L., Volmar, C.H.,Stoddard, P.K., 2001. Plasticity of the electric organ discharge waveform of male Brachyhypopomus pinnicaudatus. II. Social effects. J. Comp. Physiol. A. 187, 45-52.

Franchina, C.R.,Stoddard, P.K., 1998. Plasticity of the electric organ discharge waveform of the electric fish Brachyhypopomus pinnicaudatus I. Quantification of day-night changes. J. Comp. Physiol. A. 183, 759-768.

Gibson, R.M., 1996. Female choice in sage grouse: the roles of attraction and active comparison. Behav. Ecol. Sociobiol. 39, 55-59.

Godwin, J., Sawby, R., Warner, R.R., Crews, D.,Grober, M.S., 2000. Hypothalamic arginine vasotocin $\mathrm{mRNA}$ abundance variation across sexes and with sex change in a coral reef fish. Brain. Behav. Evol. 55, $77-84$.

Goldina, A., Markham, M.R.,Stoddard, P.K., Evolution of circadian and melanocortin-induced plasticity in communication signals of gymnotiform electric fish. Society For Neuroscience, Atlanta, GA, 2006. 
Goodson, J.L.,Bass, A.H., 2000a. Forebrain peptide modulation of sexually polymorphic vocal circuitry. Nature. 403, 769-772.

Goodson, J.L.,Bass, A.H., 2000b. Vasotocin innervation and modulation of vocal-acoustic circuitry in the teleost, Porichthys notatus. J. Comp. Neurol. 422, 363-379.

Goodson, J.L.,Bass, A.H., 2001. Social behavior functions and related anatomical characteristics of vasotocin/vasopressin systems in vertebrates. Brain Res. Rev. 35, 246-265.

Goy, R.W.,McEwen, B.S., 1980. Sexual differentiation of the brain. MIT Press, Cambridge.

Grober, M.S.,Sunobe, T., 1996. Serial adult sex change involves rapid and reversible changes in forebrain neurochemistry. Neuroreport. 7, 29452949.

Hagedorn, M., The ecology, courtship, and mating of gymnotiform electric fish. In: Heiligenberg, W., (Ed.), Electroreception. Wiley, New York, 1986, pp. 497-526.

Hagedorn, M., 1988. Ecology and behavior of a pulse-type electric fish, Hypopomus occidentalis (Gymnotiformes, Hypopomidae), in a freshwater stream in Panama. Copeia. 324-335.

Hagedorn, M., 1995. The electric fish Hypopomus occidentalis can rapidly modulate the amplitude and duration of its electric organ discharges. Anim. Behav. 49, 1409-1413.

Hagedorn, M.,Carr, C., 1985. Single electrocytes produce a sexually dimorphic signal in South American electric fish, Hypopomus occidentalis, (Gymnotiformes, Hypopomidae). J. Comp. Physiol. A. 156, $511-523$.

Hagedorn, M.,Heiligenberg, W., 1985. Court and spark: electric signals in the courtship and mating of gymnotoid fish. Anim. Behav. 33, 254-265.

Hagedorn, M.,Zelick, R., 1989. Relative dominance among males is expressed in the electric organ discharge characteristics of a weakly electric fish. Anim. Behav. 38, 520-525. 
Herfeld, S.,Moller, P., 1998. Effects of 17alpha-methyltestosterone on sexually dimorphic characters in the weakly discharging electric fish, Brienomyrus niger (Gunther, 1866) (Mormyridae): electric organ discharge, ventral body wall indentation, and anal-fin ray bone expansion. Horm. Behav. 34, 303-319.

Hoglund, E., Balm, P.H.,Winberg, S., 2000. Skin darkening, a potential social signal in subordinate arctic charr (Salvelinus alpinus): the regulatory role of brain monoamines and pro-opiomelanocortin-derived peptides. J. Exp. Biol. 203, 1711-1721.

Hoglund, E., Balm, P.H.M.,Winberg, S., 2002. Stimulatory and inhibitory effects of $5 \cdot \mathrm{HT}_{1 \mathrm{~A}}$ receptors on adrenocorticotropic hormone and cortisol secretion in a teleost fish, the Arctic charr (Salvelinus alpinus). Neurosci. Lett. 324, 193-196.

Hopkins, C.D., 1974. Electric communication: functions in the social behavior of Eigenmannia virescens. Behaviour. 50, 270-306.

Hopkins, C.D., Functions and mechanisms in electroreception. In: Northcutt, R.G., Davis, R.E., Eds.), Fish Neurobiology. University of Michigan Press, Ann Arbor, 1983, pp. 215-259.

Hopkins, C.D., 1991. Hypopomus pinnicaudatus (Hypopomidae), a new species of gymnotiform fish in French Guiana. Copeia. 151-161.

Hopkins, C.D., 1999a. Design features for electric communication. J. Exp. Biol. 202, 1217-1228.

Hopkins, C.D., Signal evolution in electric communication. In: Hauser, M.D., Konishi, M., Eds.), Design of Animal Communication. MIT Press, Cambridge, Massachusetts, 1999b, pp. 461-491.

Hopkins, C.D., Comfort, N.C., Bastian, J.,Bass, A.H., 1990. Functional analysis of sexual dimorphism in an electric fish, Hypopomus pinnicaudatus, order Gymnotiformes. Brain Behavior and Evolution. $35,350-367$.

Hoyer, D., 5-hydroxytryptamine receptors and effector coupling mechanisms in peripheral tissues. In: Fozard, J.R., (Ed.), Peripheral Actions of 5HT. Oxford University Press, Oxford, 1989, pp. 72-99. 
Hoyer, D., Clarke, D.E., Fozard, J.R., Hartig, P.R., Martin, G.R., Mylecharane, E.J., Saxena, P.R.,Humphrey, P.P., 1994. International Union of Pharmacology classification of receptors for 5hydroxytryptamine (Serotonin). Pharmacol. Rev. 46, 157-203.

Hoyer, D., Hannon, J.P.,Martin, G.R., 2002. Molecular, pharmacological and functional diversity of $5 \cdot \mathrm{HT}$ receptors. Pharmacol. Biochem. Behav. 71, $533-554$.

Joppa, M.A., Rowe, R.K.,Meisel, R.L., 1997. Effects of serotonin 1A and 1B receptor agonists on social aggression in male and female Syrian hamsters. Pharmacol. Biochem. Behav. 58, 349-353.

Jorgensen, H., Kjaer, A., Warberg, J.,Knigge, U., 2001. Differential effect of serotonin $5-\mathrm{HT}_{1 \mathrm{~A}}$ receptor antagonists on the secretion of corticotropin and prolactin. Neuroendocrinology. $73,322-333$.

Jorgensen, H., Knigge, U., Kjaer, A., Vadsholt, T.,Warberg, J., 1998. Serotonergic involvement in stress-induced ACTH release. Brain Res. $811,10-20$.

Jorgensen, H., Knigge, U.,Warberg, J., 1999. Adrenocorticotropic hormone secretion in rats induced by stimulation with serotonergic compounds. J. Neuroendocrinol. 11, 283-290.

Kawasaki, M.,Heiligenberg, W., 1989. Distinct mechanisms of modulation in a neuronal oscillator generate different social signals in the electric fish Hypopomus. J. Comp. Physiol. A. 165, 731-741.

Kelley, D.B., 1988. Sexually dimorphic behaviors. Annu. Rev. Neurosci. 11, $225-251$.

Kime, D.E., 1993. 'Classical' and 'non-classical' reproductive steroids in fish. Rev. Fish Biol. Fish. 3, 160-180.

Knight, W.R., Moor, E., Hiemstra, Y.,Bohus, B., The testosterone-dependent vasopressinergic neurons in the medial amygdala and lateral septum: involvement in social behavior of male rats. In: Jaard, S., Jamison, R., Eds.), Vasopressin. INSERM/Libbey, Paris, 1990, pp. 213-220.

Korzan, W.J., Summers, T.R.,Summers, C.H., 2000. Monoaminergic activities of limbic regions are elevated during aggression: influence of sympathetic social signalling. Brain Res. 870, 170-178. 
Landsman, R.E., 1991. Captivity affects behavioral physiology: Plasticity in signaling sexual identity. Experientia. 47, 31-38.

Larsen, D.A., Swanson, P., Dickey, J.T., Rivier, J.,Dickhoff, W., W., 1998. In vitro thyrotropin releasing activity of corticotropin-releasing hormonefamily peptides in Coho salmon, Oncorhynchus kisutch. Gen. Comp. Endocrinol. 109, 276-285.

Lee, J.S.F.,Bass, A.H., 2005. Differential effects of 11-ketotestosterone on dimorphic traits in a teleost with alternative male reproductive morphs. Horm. Behav. 47, 523-531.

Lissman, H.W., 1958. On the function and evolution of electric organs in fish. J. Exp. Biol. 35, 156-193.

Lissman, H.W., Ecological studies on gymnotids. In: Chagas, C., Carvalho, A.P.d., Eds.), Bioelectrogenesis. Elsevier Publishing Company, Amsterdam, 1961, pp. 215-226.

Lund, T.D., Hinds, L.R.,Handa, R.J., 2006. The androgen $5 \alpha$ dihydrotestosterone and its metabolite $5 \alpha$-androstan-3 $3,17 \beta$-diol inhibit hypolthalamo-pituitary-adrenal response to stress by acting through estrogen receptor $\beta$-expressing neurons in the hypothalamus. J. Neurosci. 26, 1448-1456.

Macey, M.J., Pickford, G.E.,Peter, R.E., 1974. Forebrain localization of the spawning reflex response to exogenous neurohypophyseal hormones in the killifish, Fundulus heteroclitus. J. Exp. Zool. 190, 269-279.

Markham, M.R.,Stoddard, P.K., 2005. Adrenocorticotropic hormone enhances the masculinity of an electric communication signal by modulating the waveform and timing of action potentials within individual cells. J. Neurosci. 25, 8746-87543.

Matter, J.M., Ronan, P.J.,Summers, C.H., 1998. Central monoamines in freeranging lizards: differences associated with social roles and territoriality. Brain. Behav. Evol. 51, 23-32.

Metz, J.R., Geven, E.J.W., van den Burg, E.H.,Flik, G., 2005. ACTH, $\alpha-M S H$, and control of cortisol release: cloning, sequencing, and functional expression of the melanocortin- 2 and melanocortin -5 receptor in Cyprinus carpio. American Journal of Physiology -- Regulatory, Integrative and Comparative Physiology. 289, R814-826. 
Metz, J.R., Peters, J.J.M.,Flik, G., 2006. Molecular biology and physiology of the melanocortin system in fish: A review. Gen. Comp. Endocrinol. 148, 150-162.

Meyer, J.H., 1983. Steroid influences upon the discharge frequencies of a weakly electric fish. J. Comp. Physiol. A. 160, 385-394.

Meyer, J.H., Leong, M.,Keller, C.H., 1987. Hormone-induced and maturational changes in electric organ discharges and electroreceptor tuning in the weakly electric fish Apternotus. J. Comp. Physiol. A. 160, $384-394$.

Meyer, J.H., Zakon, H.H.,Heiligenberg, W., 1984. Steroid influences upon the electrosensory system of weakly electric fish: direct effects upon discharge frequencies with indirect effects upon electroreceptor tuning. J. Comp. Physiol. A. 154, 625-631.

Millan, M.J., Rivet, J.M., Canton, H., Lejeune, F., Bervoets, K., Brocco, M., Gobert, A., Lefebvre de Ladonchamps, B., Le Marouille Girardon, S., Verriele, L., Laubie, M.,Lavielle, G., 1992. S 14671: a naphtylpiperazine 5-hydroxytryptamine $1 \mathrm{~A}$ agonist of exceptional potency and high efficacy possessing antagonistic activity at 5hydroxytryptamine $1 \mathrm{c} / 2$ receptors. J. Pharmacol. Exp. Ther. 262, 451463.

Mills, A.,Zakon, H.H., 1987. Coordination of EOD frequency and pulse duration in a weakly electric wave fish: the influence of androgens. J. Comp. Physiol. A. 161, 417-430.

Mills, A.,Zakon, H.H., 1991. Chronic androgen treatment increases action potential duration in the electric organ of Sternopygus. J. Neurosci. 11, 2349-2361.

Narins, P.M.,Capranica, R.R., 1980. Neural adaptations for processing the two-note call of the Puerto Rican treefrog, Eleutherodactylus coqui. Brain. Behav. Evol. 17, 48-66.

Norris, D.O., 1997. Vertebrate Endocrinology. Academic Press, Inc., San Diego.

Norris, D.O., 2000. Endocrine disrupters of the stress axis in natural populations: How can we tell? American Zoologist. 40, 393-401. 
Oliveira, R.F., Carneiro, L.A., Canario, A.V.M.,Grober, M.S., 2001a. Effects of androgens on social behavior and morphology of alternative reproductive males of the azorean rock-pool blenny. Horm. Behav. 39, 157-166.

Oliveira, R.F., Carneiro, L.A., Goncalves, D.M., Canario, A.V.M.,Grober, M.S., 2001b. 11-ketotestosterone inhibits the alternative mating tactic in sneaker males of the peacock blenny, Salaria pavo. Brain. Behav. Evol. $58,28-37$.

Oliveira, R.F., Ros, A.F.H.,Goncalves, D.M., 2005. Intra-sexual variation in male reproduction in teleost fish: a comparative approach. Horm. Behav. 48, 430-439.

Ota, Y., Ando, H.,Ueda, A., 1999. Differences in seasonal expression of neurohypophysial hormone genes in ordinary and precocious male masu salmon. Gen. Comp. Endocrinol. 116, 40-48.

Peroutka, S.J.,Howell, T.A., 1994. The molecular evolution of G proteincoupled receptors: focus on 5-hydroxytryptamine receptors. Neuropharmacology. 33, 319-324.

Perreault, H., Semsar, K.,Godwin, J., 2003. Fluoxetine treatment decreases territorial aggression in a coral reef fish. Physiol. Behav. 79, 719-724.

Pickford, G.E.,Strecker, E.L., 1977. The spawning reflex of the killifish, Fundulus heteroclitus: isotocin is relatively inactive in comparison with arginine vasotocin. Gen. Comp. Endocrinol. 32, 132-137.

Pope, D.S., 2000. Testing function of fiddler crab claw waving by manipulating social context. Behav. Ecol. Sociobiol. 47, 432-437.

Ramage, A., 2005. Problems of drug selectivity and dose -- pharmacology. J. Physiol. (Lond). 569, 711'.

Rotllant, J., Balm, P.H.M., Ruane, N.M., Perez-Sanchez, J., WendelaarBonga, S.E.,Tort, L., 2000. Pituitary proopiomelanocortin-derived peptides and hypothalamus-pituitary-interrenal axis activity in the gilthead sea bream (Sparus aurata) during prolonged crowding stress: differential regulation of adrenocorticotropin hormone and $\alpha^{-}$ melanocyte-stimulating hormone release by corticotropin-releasing hormone and thyrotropin-releasing hormone. Gen. Comp. Endocrinol. $119,152 \cdot 163$. 
Sanchez, C., 1997. Interaction studies of 5-HT1A receptor antagonists and selective 5-HT reuptake inhibitors in isolated aggressive mice. Eur. J. Pharmacol. 334, 127-132.

Saphier, D., Farrar, G.E.,Welch, J.E., 1995. Differential inhibition of stressinduced adrenocortical responses by $5 \cdot \mathrm{HT}_{1 \mathrm{~A}}$ agonists and by $5 \cdot \mathrm{HT}_{2}$ and 5- $\mathrm{HT}_{3}$ antagonists. Psychoneuroendocrinology. 20, 239-257.

Schechter, L.E.,Simansky, K.J., 1988. 1-(2, 5-Dimethoxy-4-iodophenyl)-2amino-propane (DOI) exerts and anorexic action that is blocked by 5 HT2 antagonists in rats. Psychopharmacology (Berl). 94, 342-346.

Scheuber, H., Jacot, A.,Brinkhof, M.W.G., 2003a. Condition dependence of a multicomponent sexual signal in the field cricket Gryllus campestris. Anim. Behav. 65, 721-727.

Scheuber, H., Jacot, A.,Brinkhof, M.W.G., 2003b. The effect of past condition on a multicomponent sexual signal. Proc. R. Soc. London, B. 270, 17791784.

Schreiber, R., Brocco, M., Audinot, V., Gobert, A., Veiga, S.,Millan, M.J., 1995. (1-2, 5-dimethoxy-4 iodophenyl)-2-aminopropane)-induced headtwitches in the rat are mediated by 5 -hydroxytryptamine $(5-\mathrm{HT}) 2 \mathrm{~A}$ receptors: modulation by novel $5-\mathrm{HT}_{2 \mathrm{~A}} / 2 \mathrm{C}$ antagonists, $\mathrm{D} 1$ antagonists and $5 \cdot \mathrm{HT}_{1 \mathrm{~A}}$ agonists. J. Pharmacol. Exp. Ther. 273, 101-112.

Siegel, S.,Castellan, N.J., 1988. Nonparametric Statistics for Behavioural Science. McGraw-Hill Publishing Co.

Silva, A., Quintana, L., Galeano, M., Errandonea, P.,Macadar, O., 1999. Water temperature sensitivity of EOD waveform in Brachyhypopomus pinnicaudatus. J. Comp. Physiol. A. 185, 187-197.

Simon, N.G., Hormonal processes in the development and expression of aggressive behavior. Hormones, Brain, and Behavior. Elsevier, 2002, pp. 339-391.

Simon, N.G., Cologer-Clifford, A., Lu, S., McKenna, S.E.,Hu, S., 1998. Testosterone and its metabolites modulate $5 \mathrm{HT}_{1 \mathrm{~A}}$ and $5 \mathrm{HT}_{1 \mathrm{~B}}$ agonist effects on intermale aggression. Neurosci. Biobehav. Rev. 23, 325-336.

Smythe, G.A., Gleeson, R.M.,Stead, B.M., 1988. Mechanisms of 5-hydroxy-Ltryptophan-induced adrenocorticotropin release: a major role for central noradrenergic drive. Neuroendocrinology. 47, 389-397. 
Sperry, T.S., Moore, I.T., Meddle, S.L., Brenowitz-Fredericks, Z.M.,Wingfield, J.C., 2005. Increased sensitivity of the serotonergic system during the breeding season in free-living American tree sparrows. Behav. Brain Res. 157, 119-126.

Sperry, T.S.,Thomas, P., 1999. Characterization of two nuclear androgen receptors in Atlantic croaker: Comparison of their biochemical properties and binding specificities. Endocrinology. 140, 1602-1611.

Sperry, T.S.,Thomas, P., 2000. Androgen binding profiles of two distinct nuclear androgen receptors in Atlantic croaker (Micropogonias undulatus). J. Steroid Biochem. Mol. Biol. 73, 93-103.

Stoddard, P.K., 2002. Electric signals: Predation, sex and environmental constraints. Advances in the Study of Behavior. 31, 201-242.

Stoddard, P.K., Plasticity of the electric organ discharge waveform: contexts, mechanisms, and implications for electrocommunication. In: Ladich, F., et al., Eds.), Communication in Fishes. Science Publisher, Inc., Enfield, NH, 2006.

Stoddard, P.K., Markham, M.R.,Salazar, V.L., 2003. Serotonin modulates the electric waveform of the gymnotiform electric fish Brachyhypopomus pinnicaudatus. J. Exp. Biol. 206, 1353-1362.

Stoddard, P.K., Markham, M.R., Salazar, V.L.,Allee, S.J., 2006a. Circadian Rhythms in Electric Waveform Structure and Rate in the Electric Fish Brachyhypopomus pinnicaudatus. Physiology and Behavior. In Press.

Stoddard, P.K., Zakon, H.H., Markham, M.R.,McAnelly, L., $2006 \mathrm{~b}$. Regulation and modulation of electric waveforms in gymnotiform electric fish. J. Comp. Physiol. A. 192, 613-624.

Sumpter, J.P., The endocrinology of stress. In: Iwama, G.K., et al., Eds.), Fish stress and health in aquaculture. Cambridge University Press, Cambridge, MA, 1997, pp. 95-118.

Van de Kar, L.D., Javed, A., Zhang, Y.H., Serres, F., Raap, D.K.,Gray, T.S., 2001. 5-HT2A receptors stimulate ACTH, corticosterone, oxytocin, renin, and prolactin release and activate hypothalamic CRF and oxytocin-expressing cells. J. Neurosci. 21, 3572-3579.

van Wijngaarden, I., Tulp, M.T.,Soudijn, W., 1990. The concept of selectivity in 5-HT receptor research. Eur. J. Pharmacol. 188, 301-312. 
Welch, J.E., Farrar, G.E., Dunn, A.J.,Saphier, D., 1993. Central 5-HT ${ }_{1 A}$ receptors inhibit adrenocortical secretion. Neuroendocrinology. 57, 272281.

Wendelaar Bonga, S.E., 1997. The stress response in fish. Physiol. Rev. 77, 591-625.

Wilhelmi, A.E., Pickford, G.E.,Sawyer, W.H., 1955. Initiation of the spawning reflex response in Fundulus by the administration of fish and mammalian neurohypophysial preparations and synthetic oxytocin. Endocrinology. 57, 243-252.

Winberg, S., Nilsson, A., Hylland, P., Soderstom, V.,Nilsson, G.E., 1997. Serotonin as a regulator of hypothalamic-pituitary-interrenal activity in teleost fish. Neurosci. Lett. 230, 113-116.

Zakon, H.H., 1993. Weakly electric fish as model systems for studying longterm steroid action on neural circuits. Brain. Behav. Evol. 42, 242-251.

Zakon, H.H., 1996. Hormonal modulation of communication signals in electric fish. Dev. Neurosci. 18, 115-123.

Zakon, H.H., Sex steroids and weakly electric fish: A model system for activational mechanisms of hormone action. In: Matsumoto, A., (Ed.), Sexual Differentiation of the Brain. CRC Press, 2000, pp. 95-112.

Zakon, H.H., Thomas, P.,Yan, H.Y., 1991. Electric organ discharge frequency and plasma sex steroid levels during gonadal recrudescence in a natural population of the weakly electric fish Sternopygus macrurus. J. Comp. Physiol. A. 169, 493-499. 


\section{VITA}

SUSAN J. AlLEE

1995

B.S., Biology

Florida State University

Tallahassee, Florida

1998

M.S., Biology

University of West Florida

Pensacola, Florida

1999-2000

Statistician II

Agency for Health Care Administration

Tallahassee, Florida

$2001-2002$

Science Teacher

Charles Flanagan High School

Pembroke Pines, Florida

PUBLICATIONS AND PRESENTATIONS

Stoddard, P.K, M.R. Markham, V.L. Salazar, and S.J. Allee. 2007.

Circadian Rhythms in Electric Waveform Structure and Rate in the Electric Fish Brachyhypopomus pinnicaudatus. Physiology \& Behavior.

Gulf Toadfish (Opsanus beta) Reproductive Strategies. With Wayne Bennett, University of West Florida. Southern Division American Fisheries Society Mid-Year Meeting, February 1998, Lexington, Kentucky.

Reproductive Strategies of Gulf Toadfish (Opsanus beta). With Wayne Bennett, University of West Florida. 1999 Joint meeting of the American Society of Ichthyologists and Herpetologists, American Elasmobranch Society, the Herpetologists' League, and the Society for the Study of Amphibians and Reptiles. June 1999, University Park, Pennsylvania.

Androgens Potentiate the Electric Organ Discharge. With Michael R. Markham and Philip K. Stoddard, Florida International University. Department of Biological Sciences 2004/2005 Biology Research Symposium, Miami, Florida. 
Why can't a woman be more like a man? Implanting androgens leads to partial masculinization of a communication signal. With Michael R. Markham and Philip K. Stoddard, Florida International University. Animal Behavior Society Annual Meeting. August 2005, Snowbird, Utah. 